Towards Changes in MicroRNA Expression Associated with Increases and Decreases in Adult Rat Hippocampal Neurogenesis

by

\author{
Livia A. Chyurlia \\ A thesis submitted to \\ the Faculty of Graduate and Postdoctoral Affairs \\ in partial fulfillment of the requirements of the degree of \\ Master of Science \\ in \\ Psychology
}

Carleton University

Ottawa, Canada

C2011 Livia A. Chyurlia 


$\begin{array}{ll}\begin{array}{l}\text { Library and Archives } \\ \text { Canada }\end{array} & \begin{array}{l}\text { Bibliothèque et } \\ \text { Archives Canada }\end{array} \\ \begin{array}{l}\text { Published Heritage } \\ \text { Branch }\end{array} & \begin{array}{l}\text { Direction du } \\ \text { Patrimoine de l'édition }\end{array} \\ \begin{array}{l}\text { 395 Wellington Street } \\ \text { Ottawa ON K1A ON4 } \\ \text { Canada }\end{array} & \begin{array}{l}395, \text { rue Wellington } \\ \text { Ottawa ON K1A ON4 } \\ \text { Canada }\end{array}\end{array}$

Your file Votre référence

ISBN: 978-0-494-79602-3

Our file Notre référence

ISBN: 978-0-494-79602-3

NOTICE:

AVIS:

The author has granted a nonexclusive license allowing Library and Archives Canada to reproduce, publish, archive, preserve, conserve, communicate to the public by telecommunication or on the Internet, loan, distribute and sell theses worldwide, for commercial or noncommercial purposes, in microform, paper, electronic and/or any other formats.

The author retains copyright ownership and moral rights in this thesis. Neither the thesis nor substantial extracts from it may be printed or otherwise reproduced without the author's permission.

L'auteur a accordé une licence non exclusive permettant à la Bibliothèque et Archives Canada de reproduire, publier, archiver, sauvegarder, conserver, transmettre au public par télécommunication ou par l'Internet, prêter, distribuer et vendre des thèses partout dans le monde, à des fins commerciales ou autres, sur support microforme, papier, électronique et/ou autres formats.

In compliance with the Canadian Privacy Act some supporting forms may have been removed from this thesis.

While these forms may be included in the document page count, their removal does not represent any loss of content from the thesis.
Conformément à la loi canadienne sur la protection de la vie privée, quelques formulaires secondaires ont èté enlevés de cette thèse.

Bien que ces formulaires aient inclus dans la pagination, il n'y aura aucun contenu manquant.

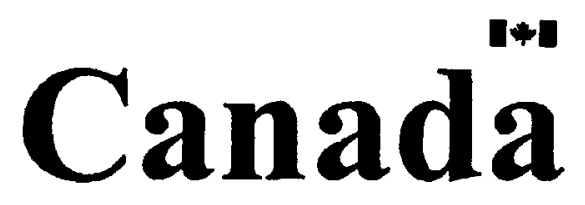




\begin{abstract}
MicroRNAs (miRNAs) are a recently discovered class of small non-coding RNAs that regulate gene expression post-transcriptionally. In animals, their function is primarily to inhibit mRNA translation, including preferentially targeting mRNAs involved in development. They have been implicated in the regulation of stem cell lineage progression, from proliferation and differentiation to maturation. In vitro studies have demonstrated that a number of microRNAs are upregulated when embryonic and/or adult neuronal progenitors proliferate and develop into neurons, but similar studies have not been performed in vivo. An added benefit of profiling microRNAs in vivo rather than in vitro is that identification of glial microRNAs as potential regulators of neurogenesis is possible. In mammals, adult neurogenesis can take place in the subgranular zone (SGZ) of the hippocampus. The present study seeks to confirm that previously identified microRNA genes are involved in the process of adult neurogenesis in vivo, as well as identify new potential microRNA genes involved in neurogenesis. In the current study, the rate of neurogenesis was manipulated in adult Sprague-Dawley rats through either three weeks of corticosterone injections to decrease neurogenesis, or voluntary wheel running to increase neurogenesis. After assessment of differences in neurogenesis by quantifying cells labeled with 5-bromo-2-deoxyuridine (BrdU) in the dorsal hippocampus using stereology, and conducting cell counts after immunohistochemical staining of Ki67 and doublecortin (DCX), a microRNA microarray study will be conducted on extracted microRNA samples from each group. Replication of changes in neurogenesis using cell counts of DCX+ cells confirmed that three weeks of voluntary wheel running increases the number of immature neurons and three weeks of daily high-dose corticosterone injections reduces this number. Therefore, it would be worthwhile to explore the miRNA profile of this tissue using a miRNA microarray to identify miRNAs that are altered in opposing directions by these manipulations and thus associated with neurogenesis. Three weeks of voluntary exercise did not alter the number of proliferating cells which is consistent with some of the literature examining time-course dependent effects of wheel running on neurogenesis. Results of three weeks of corticosterone injections showed trends toward a significant decrease in the amount of proliferating cells, however, data showed an exceptional amount of variability resulting in the need for more reliable quantification techniques or a larger sample size to detect statistical significance between the number of proliferating cells in the corticosterone injection group and controls.
\end{abstract}




\section{Acknowledgements}

First and foremost I would like to express my gratitude to Dr. John Stead for his generous amount of enthusiasm, encouragement, and counsel. Through Dr. Stead I learned more about neuroscience and than I ever imagined was possible, and was often left in awe of his ability to quickly apply scientific thinking to a variety of situations. Secondly, I would like to thank $\mathrm{PhD}$ candidate, Kerry Rennie, for sharing her expertise in immunohistochemistry and dedicating so much work and time to this research project. Her friendship and guidance have been essential to the completion of this work. I would also like to thank my departmental committee members, Dr. Hymie Anisman, and Dr. Matt Holahan, for their time and ongoing advice in several aspects of the research project. Thanks also to Dr. Bill Willmore for taking time out of his schedule to be my internal-external examiner and to Dr. Patrice Smith for acting as chair at my defense.

Almost every person at the Life Sciences Research Building contributed, in one way or another, to my thesis. Particular gratitude is owed to members of the Stead lab who contributed to this research directly (John Wallace, Krishin Singh, Mike Jaakkola), as well as those who passed on their knowledge of lab techniques (Erika Jansman), and those who supported me whenever possible (Pierce McKennirey). The countless friends that I have made in the building provided me with advice, feedback, inspiration, and most importantly, motivation. The memories we created is justification enough to have pursued this graduate degree.

Special thanks go to Diane Trenouth, and technicians Marzena Sieczkos, and Teresa Fortin, for their constant willingness to help in times of need. I would also like to express my appreciation of members of the vivarium staff that do so much during the animal-work portion of research. Thank you as well to staff members of the Department of Psychology, particularly Etelle Bourassa.

I must also acknowledge my wonderful family for their unconditional support and love. Thank you to my mother with whom I shared all my ups and downs with throughout this degree. Thanks to my brother, Peter, who always encouraged me to maximize my potential, and to my late father who I thought of every step of the way.

Lastly, it is my pleasure to express thankfulness towards my boyfriend Alex Miles, fabulous roommates Carissa DiGangi and Andrée Dion, Kerry Moloney and the other "stats girls", and my many friends who aided in keeping me happy and balanced right until the end. 


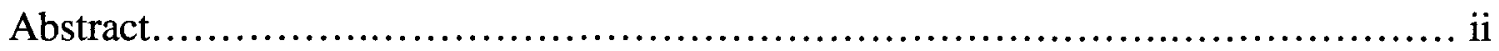

List of Abreviations....................................................................

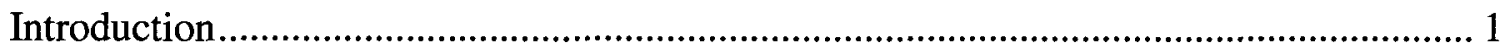

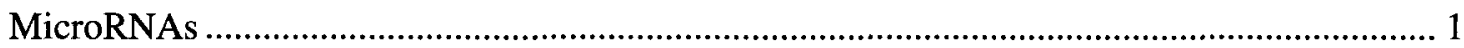

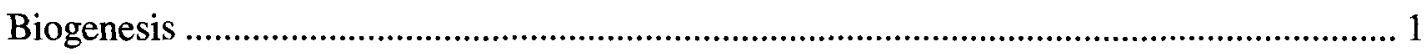

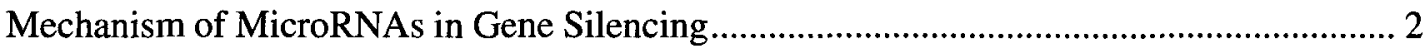

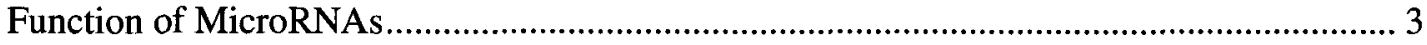

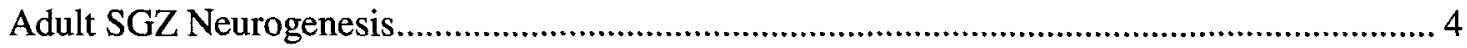

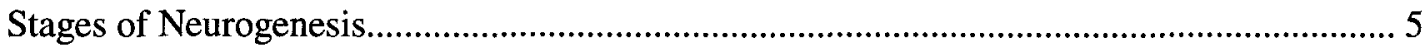

Intracellular Changes with Adult Neural Stem Cell Lineage Progression ............................... 6

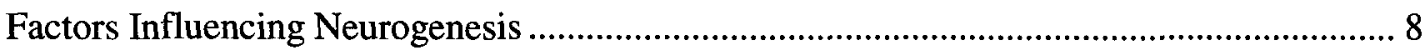

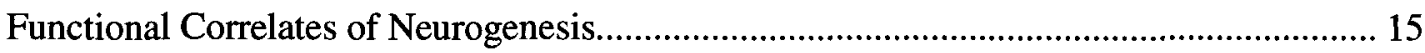

MicroRNA Involvement in Neurogenesis............................................................... 17

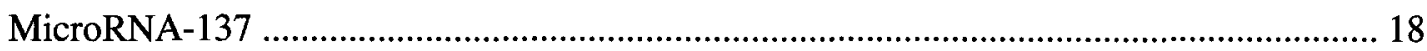

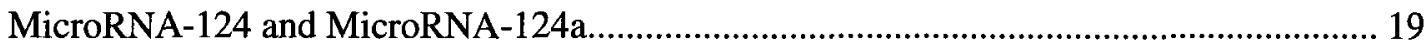

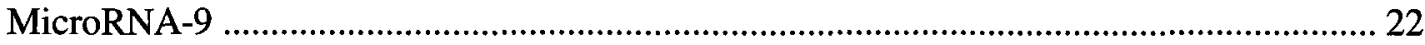

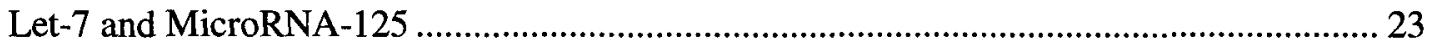

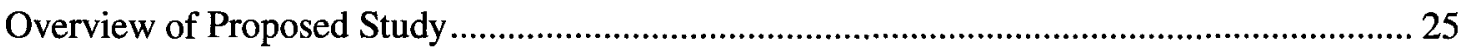

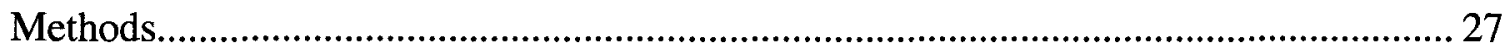

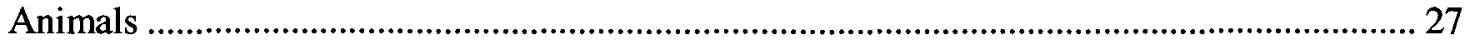


Corticosterone and Control Injections

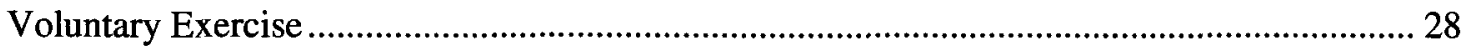

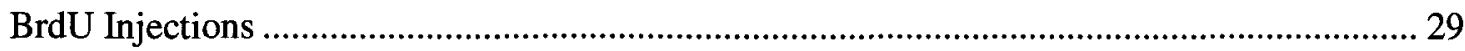

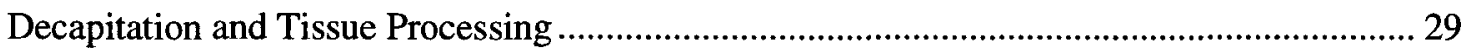

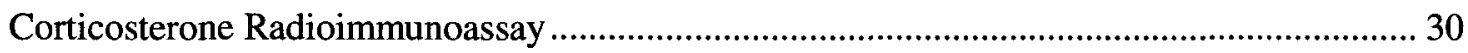

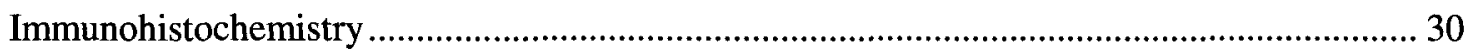

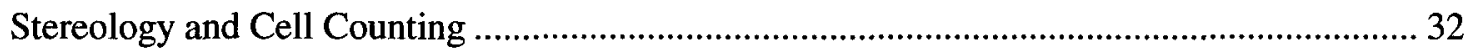

Statistical Analyses used to Assess Changes in Neurogenesis........................................... 33

Correlates of Measures of Neurogenesis and Amount of Wheel Running ............................ 33

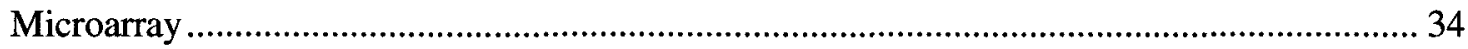

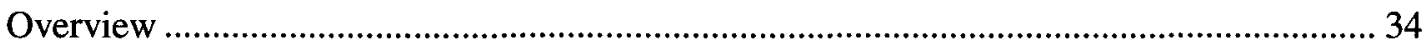

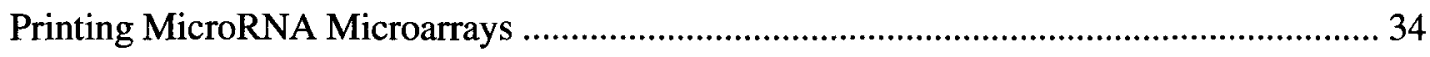

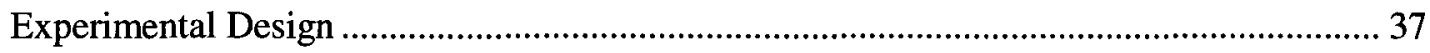

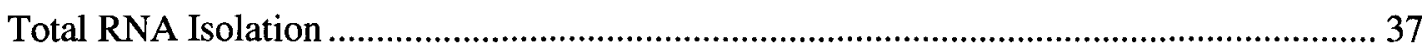

MicroRNA Labeling and Hybridization Overview ........................................................ 40

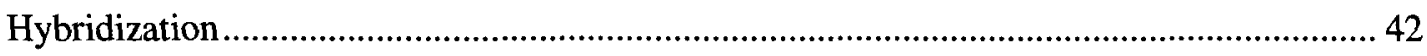

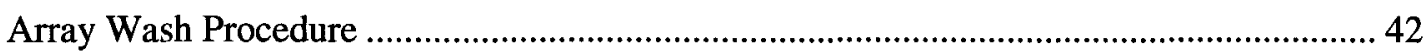

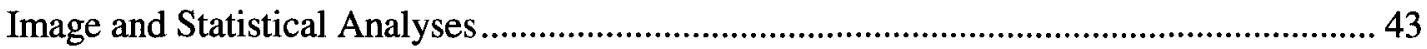

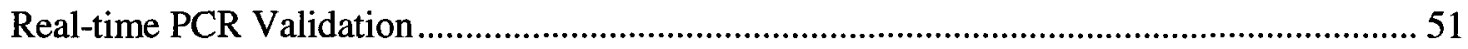

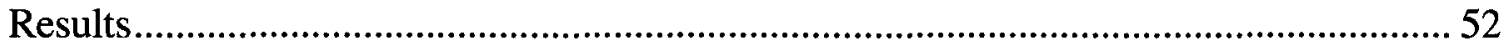

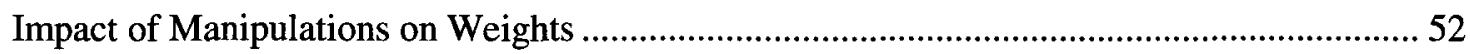




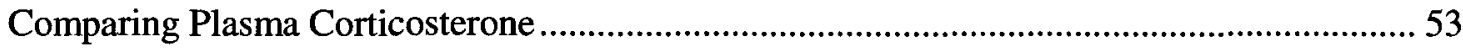

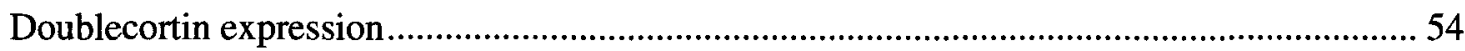

Comparing BrdU+ Cell Estimates Between Groups ......................................................... 57

Comparing Ki67+ Cell Counts Between Groups ................................................................. 59

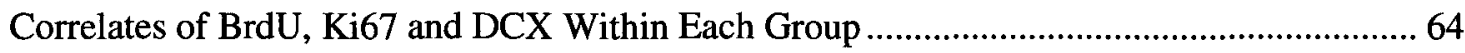

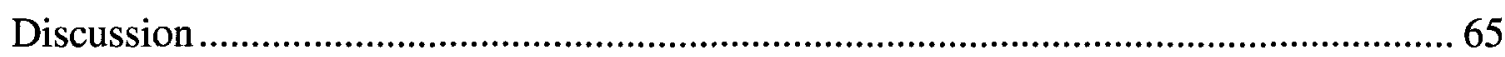

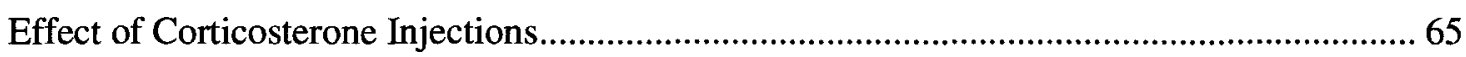

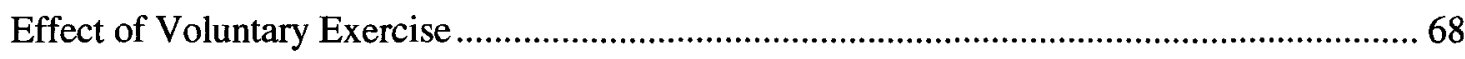

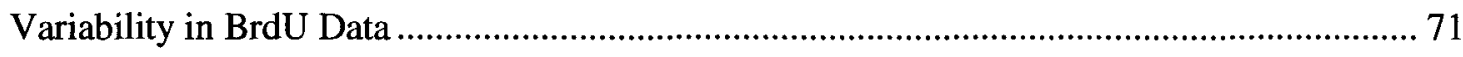

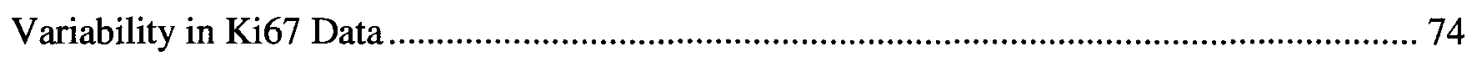

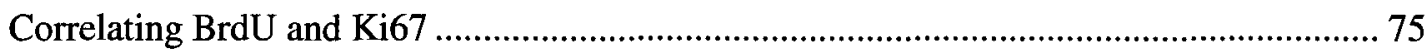

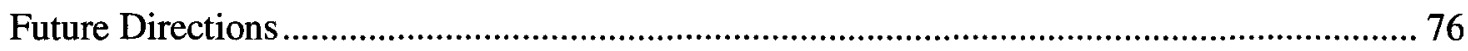

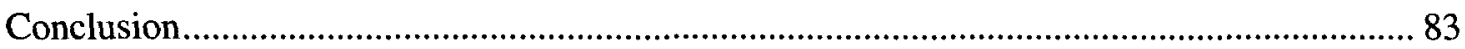


3'UTR - 3' untranslated region

\section{List of Abbreviations}

5-HT - 5-hydroxytryptamine, serotonin

aNSC - amplifying neural stem cell

BDNF - brain derived neurotrophic factor

BrdU - 5-bromo-2-deoxyuridine

BSA - Albumin from Bovine Serum

CA3 - cornu ammonis region 3

CE - coefficient error

Cort - corticosterone injection group

CREB - cyclic AMP response element-binding

Ctrl - no injection, control group

DAB - 3, 3'-Diaminobenzidine

DDT - dithiothreitol

DEPC - diethylpyrocarbonate

DG - dentate gyrus

DNA - deoxyribonucleic acid

DCX - doublecortin

FGF - fibroblast growth fact

GABA - $\gamma$-aminobutyric acid

GFAP - glial fibrillary acidic protein

GR - glucocorticoid receptor

IGF-1 - insulin-like growth factor 1 
Mecp2 - methyl-CpG-binding protein

miRNA, miR - microRNA

mRNA - messenger RNA

NMDA - N-methyl-D-aspartic acid

NSC - neural stem cell

PCA - principle components analysis

qNSC - quiescent neural stem cell

REST - RE1-Silencing Transcription factor

RNA - ribonucleic acid

RT-PCR - real-time polymerase chain reaction

SAM - significance analysis of microarrays

SDS - sodium dodecyl sulphate

SEM - standard error of the mean

SGZ - subgranular zone

Sh - short-hairpin

Sox - SRY(sex determining region Y)-box

SSC - standard saline citrate

SVZ - subventricular zone

VEGF - vascular endothelial growth factor

Veh - vehicle injection group

VEx - voluntary exercise group 


\section{Introduction}

\section{MicroRNAs}

MicroRNAs (miRNAs) are a large class of small non-coding RNAs that are present in the genomes of animals and plants (Ambros, 2004; Bartel, 2004). The end products of miRNA genes are single stranded molecules of approximately 22 nucleotides (ranging from 18 to 26 nucleotides). These molecules have a regulatory role in that they can downregulate the expression of protein by acting post-transcriptionally on messenger RNAs (mRNAs). So far, 1048 miRNAs have been discovered in the human genome and have been annotated in the online miRNA database miRBase (Griffiths-Jones, Saini, van Dongen, \& Enright, 2008) which amounts to about 1-3\% of all genes, and together they are thought to collectively regulate over $60 \%$ of all protein-coding genes (Friedman, Farh, Burge, \& Bartel, 2009).

\section{Biogenexis}

MicroRNAs are derived from primary miRNAs which are several kilobases long (Du \& Zamore, 2005) and are typically transcribed by RNA polymerase II (Kim \& Kim, 2007; Y. Lee et al., 2004). Over $25 \%$ of mammalian miRNAs are located in intronic regions of protein-coding genes (Shomron, Golan, \& Hornstein, 2009), and there is transcriptional co-regulation between proteins and intronic miRNAs (Kim \& Kim, 2007; Rodriguez, Griffiths-Jones, Ashurst, \& Bradley, 2004). Intergenic miRNAs appear to have promoter and enhancer elements as well as contain Cap structures and poly(A)-tails similar to protein-coding genes (Y. Lee et al., 2004). The enzyme Drosha works on the 
primary miRNA to excise an approximately- 65- nucleotide- long hairpin structure referred to as a precursor miRNA structure. In animals, the precursor miRNA is then exported from the nucleus into the cytoplasm by nuclear transport receptor, exportin-5 (Bohnsack, Czaplinski, \& Gorlich, 2004) where the precursor miRNA is cleaved at the bottom of its stem loop by the enzyme Dicer (Lund \& Dahlberg, 2006). The resulting double-stranded structure called a miRNA duplex then typically separates into one mature miRNA and another strand that degrades (denoted as miRNA*) when the miRNA duplex gets incorporated into RNA-induced silencing complex (Lund \& Dahlberg, 2006). In mammals, a mature miRNA incorporated into this complex can repress protein expression by driving mRNA degradation through mRNA destabilization or by inhibiting the process of translation (translational repression) (Guo, Ingolia, Weissman, \& Bartel, 2010).

\section{Mechanism of MicroRNAs in Gene Silencing}

MicroRNAs exert their effect by binding to mRNAs in the cytoplasm of cells and causing translational repression, mRNA cleavage and degradation, or in rare cases translational enhancement (Martino, di Girolamo, Orlacchio, \& Datti, 2009). In a genome-wide microarray study using exogenous miRNAs in mammalian cells, it was found that numerous transcripts were downregulated demonstrating the ability of miRNAs to affect target mRNA stability. Messenger RNAs that were significantly downregulated showed increased likelihood of containing sequences in their 3 ' untranslated regions that matched binding region sequences of the exogenous miRNAs (Lim et al., 2005). The subsequent effect of introduction of exogenous miRNAs into 
cultured cells on protein output was studied by mass spectrometry and it was found that miRNAs make fine-scale adjustments to the proteome (Baek et al., 2008). Recently it was found that in mammalian cells, destabilization of target mRNAs which results in degradation is the predominant cause of decreased protein output resulting from miRNA regulation (as opposed to decreasing translational efficiency) (Guo et al., 2010).

The 'seed region' of the miRNA, defined as bases 2-7, determines which mRNAs are targets for repression as it must have complementary base pairing to part of the target mRNA, but sequences outside the seed sequence also influence mRNA targeting specificity (Grimson et al., 2007). Furthermore, binding sites can have imperfect complementarity to the mature miRNA which gives miRNAs the potential to bind to more than one mRNA (Bentwich, 2005; Rajewsky, 2006; Sethupathy, Megraw, \& Hatzigeorgiou, 2006) and it appears that there can be more than 200 targets per miRNA (Lim et al., 2005). Furthermore, each mRNA can be targeted by several miRNAs in vitro (Poy, Spranger, \& Stoffel, 2007).

\section{Function of MicroR.VAs}

Currently, hundreds of miRNAs have been cloned from a variety of species and several have been found to regulate developmental processes (Bushati \& Cohen, 2007; Chang \& Mendell, 2007; Kloosterman \& Plasterk, 2006; Y. Zhao \& Srivastava, 2007). This role in development has left evolutionary imprints on the 3' untranslated regions of mRNAs. For example, mRNAs expressed from genes involved in ubiquitous cellular processes are significantly depleted of miRNA target sites, compared to mRNAs of genes involved in developmental processes (Stark, Brennecke, Bushati, Russell, \& Cohen, 
2005). Furthermore, microRNAs are expressed differentially across development suggesting that they vary with, if not help regulate, developmental processes.

Temporal miRNA expression differences can be seen with stem cell lineage progression - both in embryonic development and in adult organisms. MicroRNAs are important for cell lineage differentiation of various tissue types including adult hematopoeitic, adipose, and cardiac cells (Chen, Li, Lodish, \& Bartel, 2004; Esau et al., 2004; Y. Zhao, Samal, \& Srivastava, 2005). Spatially, miRNA expression profiles vary in a manner that is both tissue- and cell-specific. There are approximately 50 miRNAs that are highly enriched in the mouse nervous system (Bak et al., 2008). Several in vitro studies have also examined miRNA expression changes in neural stem cells during neurogenesis and only one in vivo study has examined the role of miRNAs in this process as it occurs in the adult hippocampus. These studies will be described in detail in the section titled 'MicroRNA Involvement in Neurogenesis'.

\section{Adult SGZ Neurogenesis}

Neurogenesis, the birth of new neurons, is widely accepted to occur in two places in adult mammals: the anterior subventricular zone (SVZ) of the lateral ventricles, and the subgranular zone (SGZ) of the hippocampal dentate gyrus (DG) (Hagg, 2009). Neurogenesis comprises several processes: cell proliferation/birth, cell fate specification (differentiation) and migration, and cell survival, maturation and functional integration into neuronal circuitry (Ming \& Song, 2005). Newborn cells in the SGZ migrate to the granule cell layer of the hippocampus and establish themselves as granule cells in the existing circuitry there. Gould et al. (1992) found that newborn cells proliferate in the 
CHANGES IN MICRORNA EXPRESSION 5

hilar region of the DG and migrate to the granule cell layer in up to 24 hours after deoxyribonucleic acid (DNA) synthesis (Gould, Cameron, Daniels, Woolley, \& McEwen, 1992). Progenitor cells are found next to the granule cell layer, which is a dense layer of granule cells that hosts mature and new immature neurons, as well as astrocytes and oligodendrocytes. For an illustration of DG anatomy please refer to figure 1.

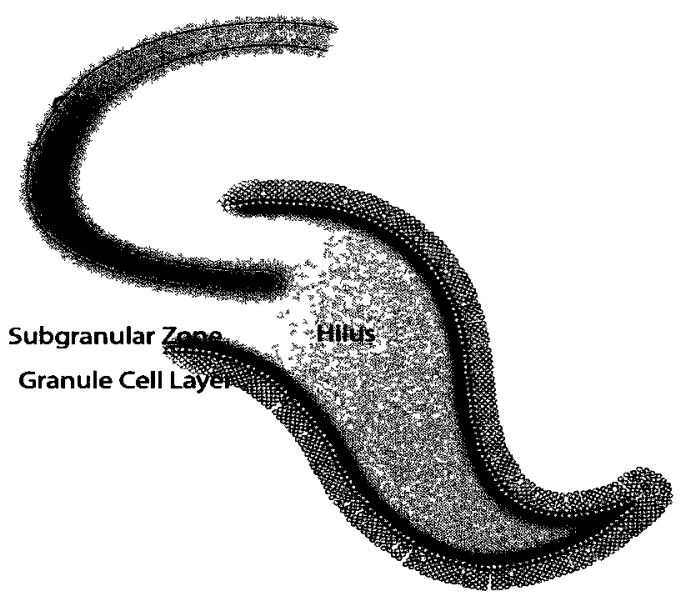

Figure 1. An illustration of the anatomy of the hippocampal dentate gyrus as seen in a coronal section of a rat brain.

Stages of Neurogenesis

Neuronal precursors can be divided into six subclasses: quiescent neural progenitors (qNSCs), amplifying neural progenitors (aNSCs), type 1 neuroblasts, type 2 neuroblasts, immature neurons and finally granule cells (Encinas, Vaahtokari, \& Enikolopov, 2006). It is generally accepted that newborn neurons in the SGZ arise from neural stem cells (NSCs). In vitro studies have identified qNSCs and aNSCs but it is still unknown whether qNSCs give rise to aNSCs. However, lack of neurogenesis following transgenic ablation of qNSCs suggests qNSCs are the ancestral population of most new 
neurons (Garcia, Doan, Imura, Bush, \& Sofroniew, 2004). Amplifying NSCs proliferate to create cells that will become neuroblasts. If these cells survive they will migrate to the granule cell layer, mature and develop dendrites that extend into the molecular layer of the hippocampus and axons that extend towards the cornu ammonis region 3 pyramidal layer of the hippocampus proper (see Figure 1). The end result is glutamatergic excitatory dentate granule cells which are the principle neurons in the DG. Not all newborn cells survive to become fully mature and many intrinsic and extrinsic factors can determine survival rates. In fact a study by Cameron and McKay (2001) found 60\% of newborn cells die before maturation is complete; usually before two weeks. Refer to figure 2 for the timeline associated with adult SGZ neural stem cell lineage progression.

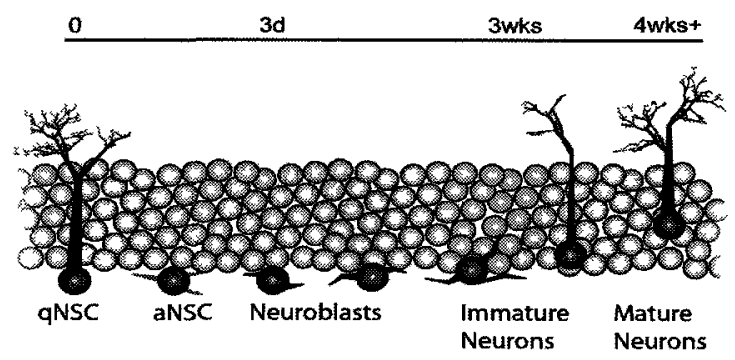

Figure 2. Time line of adult neural stem cell lineage progression.

\section{Intracellular Changes with Adult Neural Stem Cell Iineage Progression}

Since miRNAs target mRNAs, it is important to have some idea of the mRNA profiles of each cell type associated with the stages of neural stem cell lineage progression. The protein expression profile is also important as proteins are translated from mRNAs. 
Defining the mRNA and protein expression profile of NSCs is not straightforward as there is continuing controversy surrounding NSCs with regards to their location and identity in vivo (Duan, Kang, Liu, Ming, \& Song, 2008; Ma, Bonaguidi, Ming, \& Song, 2009). It has been suggested that qNSCs are a type of astrocyte that express glial fibrillary acidic protein (GFAP) and have radial glial properties. Quiescent NSCs express Sox2 (Fukuda et al., 2003; Garcia et al., 2004; Suh et al., 2007) which is also expressed in embryonic stem cells and neural epithelial cells during development and is thought to play a role in maintaining self-renewal properties (Avilion et al., 2003; Ferri et al., 2004; Zappone et al., 2000). Amplifying NSCs also probably express Sox2 as an in vivo study by Suh et al. (2007) identified two morphologically distinct populations of Sox $2^{+}$NSCs in the SGZ: a radial type and a nonradial type. The nonradial type, hypothesized to be aNCSs, were also found to be multipotent (meaning they could give rise to more than one cell type) but generated many more neurons than astrocytes, and were self-renewing (a required characteristic of aNSCs). A protein that can be associated with these NSCs and the proliferative stage is a nuclear protein called Ki67 which is likely necessary for cell proliferation as it is expressed only during mitosis. Survival can be assessed as neuroblasts and immature neurons are unique in that they express the protein doublecortin (DCX) (M. S. Rao \& Shetty, 2004). Doublecortin is a microtubule associated protein and is present throughout differentiation and migration but is not expressed in mature dentate granule neurons. Both the proteins Ki67 and DCX can be used as markers of stages of neurogenesis. 


\title{
Factors Influencing Neurogenesis
}

\author{
Extrinsic Factors
}

Wheel Running and Environmental Enrichment

Neurogenesis can be increased by exposure to an enriched environment, which typically includes access to toys, climbing structures, more space than standard housing, social housing, varied food, and a running wheel. This increase in neurogenesis has been reported to result from elevated cell survival and not from increased cell proliferation in mice (Kempermann, Kuhn, \& Gage, 1997; van Praag, Kempermann, \& Gage, 1999). Proliferation and cell survival can be measured using 5-bromo-2-deoxyuridine ( $\mathrm{BrdU})$ which is a thymidine analog. Thymidine is one of the building blocks of DNA and so if BrdU is available it gets incorporated into newly synthesized DNA thereby marking newly created cells.

A number of studies have also reported that voluntary running alone, without the other aspect of an enriched environment, can increases neurogenesis through elevated cell survival rates (Holmes, Galea, Mistlberger, \& Kempermann, 2004; van Praag, Christie, Sejnowski, \& Gage, 1999; van Praag, Kempermann et al., 1999). However these studies measured survival by quantifying BrdU+ cells after BrdU was injected at the beginning of the running treatment and so measuring BrdU+ cells is actually a measure of combined proliferation and survival of cells. One study using mice measured cell survival while holding proliferation constant by injecting BrdU two days before the running treatment 
commenced and found increased survival after 12 and 19 days of running (Snyder, Glover, Sanzone, Kamhi, \& Cameron, 2009).

Wheel running has been shown to also affect proliferation. For example, proliferation is augmented by two to three weeks of voluntary wheel running in SpragueDawley rats (Eadie, Redila, \& Christie, 2005; Redila \& Christie, 2006) and a study subjecting Sprague-Dawley rats to as little as 10 days of voluntary wheel running led to increased proliferation specifically in the dorsal DG (Bruel-Jungerman et al., 2009). A study that used female hypertensive rats found that nine days of running increases proliferation but just over three weeks of running actually decreased proliferation demonstrating that the effects of wheel running on neurogenesis can be time-course dependant (Naylor, Persson, Eriksson, Jonsdottir, \& Thorlin, 2005).

The effects of continued wheel running have been investigated by other studies. Mice that ran for four, six and eight weeks showed increased levels of DCX-expressing immature neurons which correlated with the amount of running (E. Aberg, Perlmann, Olson, \& Brene, 2008; Dubreucq, Koehl, Abrous, Marsicano, \& Chaouloff, 2010). This increase in neurogenesis may be due to increased proliferation, cell survival, or a combination of both. The effects of prolonged wheel running on survival alone have not been assessed to date. One study which investigated the effects of three and six weeks of wheel running on proliferation by measuring Ki67-expressing cells found a significant increase in wheel running mice (Bednarczyk, Aumont, Decary, Bergeron, \& Fernandes, 2009) but multiple studies using male C57BL/6 mice found that proliferation rates were similar to baseline levels after prolonged wheel running treatments such as six weeks and 
after as little as three weeks (Fuss et al., 2009; Kronenberg et al., 2006; Snyder et al., 2009). Wheel running behaviour increases over a three-week period (Clark et al., 2010). Clark et al. (2010) set out to examine whether there were differences in rates of proliferation measured after the first five day of wheel running and three weeks into a running wheel regime. When proliferation was measured by Ki67, it was found that proliferation measured early on in a wheel running treatment was increased compared to controls and compared to proliferation sampled at the end of three weeks of wheel running. Twenty-five days of running still doubled immature, DCX+cells three weeks later suggesting that maintained wheel running increases neurogenesis by supporting the survival of newly generated neurons and not through continuously elevated proliferation. The effects of voluntary wheel running on adult SGZ neurogenesis therefore could be partially dependent on time course of running, as well as strain and species. It is important to note that the method through which proliferation is measured may also alter results.

\section{Focus on Stress}

Stress can also affect neurogenesis and typically does so by reducing it. Neurogenesis is affected by stress primarily in the proliferative stage, but reduced survival has also been reported (Ma, Kim, Ming, \& Song, 2009). Stress paradigms such as footshock stress (Malberg \& Duman, 2003; Shors et al., 2007; Vollmayr, Simonis, Weber, Gass, \& Henn, 2003), social defeat stress (Czeh et al., 2001; Czeh et al., 2002; Gould, McEwen, Tanapat, Galea, \& Fuchs, 1997; Gould, Tanapat, McEwen, Flugge, \& Fuchs, 1998; Mitra, Sundlass, Parker, Schatzberg, \& Lyons, 2006; Simon, Czeh, \& 
Fuchs, 2005; van der Hart et al., 2002; Yap et al., 2006), predator odour (Tanapat, Hastings, Rydel, Galea, \& Gould, 2001), chronic unpredictable stress (R. Alonso et al., 2004; Heine, Zareno, Maslam, Joels, \& Lucassen, 2005), and acute and chronic restraint stress (Pham, Nacher, Hof, \& McEwen, 2003; Rosenbrock, Koros, Bloching, Podhorna, \& Borsini, 2005; Vollmayr et al., 2003) are all known to decrease rates of SGZ proliferation in adult rodents.

The mechanism behind the stress-induced inhibition of neurogenesis remains to be elucidated. Stressful events activate the hypothalamic-pituitary-adrenal axis through the release of corticotrophin-releasing factor from the paraventricular nucleus of the hypothalamus. This stimulates the anterior pituitary to release corticotrophin which then stimulates the adrenal glands to release glucocorticoids. In rodents, the glucocorticoid corticosterone gets released into the bloodstream, which in turn signals back to the hypothalamic-pituitary-adrenal axis in a negative feedback loop (Pariante \& Miller, 2001). Gould et al. (1992) found that adrenalectomized rats had increased cell proliferation and that this effect could be reversed by corticosterone replacement showing that the presence of corticosterone is important for effects on neurogenesis. Many stress studies administer corticosterone directly in order to examine the effects on SGZ neurogenesis. A five-day treatment with corticosterone injections significantly decreased the number of proliferating cells (measured by BrdU+ cells when BrdU was injected for the last four days of corticosterone treatment), and resulted in a smaller number of newly generated neurons after 4 weeks, in the dorsal hippocampus (measured by cells that were positive for mature neuron marker NeuN) (Karishma \& Herbert, 2002). Another study 
injecting corticosterone daily for three weeks, with BrdU being administered for the last 5 days of corticosterone treatment, counted BrdU-positive cells three weeks after the last day of corticosterone and BrdU injections and found that corticosterone-treated animals had significantly reduced counts of BrdU-positive cells compared to controls (Hellsten et al., 2002). Recently, a study administering a high dose corticosterone injection (40 $\mathrm{mg} / \mathrm{kg}$ ) to Sprague-Dawley rats daily for three weeks found significantly reduced amounts of proliferating and immature neurons in the DG of the dorsal hippocampus (Brummelte \& Galea, 2010).

The hippocampus is particularly susceptible to the effects of stress because of its high density of glucocorticoid receptors (GRs). Activation of these receptors may have a number of downstream effects such as glutamate release (Lowy, Gault, \& Yamamoto, 1993; Lowy, Wittenberg, \& Yamamoto, 1995; Yang, Huang, \& Hsu, 2005). There is evidence stress exerts its effects on proliferation work through $\mathrm{N}$-methyl-D-aspartate (NMDA) receptors which are the receptors for the neurotransmitter glutamate (Magarinos \& McEwen, 1995). Suppression of proliferation can be blocked by the NMDA receptor channel blocker MK-801 (Cameron, Tanapat, \& Gould, 1998) and the competitive NMDA receptor antagonist CGP 43487 (Magarinos \& McEwen, 1995). However, there is also evidence for a more direct effect of glucocorticoids; a study that looked at embryonic NSCs found that proliferation was decreased post corticosterone treatment by the GR-mediated downregulation of cyclin D, which is a cell cycle protein (Sundberg, Savola, Hienola, Korhonen, \& Lindholm, 2006). 


\section{Intrinsic Factors}

In young adult rats (nine to ten weeks old), approximately 9000 cells are generated daily in the hippocampus (Cameron \& McKay, 2001), compared with approximately 4000 cells in adults, of which only 3000 survive and differentiate into neurons (M. S. Rao \& Shetty, 2004). Age correlates negatively with the rate of neuronal proliferation in the SGZ (Heine, Maslam, Joels, \& Lucassen, 2004; McDonald \& Wojtowicz, 2005), though many intrinsic factors can influence the basal rate of neurogenesis. Among these are paracrine signaling molecules such as growth factors and neurotransmitters. Paracrine signaling is a form of molecular signaling where the target cell is in proximity to the signal-releasing cell. The SGZ is a neurogenic niche in which many signals exist due to its high number of afferents from several brain regions (Acsady \& Kali, 2007) and its many neuronal connections between mature granule neurons and local interneurons (Houser, 2007). The interpretation of the miRNA results will require some knowledge of potential molecular targets, and therefore a discussion of some of the molecular mechanisms, such as intrinsic signaling, underlying regulation of neurogenesis is useful.

Cell proliferation is primarily regulated by growth factor signaling (Ming \& Song, 2005; C. Zhao, Deng, \& Gage, 2008). Progenitor cells of the hippocampus are typically found in proximity to the vasculature, suggesting that circulating growth factors such as vascular endothelial growth factor (VEGF) released from the blood stream may support the function of neuronal progenitors (Alvarez-Buylla \& Lim, 2004; Palmer, Willhoite, \& Gage, 2000). Interestingly, local infusions of VEGF can promote cell proliferation (Cao 
et al., 2004; Jin et al., 2002) as well as survival when administered over longer periods of time (eight days compared to 3 days). Other growth factors that regulate cell proliferation are fibroblast growth factor 2 (FGF2), and serum insulin-like growth factor 1 (IGF-1) (Duan et al., 2008). Fibroblast growth factor 2 can promote proliferation of adult neural progenitors in vitro (Lie, Song, Colamarino, Ming, \& Gage, 2004; Trejo, Llorens-Martin, \& Torres-Aleman, 2008). Infusing FGF2 promotes SGZ proliferation in young mice but central nervous system deletion of FGF receptor 1, which binds FGF1 and FGF2 with a high affinity, decreases it (Jin et al., 2003; M. Zhao et al., 2007). This suggests that FGF2-mediated signaling is necessary for SGZ cell proliferation (C. Zhao et al., 2008). Fibroblast growth factor 1 instead exerts its effects on neurogenesis through the promotion of neural differentiation (Bartlett, Dutton, Likiardopoulos, \& Brooker, 1994). The stimulating effects of exercise on adult hippocampal neurogenesis depend, among others growth factors, on serum IGF-1. Trejo et al. either increased or decreased neurogenesis by altering serum IGF-1 levels. Mutant mice with low levels of serum IGF1 had reduced neurogenesis, and this was not improved by running. On the other hand, administration of exogenous IGF-1 restored neurogenesis in the mutant mice (Trejo, Carro, \& Torres-Aleman, 2001). Cell proliferation is maximized when IGF-1 and FGF-2 are both present (M. A. Aberg et al., 2003).

While increased cell proliferation in response to running could be mediated by growth factor signaling, decreased proliferation in response to stressors could similarly result from reduced neurotrophic signals. The increase in SGZ proliferation due to voluntary running is likely to be mediated by BDNF as well as VEGF, IGF-1 and FGF-2 
(Olson, Eadie, Ernst, \& Christie, 2006). Exercise causes increased levels of BDNF mRNA and protein (Berchtold, Kesslak, Pike, Adlard, \& Cotman, 2001; Neeper, GomezPinilla, Choi, \& Cotman, 1996; Widenfalk, Olson, \& Thoren, 1999). By injecting BDNF into the hippocampus of rats, progenitor cell proliferation and survival are enhanced (Scharfman et al., 2005). A variety of stress paradigms decrease mRNA BDNF expression in the hippocampus of rodents (Bland et al., 2007; Gronli et al., 2006; Nibuya, Takahashi, Russell, \& Duman, 1999; Pizarro et al., 2004; Smith, Makino, Kvetnansky, \& Post, 1995; Ueyama et al., 1997; Xu, Luo, Richardson, \& Li, 2004), including administrations of corticosterone (Schaaf, de Jong, de Kloet, \& Vreugdenhil, 1998; Smith et al., 1995).

\section{Functional Correlates of Neurogenesis}

Although newborn neurons in the SGZ are integrated into existing circuitry, the exact function of neurogenesis remains to be elucidated. It has been hypothesized that integration of immature neurons can contribute to unique forms of learning and memory. Additionally, there is some evidence that SGZ neurogenesis has a role in mood regulation.

\section{Learning and Memory}

The hippocampus plays a role in spatial learning and declarative memory (Barco, Bailey, \& Kandel, 2006; Manns \& Eichenbaum, 2006). The suggestion that SGZ neurogenesis has a function in learning and memory is supported by many correlative studies. However, inconsistencies with the findings are likely due to heterogeneity of animal species and strains, behavioural paradigms and procedures, and the cells targeted 
by manipulation used to alter neurogenesis (C. Zhao et al., 2008). Increases in neurogenesis achieved through running and enriched environment have been significantly positively correlated with enhanced spatial learning and recognition memory (BruelJungerman, Laroche, \& Rampon, 2005; Farmer et al., 2004; Kempermann et al., 1997; van Praag, Christie et al., 1999; van Praag, Shubert, Zhao, \& Gage, 2005). Decreases in neurogenesis, caused by irradiation (using x-rays to damage cells), pharmacological means, or transgenics, have not consistently correlated with deficits in spatial memory (Lemaire, Koehl, Le Moal, \& Abrous, 2000; Meshi et al., 2006; Raber et al., 2004; Rola et al., 2004; Saxe et al., 2006; Shors, Townsend, Zhao, Kozorovitskiy, \& Gould, 2002; Snyder, Hong, McDonald, \& Wojtowicz, 2005), place and object memory (BruelJungerman et al., 2005; Madsen, Kristjansen, Bolwig, \& Wortwein, 2003; Winocur, Wojtowicz, Sekeres, Snyder, \& Wang, 2006), or associative learning (Saxe et al., 2006; Shors et al., 2001; Winocur et al., 2006; Zhang, Zou, He, Gage, \& Evans, 2008). The learning of tasks that require use of the hippocampus such as trace-eyeblink conditioning and the Morris water maze has shown subsequent positive correlation with enhanced SGZ neurogenesis (Leuner, Gould, \& Shors, 2006), and findings by Sisti, Glass, and Shors (2007) show that it is the learning component of tasks and not simply the presence of training on the task that may cause survival of neurons.

\section{Mood Regulation}

Neurogenesis can be decreased by both hypercortisolemia and lowered serotonergic transmission, both of which are associated with depression in humans (Kempermann \& Kronenberg, 2003). Gould et al. (1992) suggested a role for SGZ 
neurogenesis in mood regulation as both humans with major depression and stressed animals show elevated levels of glucocorticoids along with reduced neurogenesis. In fact, both acute and chronic stress can decrease SGZ cell proliferation and cell survival in adult mammals. Treatment with antidepressants increases SGZ neurogenesis in adult mammals (Banasr, Soumier, Hery, Mocaer, \& Daszuta, 2006; Czeh et al., 2001; Larsen, Rosenbrock, Sams-Dodd, \& Mikkelsen, 2007; Madsen et al., 2000; Malberg, Eisch, Nestler, \& Duman, 2000; Santarelli et al., 2003). Interestingly, treatment with antidepressants can also prevent and/or reverse stress-induced decrease in neurogenesis (Czeh et al., 2001; Czeh, Simon, Schmelting, Hiemke, \& Fuchs, 2006; Hellsten et al., 2002; H. J. Lee et al., 2001; Malberg \& Duman, 2003; van der Hart et al., 2002). Furthermore, there is also a positive correlation between the efficacy of antidepressant treatment and the subsequent increase in SGZ neurogenesis (Schmidt \& Duman, 2007). Increased levels of neurogenesis may even be required for the alleviation of behavioural markers of depression such as learned helplessness in an animal model (Malberg \& Duman, 2003).

\section{MicroRNA Involvement in Neurogenesis}

Few studies have examined the role of miRNAs in adult neurogenesis using in vivo techniques and only one study to date has looked at adult SGZ neurogenesis specifically (Szulwach et al., 2010). Additionally, no studies have investigated in vivo adult SGZ neurogenesis using miRNA microarray. What follows is a review of the work that has been done on both adult and embryonic neurogenesis in vivo and in vitro 
organized by miRNA. For a summary of the following sections please refer to Table 1 at the end of the section.

\section{MicroRNA -137}

Only one study to date has investigated miRNA involvement in postnatal SGZ neurogenesis. The protein methyl-CpG-binding protein (Mecp2) influences proliferation and differentiation of adult NSCs (Kishi \& Macklis, 2004; Smrt et al., 2007; X. Zhao et al., 2003) and was found to regulate the expression of miR-137 (Szulwach et al., 2010) which has also already been implicated in the timing of adult NSC development (Silber et al., 2008). The preliminary in vitro findings showed that high levels of miR-137 lead to increased proliferation of adult NSCs but decreased differentiation, and that blocking miR-137 reduced proliferation but enhanced differentiation. The dosage of miR-137 in adult NSCs appears critical for modulating the timing of proliferation and differentiation of these cells. Further in vivo research found that when miR-137 was overexpressed in the DG in 2-month-old male mice using a miR-137 retrovirus, the percentage of retrovirus-infected cells labeled with BrdU was significantly increased one week posttransfection when compared to percentage of BrdU-positive cells of control-retrovirusinfected cells (Szulwach et al., 2010). The opposite effect was found for DCX suggesting miR-137-overexpression in adult NSCs causes cells to proliferate more but reduces differentiation capacity in vivo. MicroRNA-137 targets a mRNA called Ezh2 whose downstream effects can lead to histone modification, which is a type of epigenetic regulation that can affect the expression of many genes. It remains to be determined which genes are affected and how they could influence neurogenesis. Interestingly, 
expression of miR-137 is also regulated by epigenetic factors such as DNA methylation as seen when Mecp2 binds to methylated regions upstream of the miR-137 gene and regulates its transcription by working in conjunction with the transcription factor Sox 2 (already implicated in neurogenesis). This research not only shows how miR-137 is involved in the timing of NSC progression but demonstrates that miRNAs and epigenetic regulation affect each other to do so.

\section{MicroRNA-124 and MicroRNA-124a}

In adult SVZ neurogenesis, which may have some similarities to adult SGZ neurogenesis, it was found that miRNA-124 regulates temporal progression of NSC lineage progression (Cheng, Pastrana, Tavazoie, \& Doetsch, 2009). It is first expressed in neural progenitors of the SVZ and is increasingly expressed as neuronal differentiation takes place. Knocking out miRNA-124 in purified SVZ stem cells caused them to retain their character as dividing precursors and thus they did not differentiate into neurons. On the other hand, ectopic expression of miRNA-124 in SVZ precursors resulted in precocious neuron formation. A target of miRNA-124 is the SRY-box transcription factor Sox 9 which has been shown to be downregulated during neurogenesis in vivo. When Sox9 was overexpressed in SVZ cells in culture, neuron production was halted, whereas knockout of Sox9 lead to increased neurogenesis. Therefore, when miRNA-124 targets Sox9, neurogenesis in SVZ cells is increased by encouraging the transition from amplifying cells to neuroblasts. This study, conducted by Cheng et al. (2009), showed that miRNA-124-mediated repression of Sox9 is required for the transition of SVZ stem cells to neurons. 
In mice, miRNA-124a whose sequence is slightly different from miRNA-124 but belongs to the same family of miRNAs, is found mostly in differentiating and mature neurons compared to neural progenitors. MicroRNA-124a is conserved from worms to humans (Aboobaker, Tomancak, Patel, Rubin, \& Lai, 2005; Lagos-Quintana et al., 2002) and is thought to be the most abundantly expressed miRNA in the brain, to the extent that it represents $25-48 \%$ of all brain miRNA (Lagos-Quintana et al., 2002). Along with many neuronal genes, miRNA-124a transcription is repressed when the protein RE1 silencing transcription (REST) interacts with repressor element RE1 sites on the chromatin (Chong et al., 1995; Schoenherr \& Anderson, 1995). The transcription factor REST works on miRNA-124a in nonneuronal cells and neural progenitors but not in mature neurons. As the transition from stem cell to postmitotic neurons occurs, REST is down-regulated which allows miRNA-124a to be expressed (Ballas, Grunseich, Lu, Speh, \& Mandel, 2005). Ectoptic expression of miRNA-124a in cultured HeLa cells results in lowered expression of non-neuronal transcripts and renders the gene expression profile of those cells more similar to that of cerebral cortex cells (Lim et al., 2005). Some of the transcripts targeted in the HeLa cells are endogenous targets of miRNA-124a in neurons as was shown by inhibiting miRNA-124a activity in cultured cortical neurons. With miRNA-124a inhibited, ten transcripts that were repressed in the HeLa cells treated with miRNA-124a increased in cortical neurons. This demonstrates that some non-neuronal transcripts that miRNA-124a can repress are naturally expressed in cortical neurons but then are repressed by miRNA-124a (Conaco, Otto, Han, \& Mandel, 2006). 
One known target of miRNA-124a is that of the mRNA encoding small Cterminal domain phosphatase 1 (CTDSP1) (Visvanathan, Lee, Lee, Lee, \& Lee, 2007). This protein is normally expressed in non-neural tissues and is implicated in central nervous system development because its downregulation induces neurogenesis (Visvanathan et al., 2007). As part of the REST complex, downregulation of small Cterminal domain phosphatase 1 leads to increased expression of miRNA-124a and other neuronal transcripts under regulation by REST. This describes a double negative feedback loop that exists to maintain neuronal gene expression (Conaco et al., 2006; Wu \& Xie, 2006). The REST complex and miRNA are the repressor components in this loop. MicroRNA-124 can also target two other mRNAs of proteins that form the REST complex: Mecp2 and CoREST (Wu \& Xie, 2006). Furthermore, the transition from progenitor cell to mature neuron is mediated in part by miRNA-124a and its direct regulation of polypyrimidine tract-binding protein 1 . Downregulation of polypyrimidine tract-binding protein 1 leads to a neuronal alternative slicing pattern of several mRNAs specific to neuronal cells (Makeyev, Zhang, Carrasco, \& Maniatis, 2007).

Comparative sequence analysis has shown that transcription factors such as REST and cyclic AMP response element-binding (CREB) interact with brain-specific miRNAs to regulate the expression of neuron-specific genes. For example, there exists binding sites in the genome in the vicinity of miRNA-124 for certain transcription factors such as CREB and REST. In particular, REST and its cofactor complex are targeted by brain miRNAs such as miRNA-124, as well as miRNA-9 and miRNA-132. Brain-related 
miRNA genes are enriched with conserved cyclic AMP response elements in their regulatory regions suggesting CREB has a role in upregulating them (Wu \& Xie, 2006).

\section{MicroRNA-9}

In vitro, miRNA-124 and miRNA-9 expression increased rapidly over the course of transitioning from neuronal precursor to neurons in differentiating embryonic stem cells. Overexpression of the two together promotes neuronal differentiation and underexpression leads to the lack of differentiation (Krichevsky, Sonntag, Isacson, \& Kosik, 2006). A study by Deo et al. (2006) using in situ hybridization found that in mouse embryos neural progenitors express miRNA-9. Interestingly, miRNA-9 regulates the expression of the gene tlx (Deo et al., 2006) which controls the self-renewal of adult NSCs in vitro and in vivo (Shi et al., 2004). The protein tlx is capable of maintaining self-renewal properties of a neural stem cell by repressing transcription of genes encoding p21 (a cyclin-dependent kinase which inhibits the progression of the cell cycle), as well as phosphatase and tensin homolog. It does so by forming a complex with histone deacetylases (Sun, Yu, Evans, \& Shi, 2007). Zhao et al. (2009) also found that tlx regulates neural stem cell proliferation and differentiation both in adult cultured cells as well as in vivo in embryonic neural stem cells. Using in utero electoporation of miRNA9 into ventricular zone neural stem cells resulted in differentiation and migration of those cells, similarly to the effects of tlx. Importantly, they noted the presence of a regulatory loop between tlx and the 3' untranslated region of miRNA-9. 


\section{Let-7 and MicroRNA-125}

The miRNA let-7 is known to play a role in neural stem cell specification (Rybak et al., 2008). Mouse embryonic neural stem cells express both let-7 and miRNA-125 during differentiation in vitro (Rybak et al., 2008). The pluripotency factor lin-28 can bind to the pre-let-7 RNA and inhibit its processing by Dicer thereby reducing expression of let-7. Lin-28, however, can be repressed by both let-7 and miRNA-125 suggesting an autoregulatory circuit that ensures expression of let-7 and miRNA-125 during differentiation (Rybak et al., 2008).

MicroRNA let- $7 \mathrm{~b}$ which is a member of the let- 7 family, has also been shown to regulate neural stem cell fate decisions (C. Zhao et al., 2010). It targets Tlx and another cell cycle regulator Cyclin D1 (C. Zhao et al., 2010). Overexpression in cultured adult neural stem cells leads to reduced proliferation and increased neural differentiation, whereas knockdown results in enhanced proliferation (C. Zhao et al., 2010). This miRNA was manipulated in vivo through in utero electroporation and lead to reduced cell cycle progression of embryonic neural stem cells (C. Zhao et al., 2010). Previously, let$7 \mathrm{~b}$ has been shown to reduce self-renewal of aging neural stem cells by targeting Hmga2 (Nishino, Kim, Chada, \& Morrison, 2008). Hmga2 is capable of decreasing expression of $\mathrm{p} 16^{\mathrm{Ink4a}}$ and $\mathrm{p} 19^{\mathrm{Arf}}$ : two genes considered to be tumor suppressors by declining selfrenewal capacity of a cell (Nishino et al., 2008). Let-7b's expression level in neural stem cells over the course aging is consistent with the progressive decline in SGZ neurogenesis with age. Let-7 and let-7b regulate neural stem cells across many stages of development by targeting several molecules (Shi et al., 2010). 


\begin{tabular}{|c|c|c|c|c|c|}
\hline $\begin{array}{l}\text { miRNA } \\
\text { (reference) }\end{array}$ & 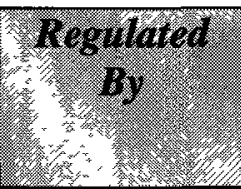 & Effect & $\begin{array}{l}\text { mRNA } \\
\text { 2arget }\end{array}$ & $\begin{array}{l}\text { Regulatory } \\
\text { Loop } \\
\text { L }\end{array}$ & $\begin{array}{l}\text { Cells used } \\
\text { in } \\
\text { Research }\end{array}$ \\
\hline $\begin{array}{l}\text { miR-137 } \\
\text { (Szulwach } \\
\text { et al., } \\
\text { 2010) }\end{array}$ & $\begin{array}{l}\text { Mecp2, } \\
\text { Sox2 }\end{array}$ & $\begin{array}{l}\text { Promotes } \\
\text { proliferation, } \\
\text { decreases } \\
\text { differentiation }\end{array}$ & Ezh2 & $\begin{array}{l}\text { Repression of } \\
\text { Ezh2 feeds back } \\
\text { to chromatin }\end{array}$ & $\begin{array}{c}\text { Adult SGZ } \\
\text { tissue }\end{array}$ \\
\hline $\begin{array}{l}\text { miR-124 } \\
\text { (Cheng et } \\
\text { al., 2009) }\end{array}$ & $\begin{array}{l}\text { REST, } \\
\text { CREB? }\end{array}$ & $\begin{array}{c}\text { Promotes } \\
\text { differentiation }\end{array}$ & Sox9 & ? & $\begin{array}{c}\text { Adult SVZ } \\
\text { tissue }\end{array}$ \\
\hline $\begin{array}{l}\text { miR-124a } \\
\text { (Conaco et } \\
\text { al., 2006) }\end{array}$ & REST & $\begin{array}{l}\text { Represses non- } \\
\text { neuronal } \\
\text { transcripts }\end{array}$ & $\begin{array}{c}\text { SCP1, } \\
\text { Mecp2, } \\
\text { CoREST, } \\
\text { PTBP1 }\end{array}$ & $\begin{array}{c}\text { Double negative } \\
\text { feedback } \\
\text { (REST, miR- } \\
\text { 124a) }\end{array}$ & $\begin{array}{c}\text { Embryonic } \\
\text { cultured } \\
\text { cortical } \\
\text { progenitors }\end{array}$ \\
\hline $\begin{array}{c}\text { miR-9 } \\
\text { (Zhao et } \\
\text { al., 2009) }\end{array}$ & Tlx & $\begin{array}{c}\text { Promotes } \\
\text { differentiation } \\
\text { when expressed } \\
\text { with miR-124 }\end{array}$ & Tlx & $\begin{array}{l}\text { Negative } \\
\text { feedback loop } \\
\text { between TLX } \\
\text { and miR-9 } \\
\text { 3'UTR }\end{array}$ & $\begin{array}{c}\text { Embryonic } \\
\text { cultured } \\
\text { neural } \\
\text { progenitors }\end{array}$ \\
\hline $\begin{array}{l}\text { let-7 and } \\
\text { miR-125 } \\
\text { (Rybak et } \\
\text { al., 2008) }\end{array}$ & $\begin{array}{c}\text { Pluripotency } \\
\text { Factor lin- } \\
28\end{array}$ & $\begin{array}{l}\text { Reduces self- } \\
\text { renewal } \\
\text { capacity }\end{array}$ & $\begin{array}{l}\operatorname{lin}-28 \\
\operatorname{lin}-41\end{array}$ & $\begin{array}{l}\text { Lin-28 and let-7, } \\
\text { let-7 and miR- } \\
125 \text { reduce lin- } \\
28\end{array}$ & $\begin{array}{c}\text { Embryonic } \\
\text { cultured } \\
\text { neural } \\
\text { stem cells }\end{array}$ \\
\hline $\begin{array}{c}\text { let-7b } \\
\text { (Zhao et } \\
\text { al., 2010) }\end{array}$ & $?$ & $\begin{array}{l}\text { Reduces self- } \\
\text { renewal } \\
\text { capacity, } \\
\text { promotes } \\
\text { differentiation }\end{array}$ & $\begin{array}{l}\text { Tlx, } \\
\text { Cyclin } \\
\text { D1, } \\
\text { Hmga2 }\end{array}$ & ? & $\begin{array}{l}\text { Cultured } \\
\text { adult } \\
\text { NSCs, } \\
\text { embryonic } \\
\text { NSCs in } \\
\text { vivo }\end{array}$ \\
\hline
\end{tabular}

Table 1. Summary of research on miRNA involvement in neurogenesis. 


\section{Overview of Proposed Study}

Adult SGZ neurogenesis is an important aspect of brain plasticity that may have functional implications for mood regulation, and learning and memory. MicroRNAs are a novel class of molecules that have already been shown to help regulate neural stem cell lineage progression both in vitro and in vivo. However, no studies to date have systematically investigated miRNA involvement in adult SGZ neurogenesis in vivo with the use of microarray technology. Finding miRNA genes whose expression is altered with an increase in neurogenesis and a decrease in neurogenesis will allow identification of miRNAs involved in the process as it occurs in vivo, as well as confirm some of the in vitro findings to date. By conducting this work in vivo there is the potential to investigate the role of non-neuronal cells such as glia in the process of neurogenesis. For this reason we manipulated neurogenesis in adult Sprague-Dawley rats using three weeks of voluntary wheel running or three weeks of daily corticosterone injections which are known respectively to robustly increase and decrease neurogenesis (Bednarczyk et al., 2009; Eadie et al., 2005; Hellsten et al., 2002; Redila \& Christie, 2006; Snyder et al., 2009; van Praag, Kempermann et al., 1999). With a subsequent miRNA microarray we expect to find that some miRNA genes have significantly altered expression between the corticosterone group (decreased neurogenesis) and their control group, as well as between the voluntary exercise treatment group, which has the opposite effect as corticosterone injections (increase in neurogenesis) and its respective control group. Wheel running and corticosterone work through different molecular pathways to alter neurogenesis, therefore, miRNA genes whose expression changes significantly and in opposite 
directions with both manipulations, will represent genes which are common to the process of neurogenesis, not just genes which are involved in only one pathway through which neurogenesis is altered.

The manipulations used have already shown that they can alter neurogenesis in the DG of the dorsal hippocampus (Bednarczyk et al., 2009; Brummelte \& Galea, 2010; Hellsten et al., 2002). To assess proliferation and early differentiation/survival in experimental and control groups, immunohistochemistry for the endogenous mitotic marker Ki67, the thymidine analogue BrdU (injected 24 hours before decapitation), and endogenous early neuronal marker DCX, will be carried out in coronal brain slices containing dorsal DG. Following assessment of changes in neurogenesis levels through stereology of BrdU-positive cells and cell counts of Ki67- and DCX-positive cells, miRNA expression will be quantified for 261 rat miRNAs using custom printed microarrays. Results from the miRNA microarray will then be validated by real-time PCR (RT-PCR). Identification of significant upregulation and downregulation of miRNA genes that occurs with changes in neurogenesis will allow for the formation of new hypotheses about how these miRNAs interact with their predicted mRNA targets to affect neurogenesis. 


\section{Methods}

\section{Animals}

Animals were 3-month-old, male Sprague-Dawley rats (between 200-250g upon arrival to Carleton University) (Charles River Laboratories, St-Hyacinthe, QC). Upon receipt to the facilities, rats were given two weeks to acclimatize. During this period they were housed in pairs because a study by Stranahan et al. (2006) showed previously that social isolation before the commencement of wheel running can delay the positive effects of running on cell proliferation. During the 3-week experimental period rats were all singly housed as the voluntary wheel running experimental group had to be single housed in order to assess individual running behaviour, thus all the other groups were also singly housed. Food and water were provided ad libitum and rats were maintained on a 12/12 light/dark cycle with lights on at 8:00 am for the duration of the entire study. All rats were weighed daily starting at 8:00 am. This experiment was approved by Carleton University Animal Care Committee (P09-03) and is in compliance with the rules and regulations of the Canadian Council on Animal Care (CCAC). Rats were randomly assigned to one of four treatment conditions on experimental day 1: vehicle injection controls, corticosterone injections, voluntary exercise (no injection), and no injection controls.

\section{Corticosterone and Control Injections}

Corticosterone injections or vehicle injections were administered daily throughout the experimental period. Administration and preparation of the injections was similar to 
that described in Hellsten et al. (2002). The corticosterone injections commenced at the beginning of the dark cycle $(8: 00 \mathrm{pm})$. Rats in the corticosterone injection and in the injection control groups $(n=10)$ were removed from their housing room one by one (in a random order each day) and brought to an injection room where they were injected subcutaneously with a suspension of $40 \mathrm{mg} / \mathrm{kg}$ corticosterone (Sigma Cat. \# 27840) in $100 \%$ ethanol $(50 \mathrm{mg} / \mathrm{ml})$ then diluted 6.25 -fold in sesame oil $(8 \mathrm{mg} / \mathrm{ml})$ (Sigma-Aldrich, Oakville, Cat. \# S3547). Control injections were made up of an identical proportion of ethanol and oil as corticosterone injections but did not contain any corticosterone. Corticosterone injections were prepared by first mixing the corticosterone and ethanol and then using a metal spatula to crush the corticosterone to produce a more homogenous suspension. Afterwards, the appropriate amount of sesame oil was added, and directly before preparing the needle the suspension was mixed vigorously with a small metal spatula and then vortexed for approximately 30 seconds. The needle gage used for corticosterone injections was $23 \mathrm{~g}$ and syringes were of a volume of $3 \mathrm{ml}$. The average daily injection volume was $2.0 \mathrm{ml}$ and $2.4 \mathrm{ml}$ for the corticosterone injection group and the vehicle injection group respectively.

\section{Voluntary Exercise}

Running wheels were provided to rats in the voluntary exercise condition only during the experimental period. Running was quantified by hooking up a bicycle speedometer (Supercycle ${ }^{\circledR M D}$ ) to the running wheels (Techniplast, $d=34 \mathrm{~cm}$ ). Readings of total distance traveled, daily distance traveled, and daily time spent running were taken every morning before weighing. Bicycle speedometers were capable of 
reading speeds as slow as 10 meters/min, however, animals may have sometimes run slower than this speed and so the bike speedometers used to quantify running behaviour only provide a limited estimate of distance traveled and time spent running. For this reason running wheel data will be analyzed as ordinal and not scalar.

\section{BrdU Injections}

Intraperitoneal BrdU (Sigma-Aldrich, Oakville, Cat. \# B5002) injections were administered on experimental day 21 at the beginning of the light cycle $(200 \mathrm{mg} / \mathrm{kg}$ at a concentration of $30 \mathrm{mg} / \mathrm{ml}$ dissolved in phosphate buffered saline) with an average injection volume of $2.6 \mathrm{ml}$. Animals were anesthetized and decapitated 24 hours following the BrdU injection.

\section{Decapitation and Tissue Processing}

Animals were euthanized by decapitation following an injection of sodium pentobarbital (C.D.M.V, St-Hyacinthe, QC) with dosage of $60 \mathrm{mg} / \mathrm{kg}$ at a volume of 200 $\mathrm{mg} / \mathrm{ml}$ on experimental day 22 . Brains were immediately removed and placed into a cooled acrylic matrix (Stoelting, Cat. \# 51382). Using razor blades, brain hemispheres were separated by slicing along the medial longitudinal fissure. Brain hemispheres used for assessment of proliferation and survival through immunohistochemistry were immediately placed in $4 \%$ PFA overnight. To collect miRNA samples from the opposite hemisphere of the brain, micropunches (18-gage) were taken from $1 \mathrm{~mm}$ slices of the dorsal DG of the hippocampus by Marzena Siecszko and stored in microcentrifuge tubes at $-80^{\circ} \mathrm{C}$. An equal number of left and right brain hemispheres were taken for 
immunohistochemistry and micropunches samples. Trunk blood was also collected during the decapitations in order to process blood plasma for corticosterone levels.

\section{Corticosterone Radioimmunoassay}

Approximately $1 \mathrm{ml}$ of trunk blood was collected in ethylenediaminetetraacetic acid-containing tubes which were subsequently placed on wet ice until centrifuged at $3600 \mathrm{rpm}$ for 8 minutes after which the supernatant was stored at $-80^{\circ} \mathrm{C}$. The plasma corticosterone levels were then measured using a standard radioimmunoassay kit for rats and mice (MP Biomedicals, Orangeburg, NY).

\section{Immunohistochemistry}

Brains collected for BrdU tissue processing were left in 4\% paraformaldehyde for two days then dehydrated in $10 \%$ sucrose solution for 1 day, $20 \%$ sucrose solution for 1 day, and then left in $30 \%$ sucrose solution until slicing which occurred within 3 weeks of decapitation. Slicing was performed on a cryostat set at $18^{\circ} \mathrm{C}$. The resulting $50 \mu \mathrm{m}$ sections were floated in $0.1 \mathrm{M}$ phosphate buffer with azide, $\mathrm{pH}$ 7.4.

Immunohistochemistry for BrdU was performed on free-floating $50 \mu \mathrm{m}$ coronal sections containing the DG of the hippocampus starting at approximately bregma $=-1.88$ $\mathrm{mm}$ and ending at bregma $=-6.04 \mathrm{~mm}$ (Paxinos and Watson, 1997). Sections were transferred into $10 \mathrm{mM}$ phosphate buffered saline (PBS) (pH 7.2) with azide and rinsed twice in PBS with azide. Then endogenous peroxidase was blocked by incubating the section in $0.3 \% \mathrm{H}_{2} \mathrm{O}_{2}$ in PBS for 30 minutes, and rinsed twice in PBS with azide. Next, sections were denatured in $2 \mathrm{~N} \mathrm{HCl}$ at $45^{\circ} \mathrm{C}$ for 1 hour in order to expose incorporated 
BrdU. Sections were then neutralized by incubating in boric acid buffer $(\mathrm{pH} 8.5)$ for 10 minutes. After three more rinses in PBS with azide, sections were left to incubate overnight at $4^{\circ} \mathrm{C}$ in primary antibody solution containing 1:1000 mouse monoclonal antiBrdU (Sigma, Saint Louis, MO) in dilution solution and $30 \mu \mathrm{l} / \mathrm{mL} 10 \%$ Triton-X. Dilution solution consists of 1:1:5 2\% Albumin from Bovine Serum (BSA), $2 \% \lambda$ Carrageenan, and PBS with azide. Both BSA (Sigma, St. Louis, MO, Cat. \# 9048-46-8) and $\lambda$-Carrageenan (Sigma, St. Louis, MO, Cat. \# C1867) are used as protein blockers. The next day, the sections were rinsed three times in PBS with azide and then left to incubate for two hours at room temperature in secondary antibody solution containing 1:100 secondary anti-mouse IgG, biotinylated species-specific whole antibody (from sheep) (GE Healthcare, Little Chalfont Buckinghamshire, UK, Cat. \# RPN1001V) in dilution solution and $30 \mu \mathrm{l} / \mathrm{mL} 10 \%$ Triton-X. After rinsing the sections three times with PBS without azide, sections were left to incubate for another two hours at room temperature in a 1:100 solution of tertiary antibody (Streptavidin-biotinylated Horseradish peroxidase complex from GE Healthcare, Little Chalfont Buckinghamshire, UK, Cat. \# RPN1051V) in dilution solution (without azide) and $30 \mu 1 / \mathrm{ml} \mathrm{10 \%} \mathrm{Triton-X.}$ After another three rinses in PBS without azide a 3, 3'-Diaminobenzidine (DAB) reaction was performed to color BrdU-positive cells. Sections were mounted onto gelatinized slides and once dry were counterstained with Pyronin Y (Sigma-Aldrich, Oakville, Cat. \# P9172). Afterwards, slides were dehydrated, cleared, and coverslipped.

Immunohistochemistry for DCX and Ki67 was also performed on 5 evenly spaced slices throughout the hippocampus, starting at approximately bregma $=-1.88 \mathrm{~mm}$ and 
ending at approximately $-6.04 \mathrm{~mm}$ (Paxinos, 1997) which is the same range tissue was sampled from for the BrdU immunohistochemistry. The staining protocol for DCX is nearly identical to that of BrdU with a few exceptions. Instead of the incubation in $\mathrm{HCl}$ and boric acid buffer there is a 30 minute incubation period in $3 \%$ normal horse serum (Vector, Burlington, ON, Canada, Cat.\# S-2000). The primary and secondary antibodies are also different in that the primary antibody is anti-DCX raised in goat (Santa Cruz Biotechnologies, Santa Cruz, California, USA, Cat. \# sc-8066) used in a proportion of 1:200 in the primary working solution, and the secondary antibody is anti-goat biotinylated secondary antibody (Vector, Burlington, ON, Canada, Cat. \# BA-9500). Immunohistochemistry for Ki67 differs from BrdU immunohistochemistry in that there is no incubation in $\mathrm{HCl}$ or boric acid buffer and that the primary antibody is anti-Ki67 (Dako, Mississauga, ON, Canada, Cat.\# M724801-8) in a proportion of 1: 500.

\section{Stereology and Cell Counting}

To quantify the number of BrdU-positive cells in the DG of the dorsal hippocampus the unbiased optical fractionator counting procedure was employed (West, Slomianka, \& Gundersen, 1991) using a semiautomatic stereology system (Stereo Investigator, MicroBrightfield). The 10x lens was used when tracing a contour around the subgranular zone and half of the granule cell layer proximal to the SGZ. Counting frame was set at 50x50 mm and grid size was $90 \times 90 \mathrm{~mm}$. Additionally, guard zones were set at $2 \mu \mathrm{m}$ and depth of fractionater was set at $20 \mu \mathrm{m}$. BrdU-positive cells were counted in every sixth slice of the hippocampus using an oil emulsion 100x lens. Estimates of total BrdU-positive cells, markers counted, coefficient error (CE Gunderson 
$\mathrm{m}=1$ ), mean mounted thickness and number of sampling sites was recorded. Cell counting for DCX and Ki67 was done on an Olympus BX61 microscope with a 40x lens. All cells in the region of interest were individually counted and recorded. The number of cells per slice was recorded and totals per five slices were tabulated.

\section{Statistical Analyses used to Assess Changes in Neurogenesis}

To assess if changes in neurogenesis occurred between experimental groups with regards to Ki67+ cell counts, DCX+ cell counts, and estimates of total BrdU+ cells in the dorsal dentate gyrus one-way ANOVAs between the four groups were conducted, specifically with three planned contrasts. The first planned contrast examined differences between the vehicle injection group and the corticosterone injection group. The second planned contrast was used to examine differences between the no injection control and the wheel running group. Lastly, to ensure that there were no differences between the two types of control groups, a planned contrast was used to compare the vehicle injection group and the no injection control. This type of analysis was also used to examine the effect of treatment on starting and final weights, and plasma corticosterone at time of decapitation.

\section{Correlates of Measures of Neurogenesis and Amount of Wheel Running}

Additionally, two-tailed Pearson correlations between measure of neurogenesis, weight, and plasma corticosterone were conducted within each experimental group. Onetailed Spearman correlations were used to investigate correlates of amount of wheel running within the wheel running group $(n=9)$. 


\section{Microarray}

The microarray data that would be generated from the methods below are not included in this thesis. The techniques and procedures that follow have been tested and optimized for this study, however, due to the lengthy data analysis that would be required prior to inclusion of this data in the final thesis I was advised by my prospectus committee on May $26^{\text {th }}, 2010$ to submit this thesis prior to completion or the microarrays.

\section{Overview}

Microarray technology allows for quantification of gene expression by measuring signal intensity from fluorescently marked miRNAs bound to corresponding DNA probes on a chip (referred to as the microarray). DNA probes for known miRNAs and control probes will be custom printed onto microarrays. Total RNA, including low molecular weight RNA, from either the right of left hemisphere is extracted from the DG of animals in each treatment group and the miRNA within these samples is labeled with the fluorescent dye. Labeling miRNAs and then hybridizing them to the array chip allows for measurement of signal intensity from thousands of spots following production of scanned image of the microarray. A two-channel reference design will be employed. Following normalization of data, significance testing will occur for each gene.

Printing MicroRNA Microarrays

The VersArray ChipWriter Pro (Bio Rad) will be used to print all microarray chips. The function of this machine is to attach oligonucleotide samples or 'probes' onto epoxide-coated microarray chips. This is done by robotically controlled pins that pick up 
oligonucleotide samples from a source plate and dab the samples onto the chips in a preprogrammed formation. Before the pins dab the sample onto the microarray slides however, the excess is first removed by blotting the pin onto a glass slide. Following the blotting of each sample, the pins are cleansed by oscillation in a water bath containing $10 \%$ ethanol in distilled water and then dried by air holes. Sonication of the water bath is also used to clean the pins more thoroughly. The series of spots produced by one pin is referred to as a grid. All the grids used to print all the probes used including controls one time is referred to as a supergrid.

Probes will be taken from the NCode Multi-Species miRNA Microarray Probe Set V2 (Invitrogen) which contains oligonucleotides complementary to existing and predicted miRNA sequences of miRNAs of several species, including 261 known rat miRNA genes. Oligonucleotide probes will be suspended in Pronto! TM Epoxide Slide Spotting Solution (Corning, Cat. \#40047) at a concentration between 20 and $50 \mathrm{uM}$ and then printed on Corning®Epoxide Coated Slides with Bar Codes (Corning, Cat. \#40043). During printing, a source plate contains suspended probes as well as various types of controls. The source plate is sealed and stored at $-20^{\circ} \mathrm{C}$ until printing. On the day of printing, source plates will be thawed at room temperature for 20 minutes and then centrifuged at 2,000 rpm for one minute. Additionally, the source plate is left to acclimatize to the humidity in the ChipWriter for 10 minutes before printing commences. Each probe will be printed on each slide at least 4 times and under ideal printing conditions. 
Ideal printing conditions (which result in the best spot size and morphology) are as follows: ambient temperature of $20-25^{\circ} \mathrm{C}$, relative humidity of $65 \%$ in the ChipWriter, and 25 washes and 30 seconds of sonication between each sample loading. The $\mathrm{z}$ chip down setting will be $109.5 \mathrm{~mm}$ as this was found to reduce spot donuting (when signal is strong on the periphery of a spot but lower in the middle) (Jansman, 2009). Additionally, unused air holes should be covered with electrical tape so that air only exits from holes aligned with pins used for printing (up to 48 can be used). After completion of printing, arrays will be stored at ambient temperature in 5-slide slide holders sealed in microarray storage pouches (Corning, Cat., \#40085). Before storage, however, microarrays can be incubated in the ChipWriter at $70 \%$ humidity for 12 hours and then dried at room temperature for 30 minutes. Stored microarrays can be used up to six months after. The quality of the printed arrays will then be tested using SYBR Green II staining on a representative sample of arrays that will be used for hybridization.

Various types of control probes will also be printed on the arrays. A first type of control is that of using a synthetic NCode sequence probe which is complementary to an NCode spike-in miRNA control which will be added to miRNA samples in a known quantity. The NCode Multi-Species miRNA Microarray Control V2 which is a synthetic $\sim 22$ nucleotide miRNA sequence, gives no cross-hybridization or interference with known miRNAs from any of the model organisms. A 2X dilution series $(0.000015$ to $100 \mu \mathrm{M})$ of this probe is printed twice per grid. This allows for future assessment of grid-to-grid variation as well as data normalization. Two other dilution series $(0.006$ to $100 \mu \mathrm{M}$ ), one for a test probe that shows high expression in the brain (miR-125a) and one 
for a test probe that shows medium expression in the brain (miR-222) will also be printed twice per grid in a random order but evenly spaced. Two types of negative controls will also be printed on chips. The first type is buffer-only spots which are used to assess carry-over contamination by enabling measurement of the difference in signal between a buffer spot printed right after another buffer spot (no risk of contamination) versus a buffer spot printed right after an $100 \mu \mathrm{M}$ NCode external control spot (Yauk et al., 2006). The second type of negative control is random hexamers $(4.5 \mu \mathrm{M})$ whose function is to control for non-specific hybridization as no miRNAs should be binding to them in the hybridization step.

\section{Experimental Design}

A two-colour reference design will be used in this study. It entails the hybridization of an experimental sample on the green channel along with a common reference sample of miRNA on the red channel on each array (Knapen, Vergauwen, Laukens, \& Blust, 2009). The reference is total RNA extracted from adult rat brain chunks. Both of the experimental and reference samples are co-hybridized to the same array resulting in quantifiable red and green signal intensities for each spot. The reference design for microarrays allows evaluation of technical variability which can then be used to detect outlier arrays that are not functioning properly as well as batch effects (given the null hypothesis that the signal from the reference channel on each array will be identical).

\section{Total RNA Isolation}

Total RNA will be extracted from micropunches of the hippocampal DG. The extraction procedure is that outlined in Invitrogen's PureLink TM RNA Micro Kit (Cat. 
\#12183016) called 'TRIzol ${ }^{\circledR}$ Plus Total Transcriptome Isolation’. For all extractions, glassware will be autoclaved overnight prior to use and all water will be RNase-free. All pipette tips used will also be RNase- and DNase-free. Centrifugations (at 12,000 x g) and incubations will occur at room temperature unless otherwise specified.

Tissue will be homogenized in $1 \mathrm{ml}$ of TRIzol for 15 seconds at medium speed and then incubated for five minutes so that nucleoprotein complexes dissociated fully. To separate the RNA, $200 \mu$ l of chloroform (Sigma) is added to the lysate and the mixture is shaken by hand for 15 seconds and then centrifuged at $4^{\circ} \mathrm{C}$. The upper colourless phase containing total RNA is pipetted into a new tube and an equal amount of $100 \%$ ethanol is added to obtain a final concentration of $50 \%$ ethanol. After vortexing, the sample is transferred to a column tube (from kit) pre-inserted into a collection tube (from kit) and centrifuged. The RNA remains bound to the column to which $500 \mu 1$ of Wash Buffer II with ethanol is added. After centrifugation and disposal of the flowthrough, this last step is repeated followed by centrifugation of the column with collection tube to dry the membrane to which the total RNA is attached. At this point the column is inserted into a recovery tube and upon addition of $14 \mu \mathrm{l}$ of RNase-Free Water (from kit) to the centre of the column and centrifugation, the total RNA $14 \mu 1$ elution found in the recovery tube can be used for quality analysis and/or stored at $-80^{\circ} \mathrm{C}$ until the labeling step in the microarray procedure. To avoid batch effects with the final arrays a randomized block design will be used to ensure that RNA extractions for animals conducted on a particular day will not all be labeled and hybridized on all the same day later in the microarray procedure. 


\section{Assessment of RNA Quality and Quantity}

One method of quantity and quality control is to use the NanoDrop 1000 Spectrophotometer (Thermo Scientific) which can determine sample concentration as well as assess RNA purity of extracted samples. A ratio of absorbances at 260 and 280 $\mathrm{nm}$ wavelengths $\left(\mathrm{A}_{260}: \mathrm{A}_{280}\right)$ of approximately 2.0 is generally considered "pure" for RNA samples. Samples that have a ratio that is appreciably lower than 2.0 may be contaminated with protein or phenol (Thermo Scientific, 2008).

A second measure of sample concentration and level of RNA degradation is provided by the Experion Automated Electrophoresis Station (Bio Rad). In order to use extracted RNA samples in downstream applications such as microarrays and RT-PCR, the RNA must be sufficiently un-degraded. The Experion measures RNA degradation by using a degradation ratio of two major ribosomal RNA fragments: the $28 \mathrm{~S}$ and $18 \mathrm{~S}$ fragments. This ratio should be approximately 2.0 and should be constant for all tissues. If the sample is degraded it will have more depletion of the larger ribosomal molecules as larger molecules degrade more rapidly than smaller molecules, and this would result in a smaller ratio. The Experion incorporates this ratio into an index of RNA integrity, called the RNA quality indicator (RQI) which can range from 1 (sample is completely degraded) to 10 (sample is perfectly intact). To continue with downstream applications such as a microarray the RQI number should be a least 7. To continue downstream with RT-PCR the RQI should be at least 5. The RQI uses an algorithm which takes into account three regions of an electrophoretic profile: the $28 \mathrm{~S}$ region, the $18 \mathrm{~S}$ region, and the pre-18S regions. The pre- $18 \mathrm{~S}$ region is a good indicator of degradation because if the 
ribosomal RNAs are degrading the molecules decrease in size resulting in an accumulation of fast-moving, low molecular weight components in the pre-18S region. The Experion software compares the results for these three regions to a series of degradation standards and assesses how degraded the sample of interest is (Denisov, Strong, Walder, Ginrich, \& Wintz, 2008).

\section{MicroRNA Labeling and Hybridization Overview}

MicroRNA is fluorescently labeled using the NCode miRNA Labeling System (Invitrogen) and then hybridized to printed microarray chips. Invitrogen's NCode miRNA Labeling System's protocol will be used to label miRNA samples prior to hybridization to microarrays. All experimental miRNA samples and the universal miRNA reference will be labeled. First a poly(A) tail will be added to the 3 ' end of the miRNA molecule by using poly A polymerase and an optimized reaction buffer. Afterwards, a short but highly specific capture sequence is ligated to the poly(A) tail using a Oligo(dT) bridge. The Alexa Fluor molecules have a sequence complementary to the capture sequence.

\section{Prewsoaking and Pre-hybridizing the Microarrays}

In order to reduce background fluorescence during storage after hybridization the microarray chips are pre-soaked before labeling in a 1:100 solution of liquid borohydride and pre-soak solution from the Corning Background Reduction Kit, for 20 minutes at $42^{\circ} \mathrm{C}$. Afterwards, the chips are washed twice in $0.1 \mathrm{X}$ saline-sodium citrate (SSC) at room temperature and dried by centrifugation at $2,500 \mathrm{rpm}$ for two minutes. This step occurs just before the labeling process. After conducting the pre-soaking there is a pre- 
hybridization step which consists of blocking the unprinted regions of the slide to ensure that hybridization does not occur in this region. This step also removes weakly bound probe DNA. Arrays incubate in a solution of $5 \mathrm{X} \mathrm{SSC}, 0.1 \%$ sodium dodecyl sulphate (SDS), and $0.1 \mathrm{mg} / \mathrm{mL}$ BSA for 60 minutes at room temperature. Afterwards, the slides are put through three 5-minute washes in $0.1 \mathrm{X} \mathrm{SSC}$ at room temperature. After a last wash in $0.1 \%$ DEPC-treated water, the arrays are dried by centrifugation at $1,600 \mathrm{xg}$ for 2 minutes. Finally the arrays can be stored in 5-slide slide holders sealed in microarray pouches until hybridization which should occur within a few hours of pre-soaking and pre-hybridization.

\section{Polyadenlyation of MicroRNA}

Polyadenylation of miRNA is carried out by adding $1 \mu \mathrm{l}$ of diluted NCode spikein control to each experimental sample as well as $5 \mathrm{X}$ reaction buffer, $25 \mathrm{mM} \mathrm{MnCl}_{2}$, diluted ATP, and Poly A Polymerase. The volumes used are those found in the NCode miRNA Labeling kit user manual. The sample incubates in this solution for 15 minutes at $37^{\circ} \mathrm{C}$.

\section{Ligation of Alexa Fluor Dye Molecules}

All procedures occurring during and after the ligation of the Alexa Fluor dyes should be conducted in dim lighting to avoid photobleaching of the dye molecules. To prepare the hybridization mix the Alexa Fluor reagents will first incubate in the dark at $50^{\circ} \mathrm{C}$ for 10 minutes. To ligate the dye molecules (which are attached to a DNA polymer that binds to poly A tails), $4 \mu$ l of Alexa Fluor 3 or 5 Rapid Ligation Mix is added to each sample depending on whether it is an experimental sample or pooled sample, as well as 
$2 \mu 1$ ofT4 DNA Ligase and $1 \mu 1$ of DEPC-treated water. This solution will incubate for 30 minutes at room temperature until the reaction is stopped by the addition of $2.5 \mu 1$ of Stop Solution from labeling kit (Invitrogen).

\section{Hybridization}

A labeled pooled reference sample will be added to each experimental sample to enable dual-colour hybridization. To increase the hybridization mix to its desired volume BSA and 2X Enhanced Hybridization Buffer are added. The mixture will incubate for 10 minutes at $65^{\circ} \mathrm{C}$ before being pipetted onto the centre of the gasket slide already placed in an Agilent hybridization chamber. Now the printed microarray chip should be placed on top with the printed side down and the chamber assembled. The chamber should be rotated vertically to ensure proper bubble formation and that the gasket slide is wet. The hybridization chamber is placed in the hybridization oven to incubate for 9.5 hours at $52^{\circ} \mathrm{C}$ rotating at $20 \mathrm{rpm}$. A randomized block design will be used to ensure that every batch of arrays hybridized, and that microarrays printed from different locations in the ChipWriter will be processed with samples from all treatment groups.

\section{Array Wash Procedure}

After removal from the oven, arrays will be washed. First, the arrays are washed in Wash Solution 1 (2X SSC, $0.2 \%$ SDS, $0.1 \mathrm{mM}$ dithiothreitol [DDT]) at $52^{\circ} \mathrm{C}$ for 20 minutes with gentle stiring $(200 \mathrm{rpm})$. This wash solution will be refreshed after 10 minutes and the arrays flipped to get equal washing on both sides. Similarly the arrays are washed in Wash Solution 2 (2X SSC, $0.1 \mathrm{mM})$ and Wash Solution $3(0.2 \mathrm{X} \mathrm{SSC}, 0.1 \mathrm{mM}$ DDT). Drying of the arrays is done by centrifugation at $2,500 \mathrm{rpm}$ for two minutes while 
in a centrifuge tube containing $20 \mu \mathrm{l}$ of 2-mercaptoethanol. Post centrifugation, the array is quickly transferred to another tube containing $20 \mu \mathrm{l}$ of 2-mercaptoethanol until scanning.

Alexa Fluor 5 dye has been shown to be easily degraded by the presence of ozone (Fare et al., 2003). Degradation is especially a risk during the washing and scanning steps so the addition of DDT in the wash solutions and the presence of 2-mercaptoethanol during the storage of arrays were precautions taken to limit the effects of ozone. Other precautions that will be taken include not labeling and hybridizing on days when the temperature is above $25^{\circ} \mathrm{C}$, as well as conducting washing and scanning in the morning between 5:30am and 8:30am because daily ozone levels are the lowest at this time. Additionally, atmospheric ozone concentrations will be recorded during all labeling, hybridization, and scanning procedures. Water in the MilliQ cleaning system tank will be emptied and refilled before making wash solutions to ensure that the water was minimally exposed to high levels of ozone. The scanner will be used only while in an office environment instead of a lab as lab equipment may increase ambient levels of ozone (Genisphere Incorporated, 2004).

\section{Image and Statistical Analyses}

\section{Overview}

Scanning will create images of each array and the program ImaGene 8.0 will be used to measure median signal intensity for each spot on the array from these images. Measurements from controls will be used to inspect the quality for each array. 
Afterwards, normalization of data will be carried out within-arrays using an algorithm for Lowess normalization and between-arrays with quantile normalization (in GeneSpring 10.0). Following normalization and removal of outliers, the program Partek will be utilized to conduct Principal Components Analysis (PCA) firstly to detect outlier arrays and remove variation due to variables other than type of injection or presence of a running wheel. Finally, statistical significance will be determined by Significance Analysis of Microarrays (SAM) (Tusher, Tibshirani, \& Chu, 2001).

\section{Microarray Scanning}

After the array is dried it is immediately scanned with the GenePix 4000B scanner (Axon Instruments) which is used to scan microarray chips and does so with a dual laser scanning system using two wavelengths to detect fluorescent signals with two highsensitivity photomultiplier tubes (PMTs). Settings for the PMTs can be changed to optimize signal detection and balance the intensity for green and red channels. First each chip will be scanned at the setting of $660 \mathrm{v}$ for the red channel and at $620 \mathrm{v}$ for the green channel. This generates a ratio of overall signal intensity. For the next scan PMT settings are adjusted based on the ratio to produce a balanced image (red and green channels have equivalent signal intensity). Images resulting from the scan should have a count ratio between 0.85 and 1.15 and will provide the data for the analysis. The scan is set for a resolution of $20 \mu \mathrm{m}$ and focus position at -20 . Each spot's signal intensity is compared to background intensity. 


\section{ImaGene Image Analysis}

The program ImaGene 8.0 is used to measure signal intensity. Images generated from GenePix 4000B can be opened in ImaGene 8.0 as well as the matching Gene Array List (GAL) file containing the IDs for each spot in grid format. ImaGene has parameters which can be adjusted to allow better alignment of the grid to the grid on the scanned image. The grids must be aligned individually for each array because sometimes there is misalignment during printing because of uneven slide arrangement in the Chip Writer or warping of the chip. The individual spots can be automatically adjusted and this will be done up to four times to line up the grid with the image. If necessary, spots will also be adjusted manually. Spot finding settings will be set to default but grid flexibility will be increased to allow deformation of the grid so that it can better match the image in case of misaligned spots.

ImaGene 8.0 also has settings to control segmentation, the differentiation of signal and background values. Automatic segmentation will be used with a background buffer of 9 pixels and a background width of 15 pixels. The lowest $20 \%$ pixel signals will be filtered out to exclude pixels from the centre of "donuts". All other parameter settings will be set to default so that background will not be subtracted and the median signal intensities for each spot are not normalized.

\section{Evaluating Grid-to-Grid Variation}

Each grid on a microarray may vary in signal intensity because of differences in pre-soaking, pre-hybridization, hybridization, washing, printing and/or pin number. Looking at the NCode external control dilution series from each grid one can assess 
whether grid-to-grid differences exist. Signal intensities from the dilution series will be evaluated as a function of grid number to look for any top-to-bottom or left-to-right variation in signal intensity across each microarray as was done by Yauk et al. (2006).

\section{Determining Presence/Absence of Signal}

An algorithm created by Andrew Williams at Health Canada written in R scripts will be applied to determine presence or absence of signal for each probe. If the median signal for each probe is greater than three standard deviations above the mean of all buffer control spots (not including those printed after 100ul NCode control spots) it will be considered present. Probes displaying signal intensities below this threshold will be marked as absent and will not be included in the rest of the analysis.

\section{Microarray Data Normalization}

Microarray experiments are subject to many sources of variation resulting in variance in measured signal intensity. Variation will be present within each chip and will also occur between chips. Variation not due to actual differences in gene expression can be eliminated through several normalization procedures. First, within-array normalization for each chip will be done followed by between-array normalization so that arrays can be compared to each other.

\section{Within-Array Normalization}

Red and green dyes are typically not incorporated equally into an array, nor are they incorporated consistently across the array during the labeling procedure. If not corrected, this "dye bias" will result in differences in signal intensity that are not actually 
due to differential gene expression (Dobbin, Kawasaki, Petersen, \& Simon, 2005). Red and green dye incorporation should be identical so that our experimental sample can be compared to a reference sample. One can use the NCode spike-in control spots to assess if red and green dyes are being incorporated equally. If not equal, the signal intensity for red and green dyes can be normalized. For this reason it is important to ensure that the dilution solution of the NCode probe will produce a wide range of signal intensities, ideally 0 units to 65,535 units (fully saturated signal) as reliable normalization can only be obtained for intensities covered by the spike-in (Sarkar et al., 2009; Yauk et al., 2006). It was found that a spike-in concentration of $50 \mathrm{X}$ was necessary to produces this range (Jansman, 2009).

Andrew Williams from Health Canada has written an algorithm in R scripts to normalize the data within each microarray using lowess normalization (locally weighted linear regression analysis) which can remove variation in signal intensity due to dye bias (Smyth \& Speed, 2003; Yauk et al., 2006). In Loess normalization, the data is split up in localized subsets and a simple linear model of signal intensity is fit to each one. Doing so allows a function, created point-by-point based on the subsets, to be created which describes variation in the entire dataset for an array (Cleveland, 1979; Cleveland \& Devlin, 1988). Locally weighted linear regressions will be created for each NCode data point and then applied to $10 \%$ of the data from the entire control series that is closest to that point. Each subset of data is fitted with a polynomial. More weight is given to spots near the data point whose response is being estimated and less weight to spots further away. The value of the regression function for the point in question is obtained by 
evaluating the local polynomial and from there the data point is adjusted to balance signal readings from green and red dye. After regression function values are computed for all NCode control series spots and a system to correct local data for both channels is generated, the correction will be applied resulting in within-chip normalization.

\section{Between-Array Normalization}

Variation in the microarray study will still be present because of between-array variation. This variation stems from differences in array processing and RNA sample concentration, number of scans, and daily atmospheric ozone concentrations. Correcting for this variation enables comparison between arrays. Quantile normalization is a robust, non-parametric approach to normalizing miRNA expression data (Bolstad, Irizarry, Astrand, \& Speed, 2003; Pradervand et al., 2009; Y. Rao et al., 2008). It makes the assumption that there is underlying common distribution of intensities across all chips (Smyth \& Speed, 2003). An algorithm can be used to divide ordered signal intensities for each array into quartiles. Then the mean for signal intensity for all the arrays is measured for all three quantiles $\left(1^{\text {st }}, 2^{\text {nd }}\right.$ and $\left.3^{\text {rd }}\right)$. Following this measurement, all chips are normalized by converting their individual mean signal for each quantile to the average mean signal of all chips and then scaling all other signal intensities in that array based on the new adjusted mean. The end result is that each array has a comparable distribution of signal intensity (Pevsner, 2009). This normalization will be done using GeneSpring 10.0.

The new adjusted value for each spot will be entered into an Excel spreadsheet and the median of values from all the technical replicates (identical probes on a single 
array chip) will be used for further analysis, unless $50 \%$ of technical replicates have an absent signal in which case that probe will be discarded from the analysis.

\section{Principal Components Analysis}

Principal Components Analysis is an exploratory technique that transforms a large number of possibly correlated variables into a smaller number of uncorrelated variables called principal components. These new variables are ordered by the amount of variance explained, such that the first principal component accounts for as much of the variability in the data as possible and becomes the $\mathrm{X}$ axis, the second principal component accounts for most of the remaining variability and becomes the $\mathrm{Y}$ axis, and so on until all the variation in the data is explained. Converting the original variables into principal components simplifies the data into a lower-dimensional picture that show patterns in the data (Shlens, 2009).

\section{Identifying Outliers}

To identify array outliers due to technical problems, PCA will be employed again. The reference channel (red channel) should be identical for all arrays since it contains a pool of all experimental miRNA and the printed microarray chips are all identical before anything has been hybridized to them. A correlation dispersion matrix with normalized eigenvector scaling will be used to standardize the data to a mean of zero and a standard deviation of one. 


\section{Evaluating Batch Effects}

Principle components analysis will also be used to test for differences by date of RNA extraction and date of hybridization. Date of hybridization could potentially lead to significant differences because of daily changes in atmospheric ozone conditions and therefore, it is important to see if there is a main effect of date of hybridization so that this effect can be subtracted from the data (which would be done by using the "remove batch effect" algorithm in Partek).

\section{Significance Testing}

Statistical significance will be tested using Significance Analysis of Microarrays (SAM), which is a nonparametric technique designed for microarray experiments (Tusher et al., 2001). A $d$ statistic is computed for each gene and represents the strength or the relationship between gene expression and the independent variable analyzed. Only one independent variable at a time can be analyzed using SAM, so the independent variables of injection type and presence of a running wheel will be analyzed separately. The $d$ statistic is based on the change in gene expression relative to the standard deviation of repeated measurements. By generating 5000 permutations of the data, SAM estimates the likelihood of genes being statistically identified by chance (false positive rate). The significance threshold is determined by a user-defined parameter called delta and based on the false positive rate. Significance testing will not be carried out on genes which are not expressed to detectable levels - thereby also decreasing the number of hypothesis tests and reducing the false discover rate correction. To define a gene as being expressed 
at detectable levels it will have to be present in the green experimental channel in at least $60 \%$ of animals.

\section{Real-time PCR Validation}

Following statistical analysis of the microarray data, miRNA genes whose expression is significantly different between treatment groups will be validated with RTPCR using TaqMan®-based detection chemistry developed by Applied Biosystems. 


\section{Results}

\section{Impact of Manipulations on Weights}

Over the course of the study, weight gain was indistinguishable between controls, with each group gaining $\sim 100 \mathrm{~g}$ over the 3 week period. The treatment of wheel running reduced the rate of weight gain and corticosterone injections prevented any weight gain (Figure 3). Therefore, by the end of the three weeks, weight of both corticosterone injection and voluntary exercise groups was significantly reduced compared with controls. Weights of animals between groups on the final day of the experiment (experimental day 21) did differ significantly $\left(F(3,33)=27.586, p \leq .001\right.$, partial $\eta^{2}=$ .715). On the last experimental day, weights of animals in the corticosterone injection group were significantly lower than those in the vehicle injection group $(t(33)=8.214, p$ $\leq .001$ ). Similarly, wheel running also resulted in reduced rate of weight gain compared with the non-running controls $(t(33)=3.419, p=.002)$. There was no difference in weight between the vehicle injection group and the control group, demonstrating that the presence of injections alone did not have a major effect on weight. Consistent with reduced weight gain in the wheel running group being the direct result of exercise, there was a significant negative correlation between distance run and weight gain over the three week treatment period $(r(7)=-.767, p=.008)$, with animals running an average of $52.07 \mathrm{~km}(S D=38.64 \mathrm{~km})$ over the 3 week period. 


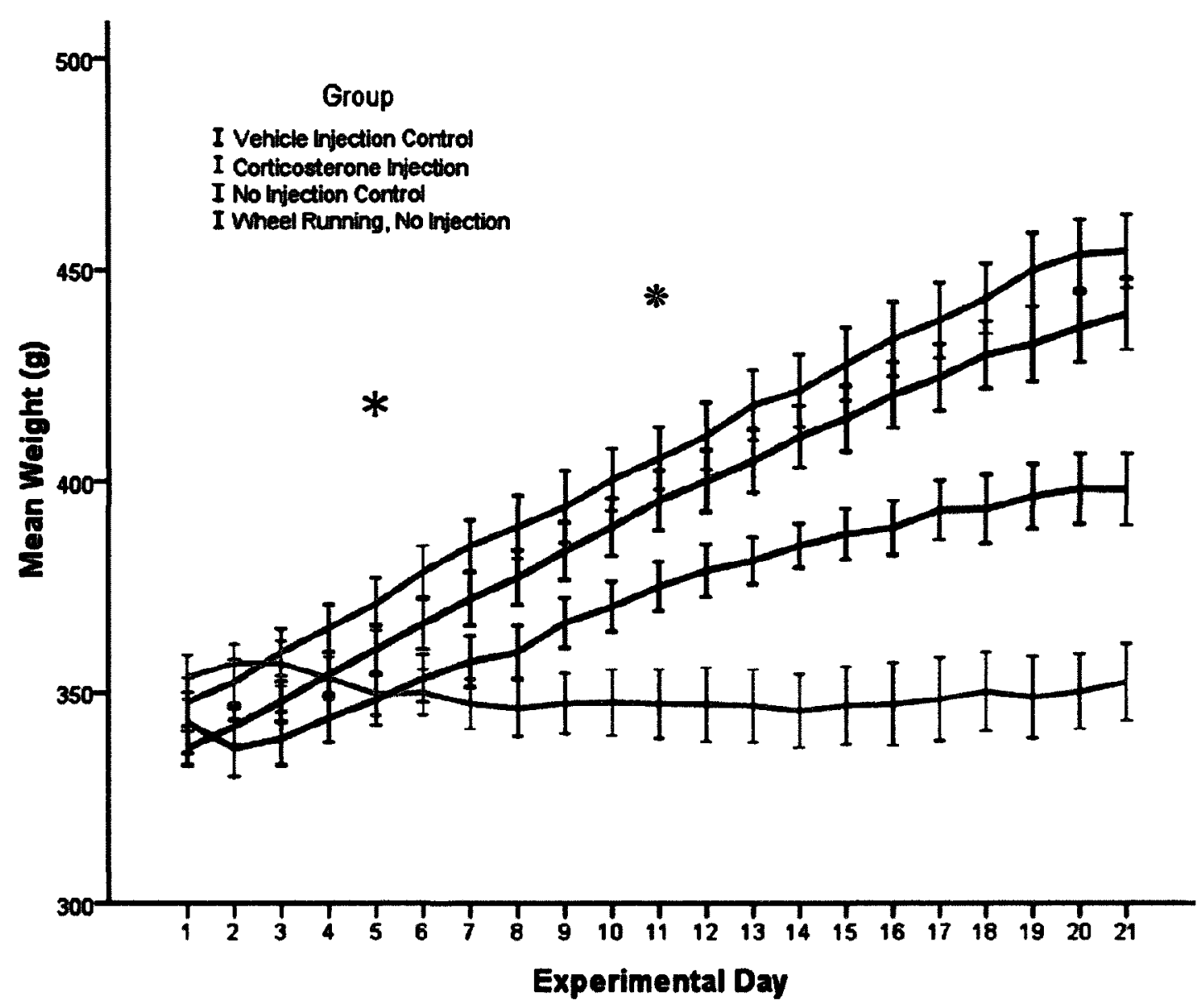

Figure 3. Average weight per experimental day by group.

Data are mean \pm SEM. * Post-hoc analysis using simple comparisons after a mixed design ANOVA, using experimental day as the repeated measure, indicated that the corticosterone injection group commenced showing differences in weight from the oil injection group on experimental day $5(t(33)=2.582, p=.014)$. ${ }^{*}$ indicates the voluntary wheel running group began to show differences in weight from their respective controls later on, after 11 days of wheel running $(t(33)=2.033, p=.05)$.

\section{Comparing Plasma Corticosterone}

Consistent with prior expectations, plasma corticosterone levels 24 hours

following the last corticosterone injection were more than 2-fold higher in the corticosterone injection group compared with the vehicle injection control group $(t(32)=$ 
$-3.108, p=.004$ ) (Figure 4). Comparisons between other groups showed a lack of effect of injection or wheel running.

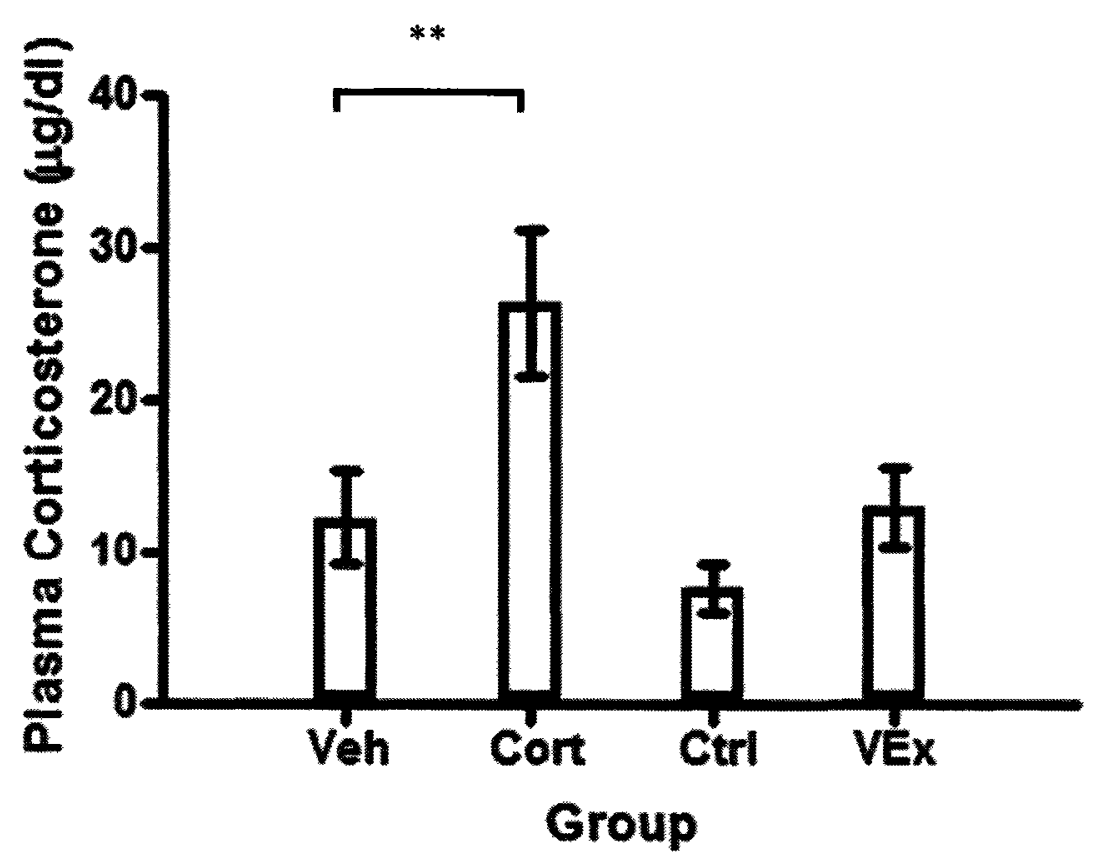

Figure 4. Plasma corticosterone by group.

Data for vehicle injection (Veh), corticosterone injection (Cort), no injection control $(\mathrm{Ctrl})$, and voluntary exercise (VEx) groups are mean \pm one standard error. ${ }^{* *} p \leq .01$.

\section{Doublecortin expression}

After three weeks of treatment there were group differences in the amount of $\mathrm{DCX}+$ cells found in the $\operatorname{SGZ}\left(F(3,33)=16.028, p \leq .001\right.$, partial $\left.\eta^{2}=.593\right)$ (Figure 5). The corticosterone injection group showed significantly lower DCX+ cell counts than the vehicle injection control group demonstrating that three weeks of daily corticosterone injections decrease the number of immature neurons $(t(33)=3.534, p=.001)$. The wheel running group showed higher DCX+cell counts than the control group $(t(33)=-2.783, p$ 
$=.009$ ). However there were no differences between the vehicle injection group and control group.

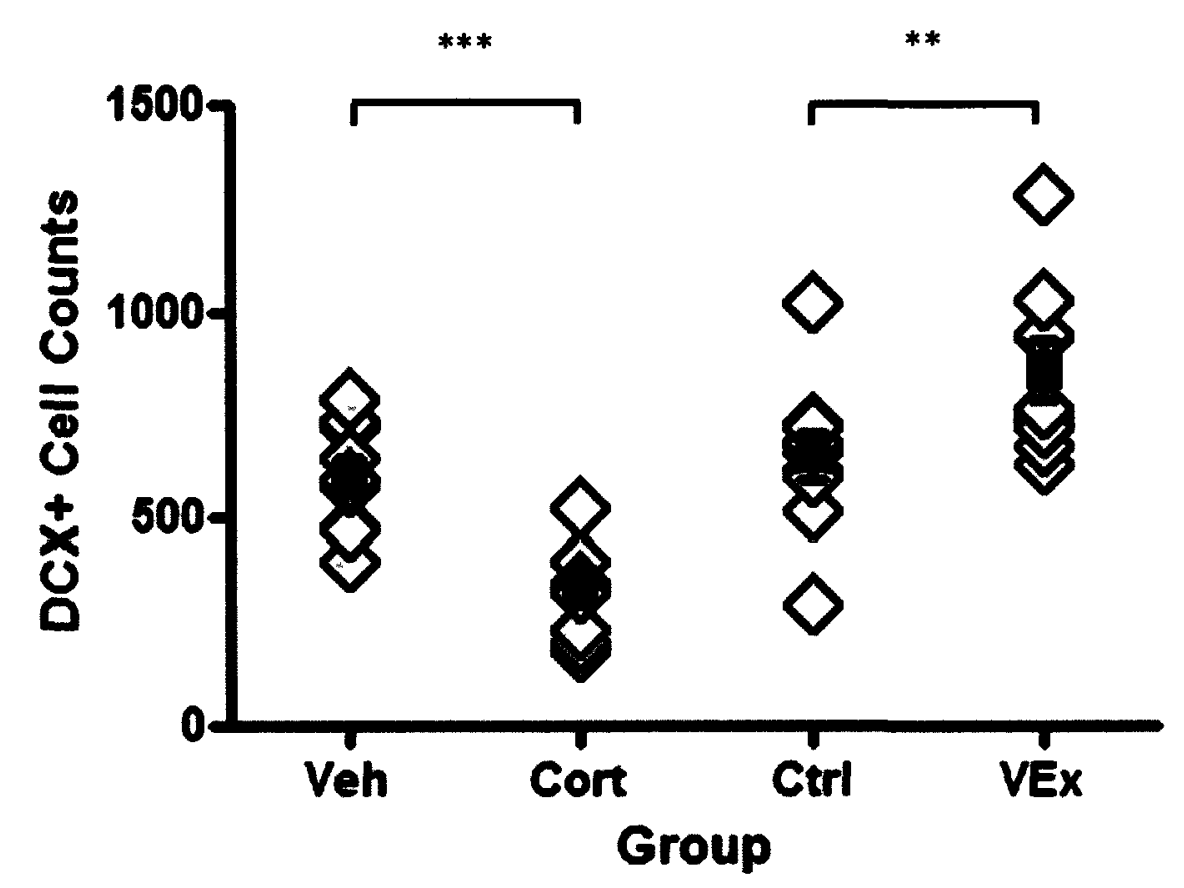

Figure 5. Doublecortin cell counts by group scatterplot.

Each case is represented by an open diamond in vehicle injection (Veh), corticosterone injection (Cort), no injection control (Ctrl), and voluntary exercise (VEx) groups. Group means are shown by the red squares with SEM error bars. $* * * p \leq .001 . * * p \leq .01$. 

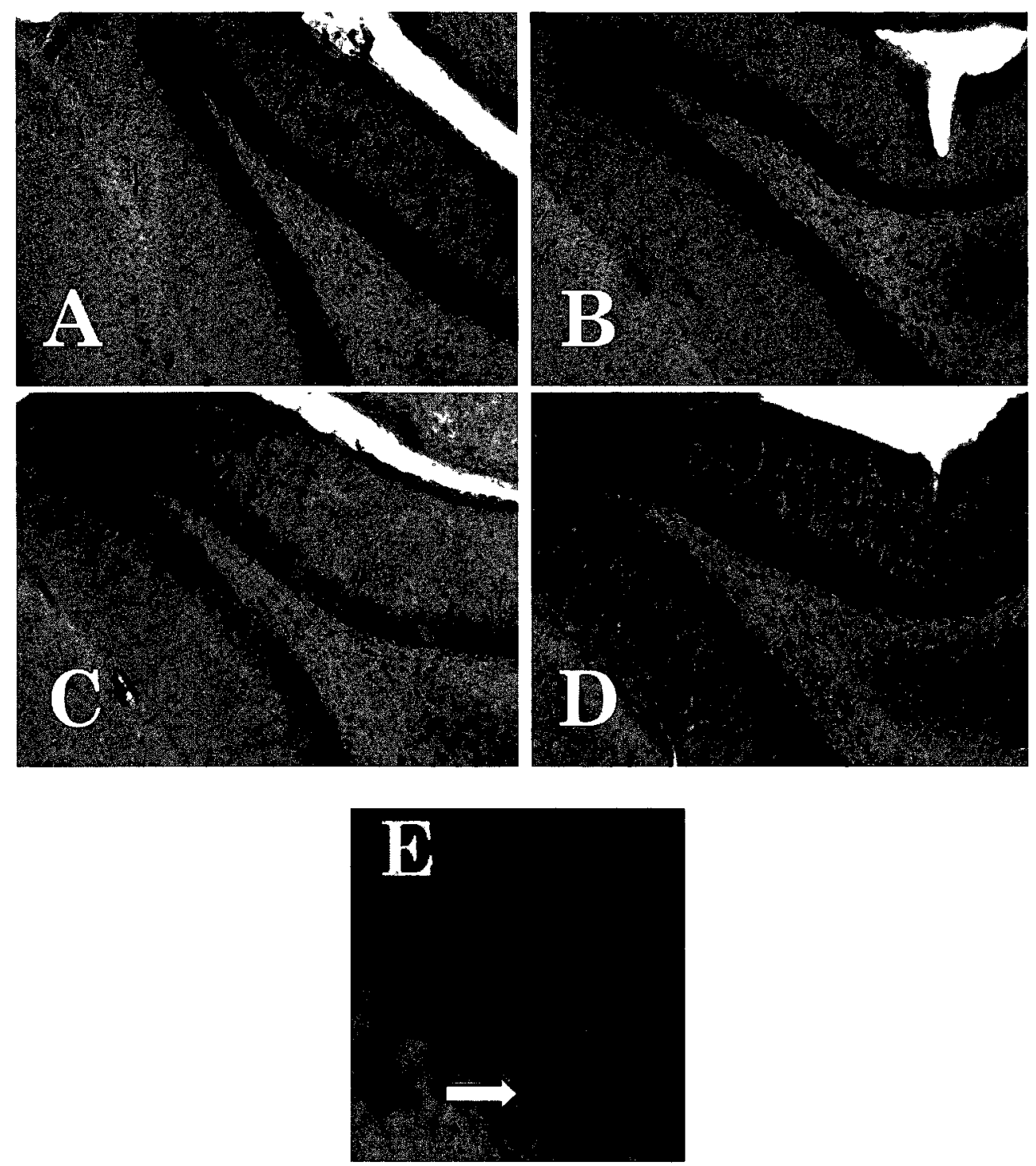

Figure 6. Immunohistochemistry for doublecortin at 10x magnification. Coronal sections stained for DCX in which cell bodies (stained black) of DCX + cells were counted
A) Vehicle injected rat
B) Corticosterone injected rat
C) No injection control rat
D) Wheel Running, no injection rat
E) Immature neurons stained for doublecortin (black) at 40x magnification. White arrow indicates one neuron stained for doublecortin. Doublecortin is a microtubule associated protein found also in dendrites therefore the dendrites also appear dark 


\section{Comparing BrdU+ Cell Estimates Between Groups}

There are no significant differences in proliferation between treatment groups as measured by estimates for total BrdU+ cells in the dorsal dentate gyrus $(F(3,33)=.517$, $p=.673$, partial $\eta^{2}=.045$ ) (Figure 7). Levene's test showed violation of the assumption of homogeneity of variance $(F(3,33)=2.928, p \leq .05)$ therefore planned contrasts where equal variances are not assumed were used. While there does appear to be a trend towards a the expected decrease in the corticosterone injection group compared to the vehicle injection group, the difference was not statistically significant $(t(33)=1.207, p=$ .236). The level of variability within each group is exceptionally high; to illustrate, standard errors of the mean (SEM) are high for each group (expressed as percentage of the mean value): vehicle injection (19\%), corticosterone injection group (22\%), no injection control group (26\%), and wheel running, no injection (31\%) (Refer to table 2). With such large within-group variability, the ability to observe small or moderate effects is compromised. 


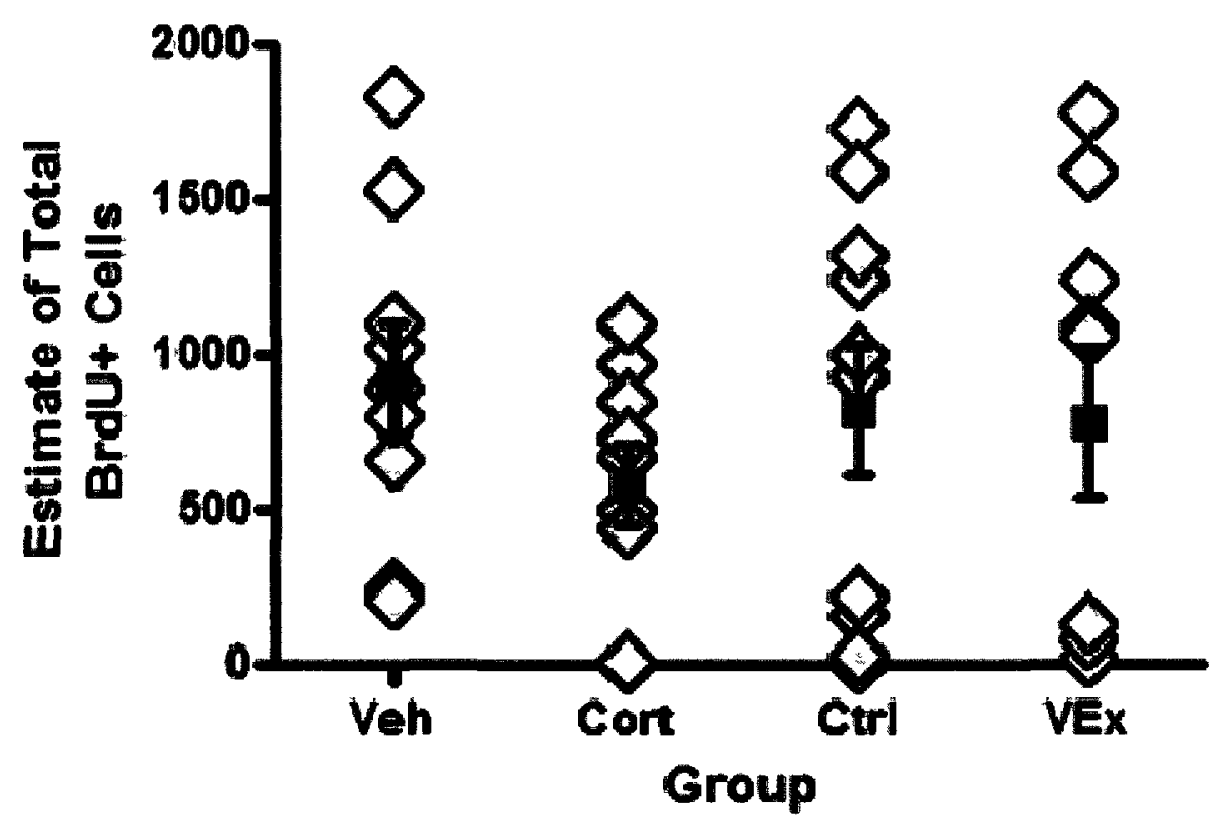

Figure 7. Estimate of total BrdU+ cells by group scatterplot.

Each case is represented by an open diamond in vehicle injection (Veh), corticosterone injection (Cort), no injection control (Ctrl), and voluntary exercise (VEx) groups. Group means are shown by the red squares with one SEM error bars. 

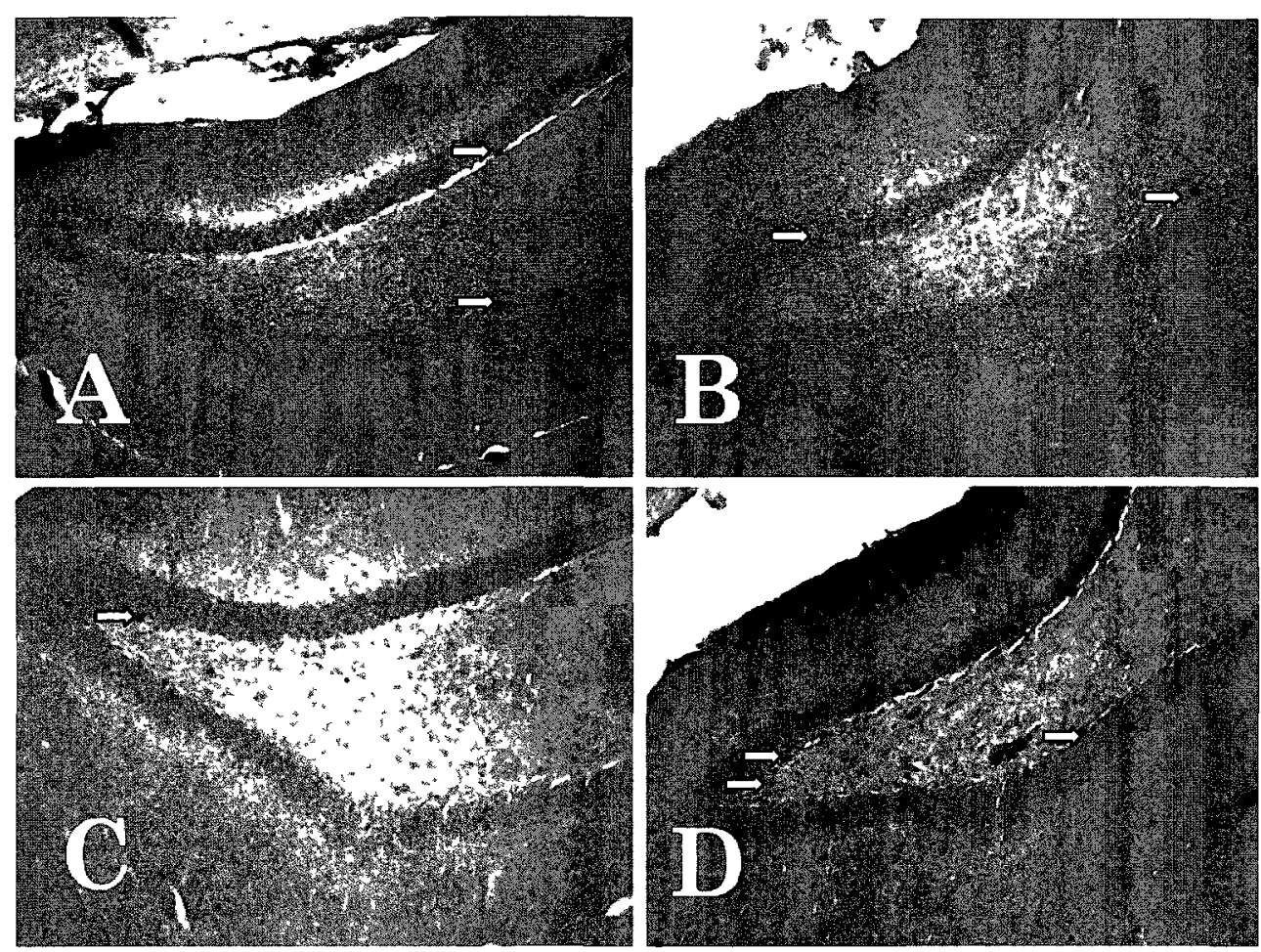

Figure 8. Immunohistochemistry for BrdU at 10x magnification.

Coronal sections stained for BrdU in which cells in random samples of tissue were counted. White arrows indicate stained cells (stained dark brown).
A) Vehicle injected rat
B) Corticosterone injected rat
C) No injection control rat
D) Wheel Running, no injection rat

\section{Comparing Ki67+ Cell Counts Between Groups}

Consistent with the BrdU data, neither wheel running nor corticosterone treatments resulted in significant differences in proliferation as measured by cells counts of Ki67-labeled cells in the dorsal dentate gyrus $\left(F(3,31)=1.173, p=.336\right.$, partial $\eta^{2}=$ .102) (Figure 9). Using Ki67 cell counts to quantify proliferation resulted in data with less variability than when proliferation was measured in BrdU-DAB stained tissue.

Standard errors of the mean for each group are expressed as percentage of the mean 
value: vehicle injection (10\%), corticosterone injection group (21\%), no injection control group (20\%), and wheel running, no injection (21\%) (See table 2). The lower degree of variability suggests that Ki67 cell counts were a better measure of proliferation than stereology of stained tissue for BrdU which may produce data with greater variability for reasons discussed in the section 'Variability in BrdU Data'. The trend for a decrease in proliferation in the corticosterone injection group compared to the vehicle injection group was even more apparent in this data, but was again not significant $(t(33)=1.369, p=$ .181). Visual inspection of the data (Figure 9) suggests that two of the corticosterone injection animals had unusually high Ki67 cell counts compared to the rest of the group which contributed to the lack of significance. However, we do not consider them as outliers based on the observed scores. Furthermore, they did not differ from the rest of the animals in the group with respect to weight, and did not demonstrate any signs of illness or abnormal behaviour during the daily monitoring throughout the experiment. 


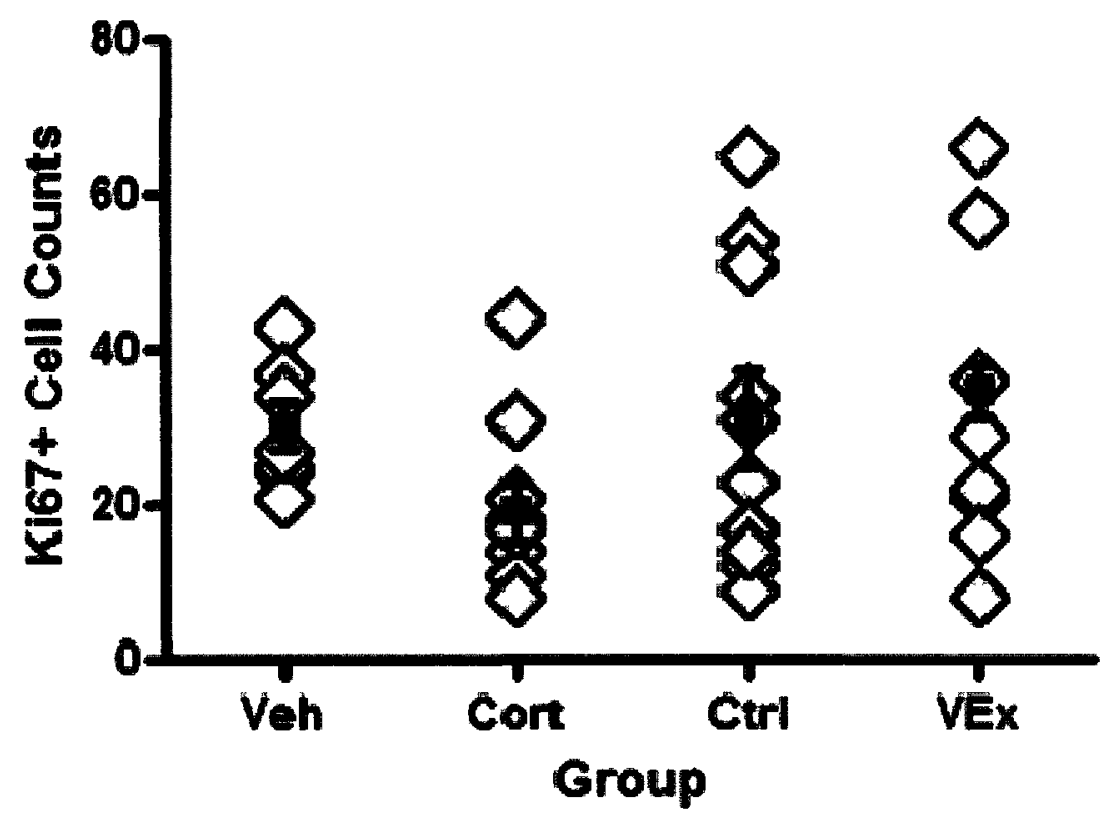

Figure 9. Ki67 cell counts by group scatterplot.

Each case is represented by an open diamond in vehicle injection (Veh), corticosterone injection (Cort), no injection control (Ctrl), and voluntary exercise (VEx) groups. Group means are shown by the red squares with SEM error bars. 

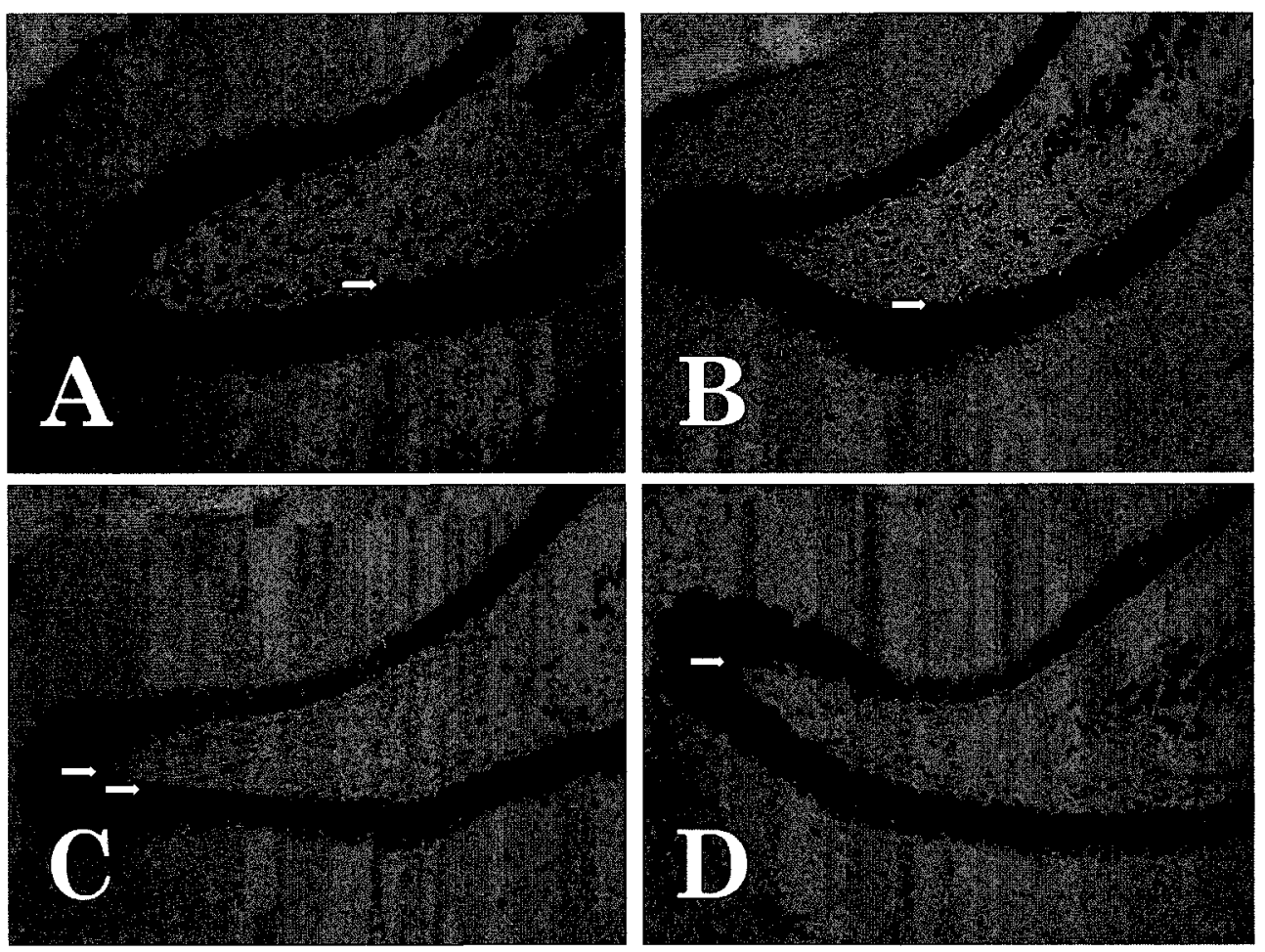

Figure 10. Immunohistochemistry for Ki67 at 10x magnification.

Coronal sections stained for BrdU. White arrows indicate stained cells (stained dark brown).

A) Vehicle injected rat

B) Corticosterone injected rat

C) No injection control rat

D) Wheel Running, no injection rat

There was an exceptional amount of variability in the BrdU data and the effect size was extremely small (partial $\eta^{2}=.045$ ) making it unlikely to find a significant effect of corticosterone on neurogenesis. An analysis of Ki67+ cells was conducted to see whether this variability was replicated in another method of measuring proliferation, or if Ki67 gave the expected results in proliferation. Ki67 data did not show as much variability but did replicate the BrdU data with regards to the lack of an expected decrease in proliferation in the corticosterone injection group compared to the vehicle 
injection group. Any effect of proliferation was too subtle in comparison to the interindividual differences and thus we have a very small effect sizes in both data sets (BrdU: partial $\eta^{2}=.045$, Ki67: partial $\eta^{2}=.102$ ). Variability, presented as one SEM divided by the sample mean expressed as a percentage, in the Ki67+ cell counts is smaller than in the BrdU data which explains why there was a stronger trend (table 2).

\begin{tabular}{|c|c|c|c|}
\hline & $\begin{array}{l}\text { BrdG Total Cell } \\
\text { Estimates (BrdU } \\
\text { cell counts orithout } \\
\text { volumetre } \\
\text { estimation) }\end{array}$ & Kí67 & DCX \\
\hline $\begin{array}{l}\text { Vehicle Injection } \\
\text { Control }\end{array}$ & $19 \%(21 \%)$ & $10 \%$ & $7 \%$ \\
\hline $\begin{array}{l}\text { Corticosterone } \\
\text { Injection }\end{array}$ & $22 \%(23 \%)$ & $21 \%$ & $11 \%$ \\
\hline $\begin{array}{l}\text { No Injection } \\
\text { Control }\end{array}$ & $26 \%(25 \%)$ & $20 \%$ & $9 \%$ \\
\hline $\begin{array}{l}\text { Wheel Running, No } \\
\text { Injection }\end{array}$ & $31 \%(31 \%)$ & $21 \%$ & $8 \%$ \\
\hline
\end{tabular}

Table 2. Showing one standard error of the mean expressed as a percentage of the group mean for each treatment group and by method of quantification of neurogenesis. BrdU cell estimates without volumetric estimation is included because we also investigated differences between treatment groups with this data (data not shown). 


\section{Correlates of BrdU, Ki67 and DCX Within Each Group}

Surprisingly, there appears to be no strong relationship between BrdU+ cell estimates, and Ki67 cell counts for any of the experimental groups, except for in the corticosterone injection group $(r(9)=.632, p=.034)$. Additionally, DCX cell counts did not associate with BrdU+ cell estimates or Ki67 cell counts for any treatment group. There does not appear to be a relationship between amount of wheel running and neurogenesis as shown by a lack of significant correlations with DCX + cell counts, estimates of total BrdU+ cells, and Ki67+ cell counts. An association between level of plasma corticosterone and measures of neurogenesis for the corticosterone injection group was not found. 


\section{Discussion}

Treatment conditions appear to have been successfully implemented as indicated by weight change, plasma corticosterone levels, and measurements of distance run. The animals in the corticosterone injection group gained significantly less weight than their vehicle injection control counterparts consistent with other chronic stress studies (Marti, Marti, \& Armario, 1994; Ottenweller, Natelson, Pitman, \& Drastal, 1989; Santos, Benjamin, Yang, Prior, \& Perdue, 2000). Plasma corticosterone levels were significantly elevated in the corticosterone injection group suggesting that corticosterone elevated plasma corticosterone levels for 24 hours after injection. Meanwhile, wheel runners gained less weight than their respective controls, most likely reflecting the increased exercise. By taking daily odometer readings we know that all rats ran each day and increased this daily running over the course of three weeks. There were no rats that did not use the running wheel as is sometimes reported in the literature (Eadie et al., 2005).

\section{Effect of Corticosterone Injections}

In our study, daily corticosterone injections resulted in decreased numbers of $\mathrm{DCX}+$ cells, but no decrease in either BdrU+ or Ki67+ cells, indicating that, at least by the end of the three-week timeframe, there was a reduction in the number of immature cells without a corresponding decrease in cell proliferation. The observed results suggest that 1) there was a minimal effect on proliferation at three weeks, but that proliferation could have decreased transiently at some point during the study, and that 2) injections decreased cell survival, potentially through a reduction in the rate of apoptosis. 
Consistent decreases in proliferation following daily corticosterone injections have been reported by studies using as few as 2-5 days of injections, or as much as three weeks of injections, suggesting that the impact of corticosterone injections is stable over this period of time (Karishma \& Herbert, 2002; Cameron \& Gould, 1994; Brummelte \& Galea, 2010). In our study, the treatment produced a decrease in the amount of proliferating cells measured by quantifying BrdU+ cells through stereology of the dorsal dentate gyrus and by cell counts of Ki67+ cells. The extent of this change (1.6-fold decrease) is similar to what has been reported (Cameron \& Gould, 1994) but in this study did not achieve statistical significance when measured in BrdU DAB-stained tissue ( $p=$ $.236)$ or in Ki67 DAB-stained tissue $(p=.181)$, although a trend for a significant decrease in the corticosterone injection group is present.

The literature on high-dose corticosterone injections demonstrates that three weeks of daily injections reduces the number of immature neurons (Karishma \& Herbert, 2002; Wong \& Herbert, 2004, 2006). The number of DCX+ cells, a measure of the number of immature neurons, is often used as an indicator of cell survival; however, counts of DCX+ cells do not exclusively measure cell survival. A decrease in the number of DCX+ cells can be a product of decreased cell survival, decreased cell proliferation, increased apoptosis, or a combination of these factors. In our study, the decrease in the number of DCX + cells after three weeks of daily corticosterone injections is likely a result of both decreased cell survival and proliferation, and an increase in the rate of apoptosis. For example, two studies examined cell survival independently of cell proliferation by administering BrdU before corticosterone treatment began, found 
decreased numbers of BrdU-retaining cells at all time points examined between one and four weeks (Wong \& Herbert, 2004, 2006). Along with a decrease in number of surviving neurons, changes in proliferation which would be reflected by DCX+cell counts days to weeks later, could also result in an alteration in number of immature neurons. In fact, acute five-day corticosterone injection treatment is known to decrease proliferation (Karishma \& Herbert, 2002) which means that five days into our study a decrease in proliferation likely took place. With fewer cells born at this time there would be less cells available to become immature neurons, and thus this decrease in proliferation at five days could be reflected in DCX+cell counts weeks later. Given the literature demonstrating both decreases in cell proliferation and survival during three weeks of daily high-dose corticosterone injections, a decrease in DCX+ cells was expected.

Normally, the majority of newborn cells do not survive due to apoptosis (Sierra et al., 2010). Therefore, reduction in this rate of apoptosis could result in an increase in survival and an increase could result in decreased cell survival. Almeida et al. (2000) used dexamethasone which is a GR agonist and thus is similar to high doses of corticosterone, and found that an eight-day injection protocol promoted cell death in the DG by increasing the ratio of the pro-apoptotic molecule Bax to the anti-apoptotic molecules Bcl-2 and Bcl- $x_{\mathbf{L}}$. Thus it is possible that a decrease in surviving neurons as measured by $\mathrm{DCX}+$ cell counts in the corticosterone injection group was in part due an increase in apoptosis. A study using primary neonatal hippocampal cultures suggests that 
both neural progenitor cells and immature neurons are sensitive to the proapoptotic effects of dexamethasone (Yu et al., 2010).

\section{Effect of Voluntary Exercise}

Originally, the treatment of voluntary wheel running was chosen for this experiment because of its robust and reproducible effects on proliferation rate. However, after three weeks of voluntary exercise, proliferation meausured by quantifying BrdU+ and Ki67+ cells was unchanged relative to controls, unlike the number of DCX+cells which was increased. In the literature, wheel running studies using Sprague Dawley rats in which animals were exposed to a running wheel for two weeks (Eadie et al., 2005), and for two weeks to a maximum of three weeks (Redila \& Christie, 2006), resulted in substantial increases in proliferation (1.5- and 1.7-fold changes) as measured by cell counts or stereology of the dentate gyrus for BrdU-labeled cells after a single dose of BrdU $24 \mathrm{~h}$ prior to decapitation. Although the study by Redila \& Christie (2006) is the most similar study in the literature to ours, because of the similar time course and strain of rats used, a comparable increase in proliferation was not replicated in our study. Instead, our data show a lack of effect of wheel running on proliferation which is consistent with literature that supports the concept that long-term wheel running, such as three weeks or more, does not increase proliferation in rodents.

In fact, some literature shows that the effects of voluntary exercise on neurogenesis are time-dependent in that proliferation is increased with short-term wheel running but not after long-term running (Clark et al., 2010; Kronenberg et al., 2006; 
Naylor et al., 2005; Snyder et al., 2009). A study utilizing female hypertensive rats which have a tendency to use the running wheel more than Sprague Dawley rats, found that just over three weeks of wheel running resulted in a 50\% decrease in BrdU-labeled cells 12 hours after BrdU was injected compared to non-running controls (Naylor et al., 2005). Multiple studies using mice that ran for approximately three weeks instead found no alterations in proliferation (Clark et al., 2010; Fuss et al., 2009; Snyder et al., 2009).

The increase in the number of immature, DCX+ neurons in the SGZ following voluntary exercise is likely due to combined effects on cell survival and transient proliferation. In the voluntary exercise literature, only one study has investigated survival independently of proliferation by injecting BrdU two days before the running wheel treatment, and it found that approximately 2-3 weeks of wheel running increases the survival of newly generated neurons (Snyder et al., 2009). A study by Clark et al. (2010) found that after 25 days of running there was a greater number of immature neurons present in the DG, measured by cells stained for immature neuron marker NeuN. They also showed that a period of enhanced proliferation (detected through cell counts of Ki67+ cells), occurring after the first five days of running, could have contributed to this increase in immature neurons seen after 20 additional days of exercise. Short-term wheel running such as 5,9 , and 10 days of running, is known to produce an increase in proliferation (Bruel-Jungerman et al., 2009; Clark et al., 2010; Naylor et al., 2005), therefore, proliferation was likely elevated early on during the exercise regime in our study as well. 
There has been one study investigating the effect of three weeks of voluntary wheel running on cell death, which found a significantly reduced amount as measured by hematoxylin staining of pyknotic cells in running mice (Fuss et al., 2010), thus the voluntary wheel running treatment may have also contributed to increased DCX+cell counts through alteration of the rate of apoptosis. Mechanistically, the association between voluntary exercise and neurogenesis may be mediated by the antiapoptotic kinase Akt. Voluntary exercise has been shown to activate Akt, and some of its downstream targets, whereas blockage of its phosphorylation resulted in the reversal of the associated effect of exercise on survival (Bruel-Jungerman et al., 2009). The resultant increase in DCX+ cells is therefore likely due to a combination of increased proliferation and survival.

Positive correlations between wheel running activity and neurogenesis, specifically changes in the number of DCX+ cells, have only been reported in prolonged wheel running studies in which mice were exposed to a running wheel for four weeks or more (E. Aberg et al., 2008; Bednarczyk et al., 2009; Clark, Brzezinkska, Puchalski, Krone, \& Rhodes, 2009; Dubreucq et al., 2010; Holmes et al., 2004). A lack of correlation in the current study maybe due to species-specific differences in how voluntary wheel running affects neurogenesis, too much error in the measurement of distance run, or it could be that the time-course of wheel running was not long enough to produce a significant correlation. 


\section{Variability in BrdU Data}

The standard error of the mean (SEM) for our experimental groups in the BrdU estimates ranged from $19-31 \%$ of the mean. Other studies that used a single dose of BrdU 24 hours before decapitation, and subsequently measured proliferation with stereology, report SEMs that range from 1-20\% in their control groups (R. Alonso et al., 2004; Cameron \& McKay, 2001; Czeh et al., 2002; Eadie et al., 2005; Malberg \& Duman, 2003; McDonald \& Wojtowicz, 2005). Lower variability in these studies cannot be explained by larger sample sizes as in most cases they were equal or smaller than the sample size used in this study $(n=10)$. In the instance where the sample size was much larger than in our study $(n=20)$, the SEM was also 20\% (Eadie et al., 2005). Rarely do these papers address the issue of high variance except for a paper by Wong et al. (2004) which justified avoiding stereology to quantify cell proliferation by referring to a study by Alonso (2000) which obtained 33\% SEM using their method of stereology which used very few sampling sites.

In unbiased stereology, as was employed in the current study, more sampling sites should lead to better results, as long as the objects being counted are uniformly randomly distributed (MBF Bioscience, 2010). In this experiment so many sampling sites were used that at least $50 \%$ of the tissue of each section was sampled through random sampling with the optical dissector. The counting frame was $50 \mathrm{~mm} \times 50 \mathrm{~mm}$ which is larger or equal to what has been employed in previous studies which contributes to the amount of tissue sampled (Czeh et al., 2006; Pham et al., 2003). Something to consider 
is that proliferation in the DG happens in spatial bursts (Palmer et al., 2000) producing tissue in which there are areas with clusters of cells, which contain approximately 20 cells each, and areas containing no proliferating cells at all. Stereology with random sampling may not be the ideal microscopy technique to use for quantifying proliferation as the distribution of cells may violate the assumption that the objects are uniformly randomly distributed. However, when the data was analyzed as number of clusters, as opposed to total number of cells, almost identical levels of variability were seen. The possibility exists as well that the assumption is violated, not because of the clusters, but because the location of proliferating cells is not uniformly randomly distributed. Other parameters used in stereology, besides number of sampling sites, that may affect the overall variability within groups are: thickness of the tissue slices, and number and frequency of slices analyzed. Some studies have used 35-40 $\mu \mathrm{m}$ sections (Bednarczyk et al., 2009; Heine et al., 2004; Malberg \& Duman, 2003) which are thinner than sections used in this experiment $(50 \mu \mathrm{m})$, however, use of thicker sections should decrease variability as they result in larger sampling sites given that there is more tissue to focus through. However, this may not hold true for the distribution of BrdU+ cells. Additionally, with thicker slices there is a larger area that is not being sampled between sampled sections when sampling sections at an identical frequency (i.e. every $6^{\text {th }}$ slice). Many stereology papers quantifying BrdU 24h post-injection or Ki67 DAB-stained cells tend to sample every $6^{\text {th }}$ slice (as was done within this study), with some studies sampling every $10^{\text {th }}$ or every $12^{\text {th }}$ (Alonso et al., 2004; Bednarczyk et al., 2009; Cameron \& McKay, 2001; Czeh et al., 2002; Heine et al., 2004; Malberg \& Duman, 2005). Other 
stereology papers utilizing a different BrdU injection schedule sometimes sample fewer slices such as every $4^{\text {th }}$ or $5^{\text {th }}$ (Bruel-Jungerman et al., 2009; Vollmayr et al., 2003; Yagita et al., 2006). One way in which the variability in the BrdU data may have been decreased is if every third section, as opposed to every sixth section, especially given that we used half-coronal slices and not full ones.

Sampling more sections or increasing sampling sites is not always the most effective way to decrease variability however. Many of our estimates had high coefficients of error (CE) which is an estimate of the variance introduced to the data by the stereological procedure. Unfortunately, CEs are rarely reported in the literature making it difficult to compare our stereological results in this respect. Estimates of total BrdU+ cells lower than approximately 100 (of which there were six out of 37) resulted in CEs that were deemed unacceptable by the general rule of thumb that the variance introduced by the stereological analysis should not account for more than $50 \%$ of the observed group variance (Gundersen \& Jensen, 1987). When CEs are unacceptable it is advisable to increase the $\mathrm{N}$ of the study as opposed to increasing sampling sites (Gundersen \& Jensen, 1987) to obtain more reliable data. There appears to be a limitation for using stereology with the random events protocol to make precise estimations when counting low frequency BrdU+ granule cells. The stereological estimation itself does not lead to increased variability as can be seen by comparing the SEM values between the values generated for the total cell estimates and the raw data of total cells counted. See Table 2 . 


\section{Variability in Ki67 Data}

If the BrdU variability was due to technical sources of error associated with using BrdU such as differences in uptake to the brain between animals, stereological procedures, and/or problems with antibodies, then we would not expect to see similar problems with Ki67. However, because Ki67 data did replicate the BrdU data with regards to lack of significant differences between treatment groups and high levels of variability, this suggests that variability is probably biological as opposed to technical. The SEMs for our experimental groups in the Ki67 data ranged from 10-20\% of the group means. Other studies that observed Ki67 data report SEMs that range from very minimal to about $20 \%$ when using cell counting or stereology (Brummelte \& Galea, 2010; Eadie et al., 2005; Fuss et al., 2010; Heine et al., 2004; Kronenberg et al., 2006; Suh et al., 2007; Stranahan et al., 2005). Although the decreased variability suggests that proliferation data derived from the Ki67 cell counts are more reliable, despite that fewer sections were sampled, the variability was still high enough to obscure any effect of corticosterone.

Although the methodology used to count Ki67+ cells is identical to that used in quantifying DCX+cells, there is less variability in the DCX data (4-11\% SEM). This is likely because there are more DCX+cells in the DG than there are proliferating cells. Furthermore, DCX + cells have started to mature and migrate, thus they are more evenly distributed throughout the tissue than proliferating cells. Variability, therefore, may be decreased because the DCX DAB-stained tissue itself is less varied. 


\section{Correlating BrdU and Ki67}

Interestingly, there is a lack of a correlation between the BrdU data and the Ki67 data, even though they are both measures of proliferation. A paper by Kee et al. (2002) investigates the appropriateness of quantifying Ki67+ cells as a measure of proliferation, and found that this method results in 50\% more cells being labeled than when using BrdU labeling after a single dose of $\mathrm{BrdU}$ is injected $24 \mathrm{~h}$ prior to decapitation. The paper proposes that the higher proportion of labeled cells is due to the fact that Ki67 is expressed during cell cycle stages S, G2, mitosis and part of G1 (Scholzen \& Gerdes, 2000) while BrdU only gets incorporated during the $\mathrm{S}$ phase which in adult NSCs is estimated to be about 9.5 hours long (Cameron \& McKay, 2001). BrdU gets incorporated into a fraction of the proliferating cells that express Ki67, however, BrdU labeling will result in larger clusters of labeled cells as BrdU-labeled cells will undergo mitosis given a 24-hour survival period, thereby marking both proliferating and newborn cells (Cameron \& McKay, 2001). The 24-hour survival period following BrdU injection in our study also leaves BrdU-labeling susceptible to the effects of apoptosis. Although there is a difference in measuring proliferation with $\mathrm{Ki} 67$ and $\mathrm{BrdU}$, the measures should still correlate with each other when data are reliable.

This study is not the only one to find discrepancies between BrdU+ and Ki67+ cell counts (Clark et al., 2010; Kronenberg et al., 2006; Tanapat, Hastings, Reeves, \& Gould, 1999). Clark et al. (2010) found that proliferation, measured after the first five days of a running treatment, was augmented when measured by Ki67, but not when measured by BrdU after injecting BrdU for five days. Clark et al. account for this 
difference by explaining that BrdU labeling, during the survival period, is susceptible to apoptosis, which is known to be increased after short term wheel running (Kitamura \& Sugiyama, 2006). This proposed effect would be exacerbated by the longer survival period relative to the 24 - hour survival period utilized in the present study. Tanapat et al. (1999) also injected BrdU for five consecutive days and explain the discrepancy between BrdU and Ki67 data in the same way as Clark et al. (2010). Instead, Kronenberg et al. (2006) performed a single injection of BrdU and allowed a survival period of 24 hours, but do not address the difference between BrdU and Ki67. Other studies performing a single injection of BrdU with a 24-hour or 2-hour survival period have reported finding comparable group differences in proliferation when quantifying BrdU+ and $\mathrm{Ki} 67+$ cells, but do not provide correlation coefficients between the two measures, and in some cases do not report any statistics for the Ki67 data (Eadie et al., 2005; Heine et al., 2004; Stranahan et al., 2006).

\section{Future Directions}

The overall objective of this study is to identify miRNAs that are differentially expressed in the DG of rats exhibiting increased and decreased rates of neurogenesis. In order to gather more information on what the changes in miRNAs represent, future studies are required to investigate the outcome of three weeks of wheel running and three weeks of daily corticosterone injections with regards to proliferation, cell survival and apoptosis, assessed separately. In these future experiments, to measure proliferation without the effects of apoptosis and mitosis on cell number, a 2-hour survival period after BrdU injection could be employed in lieu of a 24 hour survival period (Kee et al., 2002). 
In such a case, data between BrdU and $\mathrm{Ki} 67$ should correlate with each other. In retrospect, for changes in miRNAs to also represent differences in the proliferative aspect of neurogenesis, our study would require slight alterations to the voluntary exercise condition, such as using a shorter time-course of wheel running between ten days and two weeks. In future experiments quantifying proliferation I would recommend stereology of the dorsal DG for DAB-stained tissue for Ki67 as opposed to BrdU, as Ki67 and BrdU can be equivalent markers of cell proliferation (Kee et al., 2002). Furthermore, BrdU requires the added hassle of injection and inter-animal differences in BrdU uptake into the brain can present an additional source of error. Stereology without use of the random sampling as part of the random events protocol may be required to eliminate any added error derived from random sampling of a low frequency and non-uniformly randomly distributed population; instead the entire region of interest should be sampled. If the clustered nature of the proliferating cell population does contribute to increased variability in stereological methods $40 \mu \mathrm{m}$ slices, as opposed to $50 \mu \mathrm{m}$ slices, may reduce variability that comes from chance sampling of large clusters. Furthermore, this would decrease the amount of unsampled tissue between slices (when section frequency is the same) and make the study more comparable to other published experiments. In the current study, every $6^{\text {th }}$ half-coronal slice was sampled, however, most studies sample from full coronal slices so the amount of sampling could be doubled by taking every third slice instead. To increase the chances of the effect of corticosterone on proliferation being statistically significant between the corticosterone and vehicle injection control group the group sizes can also be increased to elevate power, if necessary. Survival can 
be assessed while holding proliferation constant by administering $\mathrm{BrdU}$ prior to the implementation of wheel running or corticosterone treatment and measures of apoptosis can be taken by immunohistochemistry for apoptotic markers.

Significant differences between groups in number of DCX + neurons show that the treatments of daily high-dose corticosterone injections and voluntary exercise produce decreases and increases in the amount of surviving immature neurons in the dorsal DG of the adult rat hippocampus. The tissue sampled from these animals after the three weeks contain miRNAs representing one aspect of the microenvironment in which there are surviving immature neurons. These differentially expressed miRNA genes will be identified using microarray and used to pick miRNAs of interest for follow-up studies. A miRNA of interest can be defined as one that in the miRNA microarray is shown to be differentially expressed between the corticosterone group and its controls, as well as in the wheel running group and its respective control in the opposite direction. This expression pattern suggests that the miRNA is directly involved in neurogenesis as wheel running and corticosterone injections exert their effects on neurogenesis through dissociable pathways. As this research will be conducted in vivo it allows us to identify glial miRNAs as well.

Once a miRNA of interest is identified there are multiple in vitro, in silico, and in vivo studies that can be conducted to support a role for the miRNA in the process of neurogenesis beyond its correlation with neurogenesis demonstrated by the microarray. To determine which cell types, neurons or glia, are expressing that miRNA, in situ hybridization with labeled probes targeted to the mature miRNA can be used to visualize 
the spatial distribution and to determine whether the miRNA is restricted to a particular cell-type (Cheng et al., 2009; Deo et al., 2006). This technique can also be performed in combination with immunohistochemistry for Ki67 and DCX, for example, to gather additional information on when, throughout the cell' $s$ development, the miRNA is expressed (if it is found to be expressed in neurons and not glia) (Cheng et al., 2009). Additionally, dissected tissue from the hippocampus could be sorted by fluorescenceactivated cell sorting (FACS) to examine which cell type is expressing the miRNA of interest (Cheng et al., 2009; Suh et al., 2007). In fact cultures of this cell population should be used to further examine the miRNA in vitro. Within this cell population one could make use of specialized dye stains such as DNA dye Vybrant DyeCycle to separate cells based on cell cycle stage to pinpoint when the miRNA at which stage of a cell's development the miRNA exerts its effects on neurogenesis (Cheng et al., 2009). Other in vitro techniques could be used to assess the direct role of the miRNA on neurogenesis by transfecting cultured adult neural stem cells with a synthetic miRNA duplex (J. Y. Yu, Chung, Deo, Thompson, \& Turner, 2008), miRNA expression vectors (Deo et al., 2006; Szulwach et al., 2010; Yu et al., 2008), or retroviral constructs carrying the a miRNA (Cheng et al., 2009), which would all increase levels of the miRNA of interest, and observe if this induces dose-dependant changes in the survival of immature neurons. To see the effect of reducing the function of the miRNA of interest one could inhibit miRNA activity through the use of antisense molecules such as a locked nucleic acid oligo (Kloosterman, Wienholds, Ketting, \& Plasterk, 2004), a Morpholino oligo (Flynt, Li, Thatcher, Solnica-Krezel, \& Patton, 2007) or antagomirs like $2-$-O-methyl Antisense 
RNA oligonucleotides (Meister \& Tuschl, 2004; J. Y. Yu et al., 2008). These studies should confirm whether or not the miRNA of interest plays a causal role in the process of neurogenesis which could be assessed by quantifying the number of immature neurons that are surviving.

In order to understand through which mRNA the miRNA exerts its effects, algorithms that predict mRNA targets of miRNAs based on their sequences should be used (Cheng et al., 2009; Szulwach et al., 2010; C. Zhao et al., 2010). To identify conserved miRNA targets, combing query results from miRanda, PicTar, and TargetScan databases is recommended (Griffiths, 2009). To specify mRNAs of interests one should perform a literature review as to narrow down the list of mRNA targets as the algorithms can generate several hundred targets each.

To assess a prediction that the miRNA of interest targets a particular mRNA one could conduct in vivo studies to see if the miRNA and the hypothesized target mRNA are reciprocally expressed (high levels of miRNA with low levels of mRNA, and low levels of miRNA with high levels of mRNA) which may indicate degradation of the target mRNA under normal, inhibited miRNA conditions, and under the influence miRNA over-expression. Messenger RNA expression can be assessed via northern blotting (C. Zhao et al., 2010), RT-PCR (Szulwach et al., 2010), while the protein can be assessed using western blotting or in situ hybridization (Nishino et al., 2008).

To verify that the miRNA targets the predicted mRNA binding site, one can use a luciferase reporter construct under the promoter of the 3' UTR of the mRNA (containing 
the binding site) and measure luciferase activity which should be dependent on the binding of the miRNA to the predicted 3'UTR in a dose-dependent manner (C. Zhao et al., 2009; C. Zhao et al., 2010). Further confirmation of this hypothesis could be investigated by introducing point mutations by site-directed mutagenesis to the binding site in the 3'UTR of the mRNA to disrupt the complementarity between miRNA and mRNA binding site. If introduction of the miRNA no longer represses luciferase activity there is additional evidence that predicted binding site is indeed a functional binding site for the miRNA (C. Zhao et al., 2009). Complementary mutations in the miRNA to the mutations already incurred in the mRNA binding site could then be introduced to form a mutant miRNA, which upon administration to the cells, should return to diminshing luciferase activity.

There are multiple options for investigating miRNAs in vivo. However many of the techniques that can be utilized have limitations. To directly manipulate miRNA expression in a living organism, recombinant retroviruses can be employed. It is possible to design retroviral vectors that express short hairpin (sh)-miRNAs which can then be stereotactically implanted into the DG as was done in a study by Szulwach et al. (2010). Cre/Lox technology which is used to knockout a gene in a certain tissue for a particular time-frame has been used in a study to generate a Dicerl gene deletion in adult mouse forebrain (Konopka et al., 2010). Since the biogenesis of miRNAs is dependent on the enzyme Dicer, such an animal resulted in a progressive loss of a set of miRNAs in the forebrain (including in the hippocampus) leading to enhanced memory strength after 12 weeks followed by onset of neurodegeneration. This study also confirms miRNAs as 
having a role in learning and memory. Magill et al. (2010) also used Cre/Lox technology to acutely delete the miR-212/132 gene locus in the mouse hippocampus by creating homozygous floxed miR-212/132 mice and then stereotactically injecting a retrovirus expressing Cre recombinase into the dentate gyrus. Knockout mice for specific miRNAs are limited because brain miRNAs are often transcribed from multiple loci in the genome. Many miRNAs are located in clusters with other miRNAs and so deleting just one is not possible. As miR-132 is the predominant miRNA generated from the miR-212/132 locus the study was able to establish that knockout of miR-132 led to a decrease in dendritic length, arborization, and spine density (Magill et al., 2010). Manipulating the predicted mRNA target is another option for in vivo studies; for example mRNA knockdown is also possible through the use of sh-RNAs.

In rare cases, the protein of the target $\mathrm{mRNA}$ is a nuclear receptor and thus has potential to form a feedback loop through the 3'UTR of the miRNA of interest, as was found in the case of miR-9 and nuclear receptor TLX (C. Zhao et al., 2009). To assess if the mRNA represses miRNA activity by acting on the pri-miRNA, knockout animals for the mRNA should demonstrate higher levels of pri-miRNA levels which can be measured via RT-PCR (C. Zhao et al., 2009). A sequence analysis for consensus nuclear receptor binding sites in the flanking regions of the miRNA would reveal the potential for the nuclear receptor to regulate the miRNA. Additionally, chromatin immunoprecipitation can be utilized to detect direct binding of nuclear receptors to genomic sequences. This technique can also be used to identify transcriptional co-repressors, and repressive or active chromatin markers in the vicinity of the miRNA of interest. Epigenetic regulation 
of a miRNA is possible thus the genomic qualities, such as CpG content of miRNAs should be assessed as well as the presence of epigenetic markers of histone modification. Phylogenetic conservation as well as presence of consensus binding sites for transcription factors would suggest potential for such regulation.

\section{Conclusion}

Validation of changes in neurogenesis using cell counts of DCX+ cells confirmed the results from previous studies that three weeks of voluntary wheel running increases the number of immature neurons in the dorsal DG, and three weeks of daily high-dose corticosterone injections reduces this number. Therefore, it would be worthwhile to explore the miRNA profile of this tissue using a miRNA microarray to identify miRNAs associated with changes in neurogenesis. MicroRNAs that are altered in opposing directions by these manipulations represent miRNAs of interest for followup studies. Three weeks of voluntary exercise did not alter the number of proliferating cells in the dorsal dentate gyrus when measuring BrdU+ cells or Ki67+ cells. This finding is consistent with some of the studies in the literature examining time-course dependent effects of wheel running on neurogenesis, but not others. Results of three weeks of corticosterone injections showed trends towards significantly decreasing the amount of proliferating cells in the corticosterone injection group $(p=.181)$, however, data showed exceptional amount of variability resulting in the need for a better quantification techniques or a larger sample size to detect statistical significance. 
The miRNA profile associated with changes in neurogenesis has still not been elucidated in vivo. By validating the neurogenic changes that accompany voluntary wheel running and chronic corticosterone treatments we now have the potential to relate such changes to miRNA expression. The information that can be collected from the miRNA microarray portion of this study represents new knowledge in the field of miRNAs and neurogenesis, specifically with regards to the maintenance of survival of immature neurons in the adult rat hippocampus in vivo. The miRNAs that will be identified in this study serve as a molecular guide for future studies pertaining to the process of neural stem cell lineage progression. 


\section{References}

Aberg, E., Perlmann, T., Olson, L., \& Brene, S. (2008). Running increases neurogenesis without retinoic acid receptor activation in the adult mouse dentate gyrus. Hippocampus, $18(8)$, 785-792.

Aberg, M. A., Aberg, N. D., Palmer, T. D., Alborn, A. M., Carlsson-Skwirut, C., Bang, P., et al. (2003). IGF-I has a direct proliferative effect in adult hippocampal progenitor cells. $\mathrm{Mol}$ Cell Neurosci, 24(1), 23-40.

Aboobaker, A. A., Tomancak, P., Patel, N., Rubin, G. M., \& Lai, E. C. (2005). Drosophila microRNAs exhibit diverse spatial expression patterns during embryonic development. Proc Natl Acad Sci U S A, 102(50), 18017-18022.

Acsady, L., \& Kali, S. (2007). Models, structure, function: the transformation of cortical signals in the dentate gyrus. Prog Brain Res, 163, 577-599.

Almeida, O. F., Conde, G. L., Crochemore, C., Demeneix, B. A., Fischer, D., Hassan, A. H., et al. (2000). Subtle shifts in the ratio between pro- and antiapoptotic molecules after activation of corticosteroid receptors decide neuronal fate. FASEB J, 14(5), 779-790.

Alonso, G. (2000). Prolonged corticosterone treatment of adult rats inhibits the proliferation of oligodendrocyte progenitors present throughout white and gray matter regions of the brain. Glia, 31(3), 219-231.

Alonso, R., Griebel, G., Pavone, G., Stemmelin, J., Le Fur, G., \& Soubrie, P. (2004). Blockade of $\mathrm{CRF}(1)$ or $\mathrm{V}(1 \mathrm{~b})$ receptors reverses stress-induced suppression of neurogenesis in a mouse model of depression. Mol Psychiatry, 9(3), 278-286, 224.

Alvarez-Buylla, A., \& Lim, D. A. (2004). For the long run: maintaining germinal niches in the adult brain. Neuron, 41(5), 683-686.

Ambros, V. (2004). The functions of animal microRNAs. Nature, 431(7006), 350-355.

Avilion, A. A., Nicolis, S. K., Pevny, L. H., Perez, L., Vivian, N., \& Lovell-Badge, R. (2003). Multipotent cell lineages in early mouse development depend on SOX2 function. Genes Dev, 17(1), 126-140.

Baek, D., Villen, J., Shin, C., Camargo, F. D., Gygi, S. P., \& Bartel, D. P. (2008). The impact of microRNAs on protein output. Nature, 455(7209), 64-71.

Bak, M., Silahtaroglu, A., Moller, M., Christensen, M., Rath, M. F., Skryabin, B., et al. (2008). MicroRNA expression in the adult mouse central nervous system. RNA, 14(3), 432-444.

Ballas, N., Grunseich, C., Lu, D. D., Speh, J. C., \& Mandel, G. (2005). REST and its corepressors mediate plasticity of neuronal gene chromatin throughout neurogenesis. Cell, 121(4), 645-657.

Banasr, M., Soumier, A., Hery, M., Mocaer, E., \& Daszuta, A. (2006). Agomelatine, a new antidepressant, induces regional changes in hippocampal neurogenesis. Biol Psychiatry, 59(11), 1087-1096.

Barco, A., Bailey, C. H., \& Kandel, E. R. (2006). Common molecular mechanisms in explicit and implicit memory. J Neurochem, 97(6), 1520-1533.

Bartel, D. P. (2004). MicroRNAs: genomics, biogenesis, mechanism, and function. Cell, 116(2), 281-297.

Bartlett, P. F., Dutton, R., Likiardopoulos, V., \& Brooker, G. (1994). Regulation of neurogenesis in the embryonic and adult brain by fibroblast growth factors. Alcohol Alcohol Suppl, 2 , 387-394. 
Bednarczyk, M. R., Aumont, A., Decary, S., Bergeron, R., \& Fernandes, K. J. (2009). Prolonged voluntary wheel-running stimulates neural precursors in the hippocampus and forebrain of adult CD1 mice. Hippocampus, 19(10), 913-927.

Bentwich, I. (2005). Prediction and validation of microRNAs and their targets. FEBS Lett, 579(26), 5904-5910.

Berchtold, N. C., Kesslak, J. P., Pike, C. J., Adlard, P. A., \& Cotman, C. W. (2001). Estrogen and exercise interact to regulate brain-derived neurotrophic factor mRNA and protein expression in the hippocampus. Eur J Neurosci, 14(12), 1992-2002.

Bland, S. T., Tamlyn, J. P., Barrientos, R. M., Greenwood, B. N., Watkins, L. R., Campeau, S., et al. (2007). Expression of fibroblast growth factor-2 and brain-derived neurotrophic factor mRNA in the medial prefrontal cortex and hippocampus after uncontrollable or controllable stress. Neuroscience, 144(4), 1219-1228.

Bohnsack, M. T., Czaplinski, K., \& Gorlich, D. (2004). Exportin 5 is a RanGTP-dependent dsRNA-binding protein that mediates nuclear export of pre-miRNAs. RNA, 10(2), 185 191.

Bolstad, B. M., Irizarry, R. A., Astrand, M., \& Speed, T. P. (2003). A comparison of normalization methods for high density oligonucleotide array data based on variance and bias. Bioinformatics, 19(2), 185-193.

Bruel-Jungerman, E., Laroche, S., \& Rampon, C. (2005). New neurons in the dentate gyrus are involved in the expression of enhanced long-term memory following environmental enrichment. EurJ Neurosci, 21(2), 513-521.

Bruel-Jungerman, E., Veyrac, A., Dufour, F., Horwood, J., Laroche, S., \& Davis, S. (2009). Inhibition of PI3K-Akt signaling blocks exercise-mediated enhancement of adult neurogenesis and synaptic plasticity in the dentate gyrus. PLoS One, 4(11), e7901.

Brummelte, S., \& Galea, L. A. Chronic high corticosterone reduces neurogenesis in the dentate gyrus of adult male and female rats. Neuroscience.

Bushati, N., \& Cohen, S. M. (2007). microRNA functions. Annu Rev Cell Dev Biol, 23, 175-205.

Cameron, H. A., \& McKay, R. D. (2001). Adult neurogenesis produces a large pool of new granule cells in the dentate gyrus. J Comp Neurol, 435(4), 406-417.

Cameron, H. A., Tanapat, P., \& Gould, E. (1998). Adrenal steroids and N-methyl-D-aspartate receptor activation regulate neurogenesis in the dentate gyrus of adult rats through a common pathway. Neuroscience, 82(2), 349-354.

Cao, L., Jiao, X., Zuzga, D. S., Liu, Y., Fong, D. M., Young, D., et al. (2004). VEGF links hippocampal activity with neurogenesis, learning and memory. Nat Genet, 36(8), 827835.

Chang, T. C., \& Mendell, J. T. (2007). microRNAs in vertebrate physiology and human disease. Annu Rev Genomics Hum Genet, 8, 215-239.

Chen, C. Z., Li, L., Lodish, H. F., \& Bartel, D. P. (2004). MicroRNAs modulate hematopoietic lineage differentiation. Science, 303(5654), 83-86.

Cheng, L. C., Pastrana, E., Tavazoie, M., \& Doetsch, F. (2009). miR-124 regulates adult neurogenesis in the subventricular zone stem cell niche. Nat Neurosci, 12(4), 399-408.

Chong, J. A., Tapia-Ramirez, J., Kim, S., Toledo-Aral, J. J., Zheng, Y., Boutros, M. C., et al. (1995). REST: a mammalian silencer protein that restricts sodium channel gene expression to neurons. Cell, 80(6), 949-957.

Clark, P. J., Brzezinska, W. J., Puchalski, E. K., Krone, D. A., \& Rhodes, J. S. (2009). Functional analysis of neurovascular adaptations to exercise in the dentate gyrus of young adult mice associated with cognitive gain. Hippocampus, 19(10), 937-950. 
Clark, P. J., Kohman, R. A., Miller, D. S., Bhattacharya, T. K., Haferkamp, E. H., \& Rhodes, J. S. Adult hippocampal neurogenesis and c-Fos induction during escalation of voluntary wheel running in C57BL/6J mice. Behav Brain Res, 213(2), 246-252.

Conaco, C., Otto, S., Han, J. J., \& Mandel, G. (2006). Reciprocal actions of REST and a microRNA promote neuronal identity. Proc Natl Acad Sci U S A, 103(7), 2422-2427.

Czeh, B., Michaelis, T., Watanabe, T., Frahm, J., de Biurrun, G., van Kampen, M., et al. (2001). Stress-induced changes in cerebral metabolites, hippocampal volume, and cell proliferation are prevented by antidepressant treatment with tianeptine. Proc Natl Acad Sci U S A, 98(22), 12796-12801.

Czeh, B., Simon, M., Schmelting, B., Hiemke, C., \& Fuchs, E. (2006). Astroglial plasticity in the hippocampus is affected by chronic psychosocial stress and concomitant fluoxetine treatment. Neuropsychopharmacology, 31(8), 1616-1626.

Czeh, B., Welt, T., Fischer, A. K., Erhardt, A., Schmitt, W., Muller, M. B., et al. (2002). Chronic psychosocial stress and concomitant repetitive transcranial magnetic stimulation: effects on stress hormone levels and adult hippocampal neurogenesis. Biol Psychiatry, 52(11), 1057-1065.

Deo, M., Yu, J. Y., Chung, K. H., Tippens, M., \& Turner, D. L. (2006). Detection of mammalian microRNA expression by in situ hybridization with RNA oligonucleotides. Dev Dyn, 235(9), 2538-2548.

Dobbin, K. K., Kawasaki, E. S., Petersen, D. W., \& Simon, R. M. (2005). Characterizing dye bias in microarray experiments. Bioinformatics, 21(10), 2430-2437.

Du, T., \& Zamore, P. D. (2005). microPrimer: the biogenesis and function of microRNA. Development, 132(21), 4645-4652.

Duan, X., Kang, E., Liu, C. Y., Ming, G. L., \& Song, H. (2008). Development of neural stem cell in the adult brain. Curr Opin Neurobiol, 18(1), 108-115.

Dubreucq, S., Koehl, M., Abrous, D. N., Marsicano, G., \& Chaouloff, F. CB1 receptor deficiency decreases wheel-running activity: Consequences on emotional behaviours and hippocampal neurogenesis. Exp Neurol.

Eadie, B. D., Redila, V. A., \& Christie, B. R. (2005). Voluntary exercise alters the cytoarchitecture of the adult dentate gyrus by increasing cellular proliferation, dendritic complexity, and spine density. J Comp Neurol, 486(1), 39-47.

Encinas, J. M., Vaahtokari, A., \& Enikolopov, G. (2006). Fluoxetine targets early progenitor cells in the adult brain. Proc Natl Acad Sci U S A, 103(21), 8233-8238.

Esau, C., Kang, X., Peralta, E., Hanson, E., Marcusson, E. G., Ravichandran, L. V., et al. (2004). MicroRNA-143 regulates adipocyte differentiation. J Biol Chem, 279(50), 52361-52365.

Fare, T. L., Coffey, E. M., Dai, H., He, Y. D., Kessler, D. A., Kilian, K. A., et al. (2003). Effects of atmospheric ozone on microarray data quality. Anal Chem, 75(17), 4672-4675.

Farmer, J., Zhao, X., van Praag, H., Wodtke, K., Gage, F. H., \& Christie, B. R. (2004). Effects of voluntary exercise on synaptic plasticity and gene expression in the dentate gyrus of adult male Sprague-Dawley rats in vivo. Neuroscience, 124(1), 71-79.

Ferri, A. L., Cavallaro, M., Braida, D., Di Cristofano, A., Canta, A., Vezzani, A., et al. (2004). Sox 2 deficiency causes neurodegeneration and impaired neurogenesis in the adult mouse brain. Development, 131(15), 3805-3819.

Flynt, A. S., Li, N., Thatcher, E. J., Solnica-Krezel, L., \& Patton, J. G. (2007). Zebrafish miR-214 modulates Hedgehog signaling to specify muscle cell fate. Nat Genet, 39(2), 259-263.

Friedman, R. C., Farh, K. K., Burge, C. B., \& Bartel, D. P. (2009). Most mammalian mRNAs are conserved targets of microRNAs. Genome Res, 19(1), 92-105. 
Fukuda, S., Kato, F., Tozuka, Y., Yamaguchi, M., Miyamoto, Y., \& Hisatsune, T. (2003). Two distinct subpopulations of nestin-positive cells in adult mouse dentate gyrus. J Neurosci, 23(28), 9357-9366.

Fuss, J., Ben Abdallah, N. M., Vogt, M. A., Touma, C., Pacifici, P. G., Palme, R., et al. Voluntary exercise induces anxiety-like behavior in adult C57BL/6J mice correlating with hippocampal neurogenesis. Hippocampus, 20(3), 364-376.

Fuss, J., Ben Abdallah, N. M., Vogt, M. A., Touma, C., Pacifici, P. G., Palme, R., et al. (2009). Voluntary exercise induces anxiety-like behavior in adult C57BL/6J mice correlating with hippocampal neurogenesis. Hippocampus.

Garcia, A. D., Doan, N. B., Imura, T., Bush, T. G., \& Sofroniew, M. V. (2004). GFAP-expressing progenitors are the principal source of constitutive neurogenesis in adult mouse forebrain. Nat Neurosci, 7(11), 1233-1241.

Genisphere Inc. (2004). 3DNA Array 350 Manual, Appendix E: Reducing degradation of Cy 5/Alexa Fluor 647 (not peer reviewed). Accessed at

[http://www.genisphere.com/pdf/array350_10_19_04.pdf].

Gould, E., Cameron, H. A., Daniels, D. C., Woolley, C. S., \& McEwen, B. S. (1992). Adrenal hormones suppress cell division in the adult rat dentate gyrus. J Neurosci, 12(9), 3642-3650.

Gould, E., McEwen, B. S., Tanapat, P., Galea, L. A., \& Fuchs, E. (1997). Neurogenesis in the dentate gyrus of the adult tree shrew is regulated by psychosocial stress and NMDA receptor activation. $J$ Neurosci, 17(7), 2492-2498.

Gould, E., Tanapat, P., McEwen, B. S., Flugge, G., \& Fuchs, E. (1998). Proliferation of granule cell precursors in the dentate gyrus of adult monkeys is diminished by stress. Proc Natl Acad Sci U S A, 95(6), 3168-3171.

Griffiths, G. (2009). MicroRNA Target-Identification Software. Carleton University.

Griffiths-Jones, S., Saini, H. K., van Dongen, S., \& Enright, A. J. (2008). miRBase: tools for microRNA genomics. Nucleic Acids Res, 36(Database issue), D154-158.

Grimson, A., Farh, K. K., Johnston, W. K., Garrett-Engele, P., Lim, L. P., \& Bartel, D. P. (2007). MicroRNA targeting specificity in mammals: determinants beyond seed pairing. $\mathrm{Mol}$ Cell, 27(1), 91-105.

Gronli, J., Bramham, C., Murison, R., Kanhema, T., Fiske, E., Bjorvatn, B., et al. (2006). Chronic mild stress inhibits BDNF protein expression and CREB activation in the dentate gyrus but not in the hippocampus proper. Pharmacol Biochem Behav, 85(4), 842-849.

Gundersen, H. J., \& Jensen, E. B. (1987). The efficiency of systematic sampling in stereology and its prediction. $J$ Microsc, 147(Pt 3), 229-263.

Guo, H., Ingolia, N. T., Weissman, J. S., \& Bartel, D. P. Mammalian microRNAs predominantly act to decrease target mRNA levels. Nature, 466(7308), 835-840.

Hagg, T. (2009). From neurotransmitters to neurotrophic factors to neurogenesis. Neuroscientist, 15(1), 20-27.

Heine, V. M., Maslam, S., Joels, M., \& Lucassen, P. J. (2004). Prominent decline of newborn cell proliferation, differentiation, and apoptosis in the aging dentate gyrus, in absence of an age-related hypothalamus-pituitary-adrenal axis activation. Neurobiol Aging, 25(3), 361375.

Heine, V. M., Zareno, J., Maslam, S., Joels, M., \& Lucassen, P. J. (2005). Chronic stress in the adult dentate gyrus reduces cell proliferation near the vasculature and VEGF and Flk-1 protein expression. Eur J Neurosci, 21(5), 1304-1314. 
Hellsten, J., Wennstrom, M., Mohapel, P., Ekdahl, C. T., Bengzon, J., \& Tingstrom, A. (2002). Electroconvulsive seizures increase hippocampal neurogenesis after chronic corticosterone treatment. Eur J Neurosci, 16(2), 283-290.

Holmes, M. M., Galea, L. A., Mistlberger, R. E., \& Kempermann, G. (2004). Adult hippocampal neurogenesis and voluntary running activity: circadian and dose-dependent effects. $J$ Neurosci Res, 76(2), 216-222.

Houser, C. R. (2007). Interneurons of the dentate gyrus: an overview of cell types, terminal fields and neurochemical identity. Prog Brain Res, 163, 217-232.

Jin, K., Sun, Y., Xie, L., Batteur, S., Mao, X. O., Smelick, C., et al. (2003). Neurogenesis and aging: FGF-2 and HB-EGF restore neurogenesis in hippocampus and subventricular zone of aged mice. Aging Cell, 2(3), 175-183.

Jin, K., Zhu, Y., Sun, Y., Mao, X. O., Xie, L., \& Greenberg, D. A. (2002). Vascular endothelial growth factor (VEGF) stimulates neurogenesis in vitro and in vivo. Proc Natl Acad Sci U $S A, 99(18), 11946-11950$.

Karishma, K. K., \& Herbert, J. (2002). Dehydroepiandrosterone (DHEA) stimulates neurogenesis in the hippocampus of the rat, promotes survival of newly formed neurons and prevents corticosterone-induced suppression. Eur J Neurosci, 16(3), 445-453.

Kempermann, G., \& Kronenberg, G. (2003). Depressed new neurons--adult hippocampal neurogenesis and a cellular plasticity hypothesis of major depression. Biol Psychiatry, 54(5), 499-503.

Kempermann, G., Kuhn, H. G., \& Gage, F. H. (1997). More hippocampal neurons in adult mice living in an enriched environment. Nature, 386(6624), 493-495.

Kim, Y. K., \& Kim, V. N. (2007). Processing of intronic microRNAs. EMBO J, 26(3), 775-783.

Kishi, N., \& Macklis, J. D. (2004). MECP2 is progressively expressed in post-migratory neurons and is involved in neuronal maturation rather than cell fate decisions. Mol Cell Neurosci, 27(3), 306-321.

Kitamura, T., \& Sugiyama, H. (2006). Running wheel exercises accelerate neuronal turnover in mouse dentate gyrus. Neurosci Res, 56(1), 45-52.

Kloosterman, W. P., \& Plasterk, R. H. (2006). The diverse functions of microRNAs in animal development and disease. Dev Cell, 11(4), 441-450.

Kloosterman, W. P., Wienholds, E., Ketting, R. F., \& Plasterk, R. H. (2004). Substrate requirements for let-7 function in the developing zebrafish embryo. Nucleic Acids Res, 32(21), 6284-6291.

Knapen, D., Vergauwen, L., Laukens, K., \& Blust, R. (2009). Best practices for hybridization design in two-colour microarray analysis. Trends Biotechnol, 27(7), 406-414.

Konopka, W., Kiryk, A., Novak, M., Herwerth, M., Parkitna, J. R., Wawrzyniak, M., et al. MicroRNA Loss Enhances Learning and Memory in Mice. J Neurosci, 30(44), 1483514842.

Krichevsky, A. M., Sonntag, K. C., Isacson, O., \& Kosik, K. S. (2006). Specific microRNAs modulate embryonic stem cell-derived neurogenesis. Stem Cells, 24(4), 857-864.

Kronenberg, G., Bick-Sander, A., Bunk, E., Wolf, C., Ehninger, D., \& Kempermann, G. (2006). Physical exercise prevents age-related decline in precursor cell activity in the mouse dentate gyrus. Neurobiol Aging, 27(10), 1505-1513.

Lagos-Quintana, M., Rauhut, R., Yalcin, A., Meyer, J., Lendeckel, W., \& Tuschl, T. (2002). Identification of tissue-specific microRNAs from mouse. Curr Biol, 12(9), 735-739.

Larsen, M. H., Rosenbrock, H., Sams-Dodd, F., \& Mikkelsen, J. D. (2007). Expression of brain derived neurotrophic factor, activity-regulated cytoskeleton protein mRNA, and enhancement of adult hippocampal neurogenesis in rats after sub-chronic and chronic 
treatment with the triple monoamine re-uptake inhibitor tesofensine. Eur J Pharmacol, 555(2-3), 115-121.

Lee, H. J., Kim, J. W., Yim, S. V., Kim, M. J., Kim, S. A., Kim, Y. J., et al. (2001). Fluoxetine enhances cell proliferation and prevents apoptosis in dentate gyrus of maternally separated rats. Mol Psychiatry, 6(6), 610, 725-618.

Lee, Y., Kim, M., Han, J., Yeom, K. H., Lee, S., Baek, S. H., et al. (2004). MicroRNA genes are transcribed by RNA polymerase II. EMBO J, 23(20), 4051-4060.

Lemaire, V., Koehl, M., Le Moal, M., \& Abrous, D. N. (2000). Prenatal stress produces learning deficits associated with an inhibition of neurogenesis in the hippocampus. Proc Natl Acad Sci U S A, 97(20), 11032-11037.

Leuner, B., Gould, E., \& Shors, T. J. (2006). Is there a link between adult neurogenesis and learning? Hippocampus, 16(3), 216-224.

Lie, D. C., Song, H., Colamarino, S. A., Ming, G. L., \& Gage, F. H. (2004). Neurogenesis in the adult brain: new strategies for central nervous system diseases. Annu Rev Pharmacol Toxicol, 44, 399-421.

Lim, L. P., Lau, N. C., Garrett-Engele, P., Grimson, A., Schelter, J. M., Castle, J., et al. (2005). Microarray analysis shows that some microRNAs downregulate large numbers of target mRNAs. Nature, 433(7027), 769-773.

Lowy, M. T., Gault, L., \& Yamamoto, B. K. (1993). Adrenalectomy attenuates stress-induced elevations in extracellular glutamate concentrations in the hippocampus. $J$ Neurochem, 61(5), 1957-1960.

Lowy, M. T., Wittenberg, L., \& Yamamoto, B. K. (1995). Effect of acute stress on hippocampal glutamate levels and spectrin proteolysis in young and aged rats. $J$ Neurochem, 65(1), 268-274.

Lund, E., \& Dahlberg, J. E. (2006). Substrate selectivity of exportin 5 and Dicer in the biogenesis of microRNAs. Cold Spring Harb Symp Quant Biol, 71, 59-66.

Ma, D. K., Bonaguidi, M. A., Ming, G. L., \& Song, H. (2009). Adult neural stem cells in the mammalian central nervous system. Cell Res, 19(6), 672-682.

Ma, D. K., Kim, W. R., Ming, G. L., \& Song, H. (2009). Activity-dependent extrinsic regulation of adult olfactory bulb and hippocampal neurogenesis. Ann N Y Acad Sci, 1170, 664-673.

Madsen, T. M., Kristjansen, P. E., Bolwig, T. G., \& Wortwein, G. (2003). Arrested neuronal proliferation and impaired hippocampal function following fractionated brain irradiation in the adult rat. Neuroscience, 119(3), 635-642.

Madsen, T. M., Treschow, A., Bengzon, J., Bolwig, T. G., Lindvall, O., \& Tingstrom, A. (2000). Increased neurogenesis in a model of electroconvulsive therapy. Biol Psychiatry, 47(12), 1043-1049.

Magarinos, A. M., \& McEwen, B. S. (1995). Stress-induced atrophy of apical dendrites of hippocampal CA3c neurons: involvement of glucocorticoid secretion and excitatory amino acid receptors. Neuroscience, 69(1), 89-98.

Makeyev, E. V., Zhang, J., Carrasco, M. A., \& Maniatis, T. (2007). The MicroRNA miR-124 promotes neuronal differentiation by triggering brain-specific alternative pre-mRNA splicing. Mol Cell, 27(3), 435-448.

Malberg, J. E., \& Duman, R. S. (2003). Cell proliferation in adult hippocampus is decreased by inescapable stress: reversal by fluoxetine treatment. Neuropsychopharmacology, 28(9), 1562-1571.

Malberg, J. E., Eisch, A. J., Nestler, E. J., \& Duman, R. S. (2000). Chronic antidepressant treatment increases neurogenesis in adult rat hippocampus. J Neurosci, 20(24), 91049110. 
Manns, J. R., \& Eichenbaum, H. (2006). Evolution of declarative memory. Hippocampus, 16(9), 795-808.

Marti, O., Marti, J., \& Armario, A. (1994). Effects of chronic stress on food intake in rats: influence of stressor intensity and duration of daily exposure. Physiol Behav, 55(4), 747753.

Martino, S., di Girolamo, I., Orlacchio, A., \& Datti, A. (2009). MicroRNA implications across neurodevelopment and neuropathology. J Biomed Biotechnol, 2009, 654346.

McDonald, H. Y., \& Wojtowicz, J. M. (2005). Dynamics of neurogenesis in the dentate gyrus of adult rats. Neurosci Lett, 385(1), 70-75.

Meister, G., \& Tuschl, T. (2004). Mechanisms of gene silencing by double-stranded RNA. Nature, 431(7006), 343-349.

Meshi, D., Drew, M. R., Saxe, M., Ansorge, M. S., David, D., Santarelli, L., et al. (2006). Hippocampal neurogenesis is not required for behavioral effects of environmental enrichment. Nat Neurosci, 9(6), 729-731.

MFB Bioscience (2010). Using the Optical Fractionator in non-uniform cell distributions. Retrieved from http://www.mbfbioscience.com/faqs/using-the-optical-fractionator-innon-uniform-cell-distributions. (2010, December 7).

Ming, G. L., \& Song, H. (2005). Adult neurogenesis in the mammalian central nervous system. Annu Rev Neurosci, 28, 223-250.

Mitra, R., Sundlass, K., Parker, K. J., Schatzberg, A. F., \& Lyons, D. M. (2006). Social stressrelated behavior affects hippocampal cell proliferation in mice. Physiol Behav, 89(2), 123-127.

Naylor, A. S., Persson, A. I., Eriksson, P. S., Jonsdottir, I. H., \& Thorlin, T. (2005). Extended voluntary running inhibits exercise-induced adult hippocampal progenitor proliferation in the spontaneously hypertensive rat. J Neurophysiol, 93(5), 2406-2414.

Neeper, S. A., Gomez-Pinilla, F., Choi, J., \& Cotman, C. W. (1996). Physical activity increases mRNA for brain-derived neurotrophic factor and nerve growth factor in rat brain. Brain Res, 726(1-2), 49-56.

Nibuya, M., Takahashi, M., Russell, D. S., \& Duman, R. S. (1999). Repeated stress increases catalytic TrkB mRNA in rat hippocampus. Neurosci Lett, 267(2), 81-84.

Nishino, J., Kim, I., Chada, K., \& Morrison, S. J. (2008). Hmga2 promotes neural stem cell selfrenewal in young but not old mice by reducing p16Ink4a and p19Arf Expression. Cell, 135(2), 227-239.

Olson, A. K., Eadie, B. D., Ernst, C., \& Christie, B. R. (2006). Environmental enrichment and voluntary exercise massively increase neurogenesis in the adult hippocampus via dissociable pathways. Hippocampus, 16(3), 250-260.

Ottenweller, J. E., Natelson, B. H., Pitman, D. L., \& Drastal, S. D. (1989). Adrenocortical and behavioral responses to repeated stressors: toward an animal model of chronic stress and stress-related mental illness. Biol Psychiatry, 26(8), 829-841.

Palmer, T. D., Willhoite, A. R., \& Gage, F. H. (2000). Vascular niche for adult hippocampal neurogenesis. J Comp Neurol, 425(4), 479-494.

Pariante, C. M., \& Miller, A. H. (2001). Glucocorticoid receptors in major depression: relevance to pathophysiology and treatment. Biol Psychiatry, 49(5), 391-404.

Pevsner, J. (2009). Analysis of genomic DNA with the UCSC genome browser. Methods Mol Biol, 537, 277-301. 
Pham, K., Nacher, J., Hof, P. R., \& McEwen, B. S. (2003). Repeated restraint stress suppresses neurogenesis and induces biphasic PSA-NCAM expression in the adult rat dentate gyrus. Eur J Neurosci, 17(4), 879-886.

Pizarro, J. M., Lumley, L. A., Medina, W., Robison, C. L., Chang, W. E., Alagappan, A., et al. (2004). Acute social defeat reduces neurotrophin expression in brain cortical and subcortical areas in mice. Brain Res, 1025(1-2), 10-20.

Poy, M. N., Spranger, M., \& Stoffel, M. (2007). microRNAs and the regulation of glucose and lipid metabolism. Diabetes Obes Metab, 9 Suppl 2, 67-73.

Pradervand, S., Weber, J., Thomas, J., Bueno, M., Wirapati, P., Lefort, K., et al. (2009). Impact of normalization on miRNA microarray expression profiling. $R N A, 15(3), 493-501$.

Raber, J., Fan, Y., Matsumori, Y., Liu, Z., Weinstein, P. R., Fike, J. R., et al. (2004). Irradiation attenuates neurogenesis and exacerbates ischemia-induced deficits. Ann Neurol, 55(3), 381-389.

Rajewsky, N. (2006). microRNA target predictions in animals. Nat Genet, 38 Suppl, S8-13.

Rao, M. S., \& Shetty, A. K. (2004). Efficacy of doublecortin as a marker to analyse the absolute number and dendritic growth of newly generated neurons in the adult dentate gyrus. Eur J Neurosci, 19(2), 234-246.

Rao, Y., Lee, Y., Jarjoura, D., Ruppert, A. S., Liu, C. G., Hsu, J. C., et al. (2008). A comparison of normalization techniques for microRNA microarray data. Stat Appl Genet Mol Biol, $7(1)$, Article22.

Redila, V. A., \& Christie, B. R. (2006). Exercise-induced changes in dendritic structure and complexity in the adult hippocampal dentate gyrus. Neuroscience, 137(4), 1299-1307.

Rodriguez, A., Griffiths-Jones, S., Ashurst, J. L., \& Bradley, A. (2004). Identification of mammalian microRNA host genes and transcription units. Genome Res, 14(10A), 19021910.

Rola, R., Raber, J., Rizk, A., Otsuka, S., VandenBerg, S. R., Morhardt, D. R., et al. (2004). Radiation-induced impairment of hippocampal neurogenesis is associated with cognitive deficits in young mice. Exp Neurol, 188(2), 316-330.

Rosenbrock, H., Koros, E., Bloching, A., Podhorna, J., \& Borsini, F. (2005). Effect of chronic intermittent restraint stress on hippocampal expression of marker proteins for synaptic plasticity and progenitor cell proliferation in rats. Brain Res, 1040(1-2), 55-63.

Rybak, A., Fuchs, H., Smirnova, L., Brandt, C., Pohl, E. E., Nitsch, R., et al. (2008). A feedback loop comprising lin-28 and let-7 controls pre-let-7 maturation during neural stem-cell commitment. Nat Cell Biol, 10(8), 987-993.

Santarelli, L., Saxe, M., Gross, C., Surget, A., Battaglia, F., Dulawa, S., et al. (2003). Requirement of hippocampal neurogenesis for the behavioral effects of antidepressants. Science, 301(5634), 805-809.

Santos, J., Benjamin, M., Yang, P. C., Prior, T., \& Perdue, M. H. (2000). Chronic stress impairs rat growth and jejunal epithelial barrier function: role of mast cells. Am J Physiol Gastrointest Liver Physiol, 278(6), G847-854.

Sarkar, D., Parkin, R., Wyman, S., Bendoraite, A., Sather, C., Delrow, J., et al. (2009). Quality assessment and data analysis for microRNA expression arrays. Nucleic Acids Res, 37(2), e17.

Saxe, M. D., Battaglia, F., Wang, J. W., Malleret, G., David, D. J., Monckton, J. E., et al. (2006). Ablation of hippocampal neurogenesis impairs contextual fear conditioning and synaptic plasticity in the dentate gyrus. Proc Natl Acad Sci U S A, 103(46), 17501-17506.

Schaaf, M. J., de Jong, J., de Kloet, E. R., \& Vreugdenhil, E. (1998). Downregulation of BDNF mRNA and protein in the rat hippocampus by corticosterone. Brain Res, 813(1), 112-120. 
Scharfman, H., Goodman, J., Macleod, A., Phani, S., Antonelli, C., \& Croll, S. (2005). Increased neurogenesis and the ectopic granule cells after intrahippocampal BDNF infusion in adult rats. Exp Neurol, 192(2), 348-356.

Schmidt, H. D., \& Duman, R. S. (2007). The role of neurotrophic factors in adult hippocampal neurogenesis, antidepressant treatments and animal models of depressive-like behavior. Behav Pharmacol, 18(5-6), 391-418.

Schoenherr, C. J., \& Anderson, D. J. (1995). The neuron-restrictive silencer factor (NRSF): a coordinate repressor of multiple neuron-specific genes. Science, 267(5202), 1360-1363.

Scholzen, T., \& Gerdes, J. (2000). The Ki-67 protein: from the known and the unknown. J Cell Physiol, 182(3), 311-322.

Sethupathy, P., Megraw, M., \& Hatzigeorgiou, A. G. (2006). A guide through present computational approaches for the identification of mammalian microRNA targets. Nat Methods, 3(11), 881-886.

Shi, Y., Chichung Lie, D., Taupin, P., Nakashima, K., Ray, J., Yu, R. T., et al. (2004). Expression and function of orphan nuclear receptor TLX in adult neural stem cells. Nature, 427(6969), 78-83.

Shi, Y., Zhao, X., Hsieh, J., Wichterle, H., Impey, S., Banerjee, S., et al. MicroRNA Regulation of Neural Stem Cells and Neurogenesis. J Neurosci, 30(45), 14931-14936.

Shomron, N., Golan, D., \& Hornstein, E. (2009). An evolutionary perspective of animal microRNAs and their targets. J Biomed Biotechnol, 2009, 594738.

Shors, T. J., Mathew, J., Sisti, H. M., Edgecomb, C., Beckoff, S., \& Dalla, C. (2007). Neurogenesis and helplessness are mediated by controllability in males but not in females. Biol Psychiatry, 62(5), 487-495.

Shors, T. J., Miesegaes, G., Beylin, A., Zhao, M., Rydel, T., \& Gould, E. (2001). Neurogenesis in the adult is involved in the formation of trace memories. Nature, 410(6826), 372-376.

Shors, T. J., Townsend, D. A., Zhao, M., Kozorovitskiy, Y., \& Gould, E. (2002). Neurogenesis may relate to some but not all types of hippocampal-dependent learning. Hippocampus, 12(5), 578-584.

Sierra, A., Encinas, J. M., Deudero, J. J., Chancey, J. H., Enikolopov, G., Overstreet-Wadiche, L. S., et al. Microglia shape adult hippocampal neurogenesis through apoptosis-coupled phagocytosis. Cell Stem Cell, 7(4), 483-495.

Silber, J., Lim, D. A., Petritsch, C., Persson, A. I., Maunakea, A. K., Yu, M., et al. (2008). miR124 and miR-137 inhibit proliferation of glioblastoma multiforme cells and induce differentiation of brain tumor stem cells. $B M C M e d, 6,14$.

Simon, M., Czeh, B., \& Fuchs, E. (2005). Age-dependent susceptibility of adult hippocampal cell proliferation to chronic psychosocial stress. Brain Res, 1049(2), 244-248.

Sisti, H. M., Glass, A. L., \& Shors, T. J. (2007). Neurogenesis and the spacing effect: learning over time enhances memory and the survival of new neurons. Learn Mem, 14(5), 368375.

Smith, M. A., Makino, S., Kvetnansky, R., \& Post, R. M. (1995). Stress and glucocorticoids affect the expression of brain-derived neurotrophic factor and neurotrophin-3 mRNAs in the hippocampus. J Neurosci, 15 (3 Pt 1), 1768-1777.

Smrt, R. D., Eaves-Egenes, J., Barkho, B. Z., Santistevan, N. J., Zhao, C., Aimone, J. B., et al. (2007). Mecp2 deficiency leads to delayed maturation and altered gene expression in hippocampal neurons. Neurobiol Dis, 27(1), 77-89.

Smyth, G. K., \& Speed, T. (2003). Normalization of cDNA microarray data. Methods, 31(4), $265-$ 273. 
Snyder, J. S., Glover, L. R., Sanzone, K. M., Kamhi, J. F., \& Cameron, H. A. (2009). The effects of exercise and stress on the survival and maturation of adult-generated granule cells. Hippocampus, 19(10), 898-906.

Snyder, J. S., Hong, N. S., McDonald, R. J., \& Wojtowicz, J. M. (2005). A role for adult neurogenesis in spatial long-term memory. Neuroscience, 130(4), 843-852.

Stark, A., Brennecke, J., Bushati, N., Russell, R. B., \& Cohen, S. M. (2005). Animal MicroRNAs confer robustness to gene expression and have a significant impact on 3'UTR evolution. Cell, 123(6), 1133-1146.

Stranahan, A. M., Khalil, D., \& Gould, E. (2006). Social isolation delays the positive effects of running on adult neurogenesis. Nat Neurosci, 9(4), 526-533.

Suh, H., Consiglio, A., Ray, J., Sawai, T., D'Amour, K. A., \& Gage, F. H. (2007). In vivo fate analysis reveals the multipotent and self-renewal capacities of Sox2+ neural stem cells in the adult hippocampus. Cell Stem Cell, 1(5), 515-528.

Sun, G., Yu, R. T., Evans, R. M., \& Shi, Y. (2007). Orphan nuclear receptor TLX recruits histone deacetylases to repress transcription and regulate neural stem cell proliferation. Proc Natl Acad Sci U S A, 104(39), 15282-15287.

Sundberg, M., Savola, S., Hienola, A., Korhonen, L., \& Lindholm, D. (2006). Glucocorticoid hormones decrease proliferation of embryonic neural stem cells through ubiquitinmediated degradation of cyclin D1. J Neurosci, 26(20), 5402-5410.

Szulwach, K. E., Li, X., Smrt, R. D., Li, Y., Luo, Y., Lin, L., et al. Cross talk between microRNA and epigenetic regulation in adult neurogenesis. J Cell Biol, 189(1), 127-141.

Tanapat, P., Hastings, N. B., Reeves, A. J., \& Gould, E. (1999). Estrogen stimulates a transient increase in the number of new neurons in the dentate gyrus of the adult female rat. $J$ Neurosci, 19(14), 5792-5801.

Tanapat, P., Hastings, N. B., Rydel, T. A., Galea, L. A., \& Gould, E. (2001). Exposure to fox odor inhibits cell proliferation in the hippocampus of adult rats via an adrenal hormonedependent mechanism. J Comp Neurol, 437(4), 496-504.

Thermo Scientific (2008). NanoDrop 1000 Spectrophotometer: V3.6 User's Manual. Wilmington, DE: Thermo Fisher Scientific Inc.

Trejo, J. L., Carro, E., \& Torres-Aleman, I. (2001). Circulating insulin-like growth factor I mediates exercise-induced increases in the number of new neurons in the adult hippocampus. J Neurosci, 21(5), 1628-1634.

Trejo, J. L., Llorens-Martin, M. V., \& Torres-Aleman, I. (2008). The effects of exercise on spatial learning and anxiety-like behavior are mediated by an IGF-I-dependent mechanism related to hippocampal neurogenesis. Mol Cell Neurosci, 37(2), 402-411.

Tusher, V. G., Tibshirani, R., \& Chu, G. (2001). Significance analysis of microarrays applied to the ionizing radiation response. Proc Natl Acad Sci U S A, 98(9), 5116-5121.

Ueyama, T., Kawai, Y., Nemoto, K., Sekimoto, M., Tone, S., \& Senba, E. (1997). Immobilization stress reduced the expression of neurotrophins and their receptors in the rat brain. Neurosci Res, 28(2), 103-110.

van der Hart, M. G., Czeh, B., de Biurrun, G., Michaelis, T., Watanabe, T., Natt, O., et al. (2002). Substance $\mathrm{P}$ receptor antagonist and clomipramine prevent stress-induced alterations in cerebral metabolites, cytogenesis in the dentate gyrus and hippocampal volume. $\mathrm{Mol}$ Psychiatry, 7(9), 933-941. 
van Praag, H., Christie, B. R., Sejnowski, T. J., \& Gage, F. H. (1999). Running enhances neurogenesis, learning, and long-term potentiation in mice. Proc Natl Acad Sci U S A, 96(23), 13427-13431.

van Praag, H., Kempermann, G., \& Gage, F. H. (1999). Running increases cell proliferation and neurogenesis in the adult mouse dentate gyrus. Nat Neurosci, 2(3), 266-270.

van Praag, H., Shubert, T., Zhao, C., \& Gage, F. H. (2005). Exercise enhances learning and hippocampal neurogenesis in aged mice. J Neurosci, 25(38), 8680-8685.

Visvanathan, J., Lee, S., Lee, B., Lee, J. W., \& Lee, S. K. (2007). The microRNA miR-124 antagonizes the anti-neural REST/SCP1 pathway during embryonic CNS development. Genes Dev, 21(7), 744-749.

Vollmayr, B., Simonis, C., Weber, S., Gass, P., \& Henn, F. (2003). Reduced cell proliferation in the dentate gyrus is not correlated with the development of learned helplessness. Biol Psychiatry, 54(10), 1035-1040.

West, M. J., Slomianka, L., \& Gundersen, H. J. (1991). Unbiased stereological estimation of the total number of neurons in thesubdivisions of the rat hippocampus using the optical fractionator. Anat Rec, 231(4), 482-497.

Widenfalk, J., Olson, L., \& Thoren, P. (1999). Deprived of habitual running, rats downregulate BDNF and TrkB messages in the brain. Neurosci Res, 34(3), 125-132.

Winocur, G., Wojtowicz, J. M., Sekeres, M., Snyder, J. S., \& Wang, S. (2006). Inhibition of neurogenesis interferes with hippocampus-dependent memory function. Hippocampus, $16(3), 296-304$.

Wong, E. Y., \& Herbert, J. (2004). The corticoid environment: a determining factor for neural progenitors' survival in the adult hippocampus. Eur J Neurosci, 20(10), 2491-2498.

Wong, E. Y., \& Herbert, J. (2006). Raised circulating corticosterone inhibits neuronal differentiation of progenitor cells in the adult hippocampus. Neuroscience, 137(1), 83-92.

Wu, J., \& Xie, X. (2006). Comparative sequence analysis reveals an intricate network among REST, CREB and miRNA in mediating neuronal gene expression. Genome Biol, 7(9), R85.

Xu, H., Luo, C., Richardson, J. S., \& Li, X. M. (2004). Recovery of hippocampal cell proliferation and BDNF levels, both of which are reduced by repeated restraint stress, is accelerated by chronic venlafaxine. Pharmacogenomics $J, 4(5), 322-331$.

Yang, C. H., Huang, C. C., \& Hsu, K. S. (2005). Behavioral stress enhances hippocampal CA1 long-term depression through the blockade of the glutamate uptake. J Neurosci, 25(17), 4288-4293.

Yap, J. J., Takase, L. F., Kochman, L. J., Fornal, C. A., Miczek, K. A., \& Jacobs, B. L. (2006). Repeated brief social defeat episodes in mice: effects on cell proliferation in the dentate gyrus. Behav Brain Res, 172(2), 344-350.

Yauk, C. L., Williams, A., Boucher, S., Berndt, L. M., Zhou, G., Zheng, J. L., et al. (2006). Novel design and controls for focused DNA microarrays: applications in quality assurance/control and normalization for the Health Canada ToxArray. BMC Genomics, 7, 266.

Yu, J. Y., Chung, K. H., Deo, M., Thompson, R. C., \& Turner, D. L. (2008). MicroRNA miR-124 regulates neurite outgrowth during neuronal differentiation. Exp Cell Res, 314(14), 26182633.

Yu, S., Patchev, A. V., Wu, Y., Lu, J., Holsboer, F., Zhang, J. Z., et al. Depletion of the neural precursor cell pool by glucocorticoids. Ann Neurol, 67(1), 21-30.

Zappone, M. V., Galli, R., Catena, R., Meani, N., De Biasi, S., Mattei, E., et al. (2000). Sox2 regulatory sequences direct expression of a (beta)-geo transgene to telencephalic neural 
stem cells and precursors of the mouse embryo, revealing regionalization of gene expression in CNS stem cells. Development, 127(11), 2367-2382.

Zhang, C. L., Zou, Y., He, W., Gage, F. H., \& Evans, R. M. (2008). A role for adult TLX-positive neural stem cells in learning and behaviour. Nature, 451(7181), 1004-1007.

Zhao, C., Deng, W., \& Gage, F. H. (2008). Mechanisms and functional implications of adult neurogenesis. Cell, 132(4), 645-660.

Zhao, C., Sun, G., Li, S., Lang, M. F., Yang, S., Li, W., et al. MicroRNA let-7b regulates neural stem cell proliferation and differentiation by targeting nuclear receptor TLX signaling. Proc Natl Acad Sci U S A, 107(5), 1876-1881.

Zhao, C., Sun, G., Li, S., \& Shi, Y. (2009). A feedback regulatory loop involving microRNA-9 and nuclear receptor TLX in neural stem cell fate determination. Nat Struct Mol Biol, 16(4), 365-371.

Zhao, M., Li, D., Shimazu, K., Zhou, Y. X., Lu, B., \& Deng, C. X. (2007). Fibroblast growth factor receptor-1 is required for long-term potentiation, memory consolidation, and neurogenesis. Biol Psychiatry, 62(5), 381-390.

Zhao, X., Ueba, T., Christie, B. R., Barkho, B., McConnell, M. J., Nakashima, K., et al. (2003). Mice lacking methyl-CpG binding protein 1 have deficits in adult neurogenesis and hippocampal function. Proc Natl Acad Sci U S A, 100(11), 6777-6782.

Zhao, Y., Samal, E., \& Srivastava, D. (2005). Serum response factor regulates a muscle-specific microRNA that targets Hand2 during cardiogenesis. Nature, 436(7048), 214-220.

Zhao, Y., \& Srivastava, D. (2007). A developmental view of microRNA function. Trends Biochem Sci, 32(4), 189-197. 